\title{
DOES FEDERALLY-FUNDED JOB TRAINING WORK? NONEXPERIMENTAL ESTIMATES OF WIA TRAINING IMPACTS USING LONGITUDINAL DATA ON WORKERS AND FIRMS
}

\author{
Fredrik Andersson \\ Harry J. Holzer \\ Julia I. Lane \\ David Rosenblum \\ Jeffrey Smith \\ Working Paper 19446 \\ http://www.nber.org/papers/w19446 \\ NATIONAL BUREAU OF ECONOMIC RESEARCH \\ 1050 Massachusetts Avenue \\ Cambridge, MA 02138 \\ September 2013
}

We thank the Charles Stewart Mott Foundation and the National Science Foundation for generous financial support of this project and Carolyn Heinrich, Kevin Hollenbeck, Adriana Kugler, Peter Mueser, and Ken Troske for helpful discussions. We also thank seminar participants at McMaster, Simon Fraser and the Institute for Fiscal Studies and conference participants at CESifo, IZA/SoLE, the Institute for Research on Poverty Summer Research Workshop, and the New Developments in Human Capital in Jerusalem conference for their helpful comments. The views here are solely those of the authors and not necessarily those of the U.S. Census Bureau, the Office of the Comptroller of the Currency, or the National Bureau of Economic Research.

NBER working papers are circulated for discussion and comment purposes. They have not been peerreviewed or been subject to the review by the NBER Board of Directors that accompanies official NBER publications.

(C) 2013 by Fredrik Andersson, Harry J. Holzer, Julia I. Lane, David Rosenblum, and Jeffrey Smith. All rights reserved. Short sections of text, not to exceed two paragraphs, may be quoted without explicit permission provided that full credit, including $(\subset$ notice, is given to the source. 
Does Federally-Funded Job Training Work? Nonexperimental Estimates of WIA Training Impacts Using Longitudinal Data on Workers and Firms

Fredrik Andersson, Harry J. Holzer, Julia I. Lane, David Rosenblum, and Jeffrey Smith

NBER Working Paper No. 19446

September 2013

JEL No. I38,J08,J24

\begin{abstract}
$\underline{\text { ABSTRACT }}$
We study the job training provided under the US Workforce Investment Act (WIA) to adults and dislocated workers in two states. Our substantive contributions center on impacts estimated nonexperimentally using administrative data. These impacts compare WIA participants who do and do not receive training. In addition to the usual impacts on earnings and employment, we link our state data to the Longitudinal Employer Household Dynamics (LEHD) data at the U.S. Census Bureau, which allows us to estimate impacts on the characteristics of the firms at which participants find employment. We find moderate positive impacts on employment, earnings and desirable firm characteristics for adults, but not for dislocated workers. Our primary methodological contribution consists of assessing the value of the additional conditioning information provided by the LEHD relative to the data available in state Unemployment Insurance (UI) earnings records. We find that value to be zero.
\end{abstract}

Fredrik Andersson

Economics Department

The Office of the Comptroller of the Currency 4007 th St. SW

Washington, DC 20219

Fredrik.Andersson@occ.treas.gov

Harry J. Holzer

Georgetown Public Policy Institute

Old North 401

Georgetown University

37 and $\mathrm{O}$ St. NW

Washington DC 20057

hjh4@georgetown.edu
David Rosenblum

Cornell University

424 Apple Drive

Exton, PA 19341

dbr26@cornell.edu

Jeffrey Smith

Department of Economics

University of Michigan

238 Lorch Hall

611 Tappan Street

Ann Arbor, MI 48109-1220

and NBER

econjeff@umich.edu

Julia I. Lane

American Institutes of Research

jlane@air.org 


\section{Introduction}

Experimental evaluations of large-scale active labor market programs have great value, but occur only in the United States and, even there, only every couple of decades. In other times, in other places, and for many other programs, both policymakers and scholars must continue to rely on non-experimental evaluations. ${ }^{1}$ As such, improving our stock of non-experimental evidence based on current methods and the best available data, as well as continuing to advance the methodological frontier, have great value. In that spirit, this paper provides new substantive findings on the training provided under the Workforce Investment Act (WIA), the current large federal employment and training program in the US. We also provide important new evidence on several open methodological questions in the literature. ${ }^{2}$

Our first substantive contribution consists of estimating the earnings and employment impacts of receiving WIA training (and possibly other services) rather than just WIA non-training services using administrative data from two states. Building on the rich set of conditioning variables in our data, particularly the pre-program labor market outcomes shown by the literature to matter in this context, most of our estimates rely on a "selection on observed variables" (or "unconfoundedness" ) identification strategy. Moreover, because we focus on the impact of service type conditional on WIA participation, rather than the impact of WIA versus no WIA that receives most of the attention in the literature, we do not have to worry about selection into WIA,

${ }^{1}$ Of course, experiments have issues too. See e.g. Heckman and Smith (1995) and Heckman et al. (1999).

${ }^{2}$ Relatively recent reviews of this literature include Lalonde (1995), Friedlander et al. (1997), Heckman et al. (1999), King (2004), Bergemann and van den Berg (2008), Holzer (2009), Card et al. (2010), Heinrich and King (2010), and Decker (2011). 
just selection into training conditional on selection into WIA. Our data, and the WIA institutional setup, suggest that this constitutes a less challenging identification problem.

More broadly, we read the literature that uses experiments as benchmarks to study the performance of alternative non-experimental sources of identification as indicating that high quality non-experimental evaluations, where quality refers to both data and methods, can successfully replicate the broad conclusions of experimental methods. See in particular the evidence on the importance of what goes in the conditioning set in Heckman et al. (1998) and the broad comparison of experimental and high quality (mostly European) non-experimental evaluations in the meta-analysis of Card et al. (2010). The US-focused meta-analysis of Greenberg et al. (2006) reaches a similar conclusion.

Our preferred estimates show positive, substantively relevant and statistically significant impacts of WIA training on earnings and employment over the 12 calendar quarters following WIA registration for workers served under the adult funding stream. In contrast, for workers served under the dislocated worker funding stream, we find persistently negative impacts in one state and initially negative and later marginally positive impacts in the other. These findings parallel those in closely related earlier work by Heinrich et al. (2012) and Hollenbeck (2009). Though they comport with the literature, they nonetheless represent a puzzle, as the characteristics of the workers served by the two streams do not differ as dramatically as their impact estimates. These estimates have important implications for efforts at program reform and for decisions about which registrants should receive scarce training opportunities funding by the program. At the end of the paper, we consider the implications of our estimates for the cost-benefit performance of the program. 
For our second (and most innovative) substantive contribution, we estimate impacts on the types of firms at which WIA participants obtain jobs. We can do this because, for the first time in the literature, we link administrative data from the WIA programs in our two states to the rich Longitudinal Employer-Household Dynamics (LEHD) data maintained by the U.S. Census Bureau. Motivating this analysis is the well-known fact that, controlling for worker characteristics, employer characteristics contribute importantly to worker earnings and other employer outcomes; see e.g. Abowd and Kramarz (2002), Andersson et al. (2005) and Holzer et al. (2011). If WIA and other training programs can improve the quality of the firms to which workers are "matched," then we have identified an important mechanism through which job training programs might work, over and above their effects on the worker's stock of general human capital. At the same time, we may have increased our worries about upward bias in partial equilibrium impact estimates due to displacement. Empirically, our data yield quite modest positive impacts of WIA training on the propensity of adult workers to get jobs at firms with desirable firm characteristics and some small negative impacts on the parallel propensity for displaced workers. In addition, WIA training generally leads to moderate impacts on industry of employment.

Our final substantive contribution centers on our analysis of the determinants of training receipt conditional on WIA registration. We find standard patterns for age and schooling, with younger workers more likely to receive training, along with those in the middle of the educational distribution. These patterns appear both descriptively and in our multivariate analysis, and suggest that WIA allocates training in reasonable ways along these dimensions. In contrast, we find large unconditional differences by race / ethnicity but only very small conditional 
differences. Here, our multivariate analysis sheds important light on the source of univariate disparities in the allocation of program resources.

Our primary methodological contribution lies in the examination of alternative sets of conditioning variables in the context of our preferred "selection on observed variables" identification strategy. Once again, the greatest novelty arises in our examination of variables related to the firm at which the worker last worked prior to WIA participation. As with the firm characteristic outcome variables, we do this using the linked LEHD data. We expected, based on the literature, that firm characteristics might proxy for otherwise unobserved worker characteristics and so have an effect on our estimates by reducing any remaining selection bias. In fact, we find to our surprise that the firm characteristics add essentially no value to the conditioning variables available from state UI wage record data. We also examine the value of conditioning on an additional year of pre-program earnings data relative to Heinrich et al. (2012) and the value of conditioning on a proxy for local labor markets. The former does not move the estimates, somewhat to our surprise. In contrast, local labor markets do matter. Our findings on this dimension have important implications for the design and credibility of future nonexperimental evaluations.

Our second methodological contribution arises from comparing our estimates based on "selection on observed variables" with estimates based on the bias stability assumption, which underlies difference-in-differences estimators. Broadly, we find little difference, which suggests either little selection into training based on time invariant unobserved variables that also affect outcomes or that the pre-program outcomes in our conditioning set do an adequate job of capturing stable factors like motivation and ability that we do not directly observe. Finally, we 
examine the sensitivity of our estimates to alternative econometric estimators, though this aspect of the analysis is not fully developed due to issues with access to the data. ${ }^{3}$

The remainder of the paper proceeds as follows. Sections 2 and 3 describe the WIA program and our data, respectively. Section 4 defines the treatment, and Sections 5 and 6 lay out our identification strategies and the econometric estimators that build upon them. Sections 7-9 present our empirical findings on the determinants of training receipt, as well as impacts on earnings, employment and firm characteristics. Sections 10 and 11 consider the sensitivity of the estimates to alternative identification strategies and alternative estimators. Section 12 embeds our findings in a cost-benefit framework and Section 13 concludes.

\section{The WIA program}

The Workforce Investment Act (WIA) was passed by Congress and signed into law by President Clinton in 1998, and became operational in 1999-2000; Besharov and Cottingham (2011) provide a detailed history. WIA distributes federal resources for employment and training services to state and local Workforce Investment Boards (or WIBs), with about 15 percent reserved for the former and the remainder going to the latter. Title I of WIA provides general funding streams for services to adults, dislocated workers, and youth, with the state and local WIBs allocating these funds for specific use within their regions. Adults comprise individuals 18 years and over meeting various broad criteria. Dislocated workers comprise adults who have

\footnotetext{
${ }^{3}$ The Census Bureau initially granted us access to the data for 15 months. Because of the complexity of the data, the large amount of data cleaning it required, the lags inherent in the important process of review and disclosure of results, and the coordination delays associated with four authors at different institutions (only one of whom had access to the data), we were not able to complete all of our analysis during that time interval. Census Bureau policy provides for extensions of access when a paper receives a "revise and resubmit" from a refereed journal; we hope to complete our analyses at that time..
} 
recently lost a job or are about to lose a job. WIA youth programs serve in-school and out-ofschool youth ages 18-21. The target populations for these three streams overlap to some degree; in particular, almost all clients served as dislocated workers could be served as adults. Some adult clients could be served as dislocated workers. ${ }^{4}$

As of Fiscal Year 2011, these three streams received just \$2.8B in funds, a dramatic decline in real dollars relative to peak funding for federal job training in 1980 (Holzer, 2009). Other programs within Title I and the other titles obtain additional funding, though these are for much more specific programs and populations (e.g. the Job Corps for youth, vocational rehabilitation of the disabled, etc.). Because youth receive quite different services from other participants, we restrict our attention, and our data, to individuals served under the adult and dislocated worker programs.

Participation in WIA often begins at a "One-Stop" office. These offices aim to (and sometimes actually do) provide workers with access to a variety of programs including WIA, Unemployment Insurance (UI) and the U.S. Employment Service (ES) in a single location (Blank et al. 2011). Workers may find the "One-Stop" on their own or via a referral from another agency or service provider. As described in e.g. Blank et al. (2011), WIA-funded services for adults and dislocated workers fall into four categories: self-service core services, staff-assisted core services, intensive services and training services. Recipients of self-service core services typically use computers or other resources related to job search and do not formally register for the program. As a result, they do not appear in our data. Staff-assisted core services (hereinafter

\footnotetext{
${ }^{4}$ The DOL website provides surprisingly vague summaries of the eligibility rules: http://www.doleta.gov/programs/general_info.cfm and http://www.doleta.gov/youth_services/
} 
just core services) consist of low-intensity interventions such as assisted job search or provision of labor market information. Intensive services include interventions such as assessment, case management, and short courses in topics not specific to a particular occupation such as anger management or generic work skills. Finally, training services include both classroom training in occupational skills and subsidized on-the-job training at private firms. WIA explicitly imposes no eligibility rules on core services. Low-income individuals and individuals on public assistance receive priority for intensive and training services but, unlike JTPA, WIA imposes no incomebased eligibility rules (Blank et al. 2011). ${ }^{5}$

Individual Training Accounts (ITA) fund most training under WIA; on-the-job training constitutes the key exception. ITAs represent vouchers that participants can use to purchase training at certain providers; King and Barnow (2011) document the pre-approval process and its variation over time and space. In addition to restrictions on providers and on expenditures, participants typically make their decision in consultation with a caseworker, who may encourage some choices and discourage (or even prohibit) others. As the reader will have already guessed, this feature of WIA also varies widely in implementation; see e.g. McConnell et al. (2009) and Van Horn and Fichtner (2011). Most of the training funded under ITAs consists of relatively short occupational training courses provided by community colleges, other non-profit institutions or sometimes by for-profit providers.

Normatively, WIA participants follow a path from core services to intensive services to training, where each succeeding step only occurs when the prior step fails to yield employment. In practice, there exists tremendous variation across states, across WIBs within states, and even

\footnotetext{
${ }^{5}$ See also: http://www.doleta.gov/usworkforce/wia/Runningtext.cfm
} 
across caseworkers within WIBs, as well as over time at all of these levels, in how registrants select into specific services and, most important for our study, into training. As just noted, some states structure their programs to train almost everyone who registers. Others, as documented for Wisconsin in Almandsmith et al. (2006), rely in part on the information provided by the Worker Profiling and Reemployment Services (WPRS) system, which includes predictions of likely benefit exhaustion or benefit receipt duration among UI claimants (see e.g. Black et al. (2003) and Pope and Sydnor (2011) for more on the WPRS). Other states, including the states in our study (as best we can tell from the limited information we obtained in response to our inquiries) have a more ad hoc approach. Some claimants follow the normative sequence while others do not, perhaps because they show up with a referral from a training provider or perhaps because program staff identify job skills as their key deficiency or because the training program they want to participate in starts very shortly after they register, leaving little time for the earlier stages, or perhaps because they hit it off with the caseworker, as in Behnke, Frölich, and Lechner (2010). Exhibit II-1 in D’Amico et al. (2009) illustrates this type of system.

Lurking in the background of this complex and heterogeneous program we find the WIA performance management system. This system provides rewards and punishments to states and WIBs primarily on the basis of the measured outcome levels of registrants. Through its focus on outcomes rather than value-added it may lead to "cream-skimming" (i.e. selection based on expected labor market performance) at the registration stage as well as leading WIBs to focus expensive training services on those they deem unlikely to realize good labor market outcomes without them. For more on the tainted glories of the WIA performance system, see e.g. Barnow and Smith (2004), Barnow (2011) and Heckman et al. (2011). 


\section{Data}

\subsection{States}

Despite a substantial recruiting effort on our part and despite offering what amounts to a free evaluation of the state's WIA training program, we obtained the cooperation, and thus the data, of only two states. One, State A, is a medium-sized state on the Atlantic seaboard; the other, State B, is a large, Midwestern state. Our recruiting performance parallels that of Heinrich et al. (2012) but on a smaller scale. They attempted to recruit all 50 states with the assistance of the US Department of Labor and ended up with 12. We attempted to recruit nine without the formal assistance of the US Department of Labor and ended up with two. In both cases, none of the participating states would allow public links between state-level impacts and state identities.

\subsection{WIASRD}

Individual records from the Workforce Investment Act Standard Record Data (WIASRD) constitute our first major data source. These data play a key role in program monitoring and in the WIA performance management system. The WIASRD files contain data on every individual who registered for WIA services in each state. The US Department of Labor compiles all of the WIASRD data from the local and state WIBs for each program year, tabulates them and publishes summaries online. ${ }^{6}$

For each registrant, the micro data at the local and state levels contain the following: dates of WIA registration and exit, location of WIA service receipt, personal demographics (including

\footnotetext{
${ }^{6}$ See http://www.doleta.gov/Performance/results/Reports.cfm?\#wiastann. These reports are tabulated each year for DOL by Social Policy Research Associates (SPRA) and appear on DOL's website as SPRA reports.
} 
age, education, race and gender) as well as whether the individual fits into certain categories (such as disabled, veteran status, and the like), a listing of specific services received along with starting and ending dates for each service (in state A only), and labor market outcomes for quarters before and after services were received, such as employment and quarterly earnings, drawn from state Unemployment Insurance (UI) records, and used to construct some of the WIA performance measures.

\subsection{LEHD}

The Longitudinal Employer-Household Dynamics (LEHD) Data constitute our other primary data source. The LEHD program was established at the Census Bureau in 1998 to provide information on employer and employee dynamics and the link between the two. The program draws on already existing survey and administrative data from both the demographic and economics directorates at the Bureau, and integrates them with Unemployment Insurance wage record data from its partner states. ${ }^{7}$

State Unemployment Insurance (UI) wage records sit at the core of these data. These records consist of quarterly reports filed by employers for each individual in covered employment, which includes roughly $96 \%$ of private non-farm wage and salary employment (Stevens 2007). The UI data provide less comprehensive coverage of agricultural employment and completely exclude federal government employees, self-employed individuals and independent contractors and workers in the informal sector. According to US Department of Labor (1997) UI wage records measure "gross wages and salaries, bonuses, stock options, tips, and other gratuities, and the value of meals and lodging, where supplied." They do not include employer contributions to

\footnotetext{
${ }^{7}$ For more on the LEHD, see the Census program website: http://lehd.ces.census.gov/.
} 
Social Security, health insurance, workers compensation, unemployment insurance, and private pension and welfare funds. Although UI administrative records contain some errors, staff at the LEHD program has invested substantial resources in cleaning the records and making them internally consistent; see e.g. Abowd et al. (2009).

The LEHD necessarily inherits some limitations from the underlying UI record data. Most states (including our two) do not require employers to report hours or weeks worked; as a result, we cannot measure hourly or weekly earnings and thus cannot easily distinguish between low wages and few hours worked as sources of low quarterly earnings. The data contain no information on employment separate from earnings; as such, we code employment in a calendar quarter as an indicator for non-zero earnings in a quarter, a process that will miss some extended leaves. In addition, for workers holding multiple jobs in a given calendar quarter the data provide no way to determine whether they hold them sequentially or in parallel. Finally, we have no direct information on why workers leave jobs, or on a range of personal characteristics (beyond basic demographics) typically captured in survey data. See Kornfeld and Bloom (1999), Hotz and Scholz (2002) and Wallace and Haveman (2007) for discussions comparing administrative and survey outcome measures.

The LEHD data is matched to the long-form Decennial Census data, from which we obtain basic demographic information including date of birth, place of birth, sex and a crude measure of race and ethnicity. The LEHD is also matched to a number of other Census survey data sets, but because they have relatively small samples, and we have only two states, the intersection provides too little information for us to effectively utilize. 
In addition to the large samples and long earnings histories, the matched employer data represents a marquee advantage of the LEHD data. They enable us to observe several important fixed and time-varying characteristics of workers and their firms. For workers, these include a measure of overall experience and job tenure with each employer in addition to the quarterly earnings and employment already described; for firms, they include industry, firm size, average earnings paid per quarter, and measures of turnover and job churning. Furthermore, LEHD researchers have estimated person and firm "fixed effects" based on the quarterly earnings for each; see e.g. Abowd et al. (2002). The primary limitation of the employer data centers on the reporting unit. Although we often refer to the employer as a "firm," the actual reporting unit is an administrative, rather than an economic entity; in other words, the filing unit reflects an “Employer Identification Number," or EIN, rather than a specific establishment. This represents a distinction without a difference for the approximately $70 \%$ of workers with a single establishment employer - but for those who work for a multiple establishment employer, we cannot identify the exact employing establishment within the firm.

\subsection{Analysis file}

We begin by limiting our WIASRD data to all program participants in each state who registered between 1999 and 2005, with an exit date prior to the end of our data and not prior to their registration date. The Census Bureau then converts (on our behalf) the social security numbers in the WIASRD data to personal identification numbers, as they do with the LEHD data and other datasets they hold, enabling us to link the WIASRD data with the LEHD data. For each individual included in the data, we retain employment and earnings in the LEHD data for 25 calendar quarters including the quarter of registration and 12 quarters before and after that quarter. We adjust the earnings values into 2008 constant dollars using the CPI-U-RS. 
Characteristics of employers, including industry, size and turnover rates, refer to the last employer prior to registration (when used as conditioning variables) and to the last employer in our data (when used as outcomes). Appendix Table A-1 provides comprehensive variable definitions and Appendix Table A-2 details the observations lost due to the restrictions on our analysis sample.

In all, we have a total of over 26,000 WIA registrants for state A, with nearly 16,000 in the adult program and nearly 11,000 among the dislocated; comparable sample sizes for state B are over 50,000 for the state, with 23,000 and 28,000 respectively in each subgroup.

\subsection{Descriptive statistics}

Tables 1 and 2 describe our samples of WIA registrants. Table 1 presents our conditioning variables as well as outcomes other than employment and earnings, while Table 2 presents quarterly earnings and employment.

In terms of timing, roughly three-fourths of the sample registered during the labor market downturn in 2001-03, but the sample also includes non-trivial numbers of participants before and after that period. Overall, the patterns in our two states broadly comport with the national WIASRD summaries published by DOL for the years 2001-05.

In terms of who receives training and who does not, Table 1 reveals several important patterns: First, in both states and for both funding streams, whites have a higher probability of receiving training than non-whites. Second, women receive more training among adults while men receive more among the dislocated. Third, WIA participants in the middle of the education distribution (i.e. those with high school or some college) tend to receive training more often in both funding 
streams. Fourth, relatively younger participants (in their 20s or early 30s among adults and early or late 30 s among the dislocated) differentially sort into training.

At least some of these distinctions make sense, in terms of who might make a good candidate for an investment in skills training. For instance, as in the standard human capital model, training likely makes more sense for younger workers, who have a longer time horizon over which to realize the returns from their investment. As suggested in Jacobsen et al. (2003), workers in the middle of the education distribution likely have the basic skills to master somewhat technical occupational training, while those with less than high school may well lack them. At the same time, workers who already have a college education likely already have sufficient skills or will learn what they need on the job, as in Barron et al. (1998). The multivariate models of training receipt in Section 7 reveal the extent to which these univariate differences hold up after further conditioning.

The quarterly earnings and employment data tabulated in Table 2 and graphed in Figures 1 and 2 also has stories to tell. We focus on three patterns here. First, in both states, WIA participants served as dislocated workers have substantially higher pre-program mean earnings and employment than those served as adults. This signals that even the relatively vague eligibility rules for the dislocated funding stream have real-world bite. Second, particularly in State A, trainees have about the same earnings as non-trainees within each funding stream. This suggests relatively little selection into training based on time-invariant outcome differences, consistent with our finding (discussed in more detail later on) that impact estimates based on difference-indifferences methods differ little from those based on cross-sectional methods. Third, as shown for the JTPA program in Heckman and Smith (1999), the mean earnings and employment of WIA participants in our states decline in the period leading up to registration. This literature calls 
this oft-observed pattern the Ashenfelter (1978) dip, after the first paper to point it out. In this population, the dip begins about four quarters prior to registration. The dip indicates strong selection into WIA based on transitory outcome shocks but the quite modest differences in the nature and extent of the dip between trainees and non-trainees within each funding stream and state suggest little selection into training based on differences in transitory labor market shocks among registrants, especially in State A.

\section{Treatment and the parameter of interest}

\subsection{Treatment}

This study focuses on estimating the impact of receipt of WIA training conditional on WIA registration. That is, we compare WIA participants who receive training, and perhaps also core and/or intensive services, to WIA participants who received only core and/or intensive services. Our estimates, combined with data on costs, allow us to determine whether the additional resources spent on training services, on average, have labor market effects that cover their costs. This represents an important policy question; the wide divergence across states in the fraction of WIA participants receiving training documented in e.g. Heinrich et al. (2012) suggests that policymakers do not perceive a clear consensus on this question in the literature.

As shown in Table 1, many WIA participants in both our states and both funding streams receiving training, and many do not. Median WIA enrollment duration for trainees is around three quarters in State A and around 4 quarters in State B. In contrast, the median enrollment duration for registrants receiving only core and/or intensive services is typically about a quarter shorter. These values provide only a crude guide to treatment intensity for several reasons, including data quality issues (e.g. we observe large spikes in enrollment durations at particular 
values in one state), the potential for strategic manipulation for performance management reasons as in Courty and Marschke (2004), and because training participants may have to wait for a course to start and may also receive job search assistance following training completion.

Unlike Hollenbeck (2009) and Heinrich et al. (2012), we do not attempt to estimate the impact of participating in WIA versus not participating, instead leaving this equally important question to future work. Given our additional methodological concerns, we lack the space in a single paper to address both topics. We prioritized the training analysis because we think it represents a simpler non-experimental evaluation problem. First WIA core/intensive participants represent a natural comparison group for trainees in a way that ES recipients and/or UI claimants do not for all WIA participants. Second, given the common earnings patterns for trainees shown in Table 2, combined with the substantial amount of caseworker discretion and local heterogeneity in the WIA program, we think that a selection on observed variables identification strategy has greater plausibility in the training context. Finally, focusing on training allows us to avoid difficult questions of temporal alignment that arise when comparing WIA participants to other groups.

\subsection{Parameter of interest}

We estimate the impact of receiving training relative to receiving only core and/or intensive services, for the trained. To represent our parameter of interest more formally, consider the standard potential outcomes framework captured in Frost (1920), wherein $Y_{1}$ denotes the treated outcome, in this case the outcome with training and $Y_{0}$ denotes the outcome without training. In the jargon of the literature on treatment effects (in economics) or causal inference (in statistics) we estimate the Average Treatment Effect on the Treated (ATET) given by $E\left(Y_{1}-Y_{0} \mid D=1\right)$. When combined with data on the average incremental cost of training, the ATET allows the 
analyst to perform a cost-benefit analysis on the training for the trainees who currently receive it. Our analysis does not purport to provide evidence on the effect of training on those not currently receiving it. ${ }^{8}$

\section{Identification}

\subsection{Conditional independence}

Our primary identification strategy builds on the conditional (mean) independence assumption (CIA) and assumes that, conditional on a set of observed characteristics $X$, the untreated outcome does not depend on treatment status. The literature also calls this "selection on observed variables" or unconfoundedness. Informally, this identification strategy assumes we can condition our way out of the problem of non-random selection into training among WIA enrollees. In notation, we assume $E\left(Y_{0} \mid X, D=1\right)=E\left(Y_{0} \mid X, D=0\right)$. In words, we assume that, conditional on the correct collection of pre-determined (i.e. not affected by treatment) conditioning variables, treatment is unrelated to the untreated outcome. This (very strong) assumption suffices to identify the ATET of training in our context; we offer a defense of it shortly. Following standard practice in the literature we match on the scalar propensity score, which in our context corresponds to the conditional probability of training receipt given WIA enrollment. In notation, the propensity score equals $P(X)=\operatorname{Pr}(D=1 \mid X)$. Rosenbaum and Rubin (1983) show that if the CIA given above holds then a version based on the propensity score holds as well, i.e. $E\left(Y_{0} \mid P(X), D=1\right)=E\left(Y_{0} \mid P(X), D=0\right)$. We estimate the propensity score using a

\footnotetext{
${ }^{8}$ We applied the dynamic treatment effects framework introduced in Sianesi (2004) and Fredriksson and Johansson (2008). Because nearly all trainees start training in the quarter of WIA registration or the following quarter, this analysis did not add much to what we report here.
} 
flexible probit model, promising to increase its flexibility (but not too quickly!) on that magic day when our sample size increases.

For the CIA to hold in practice requires that $X$ include all the variables that affect both training receipt and outcomes in the absence of training receipt - a tall order, indeed! Many researchers implicitly adopt the view that there exists a benevolent identification deity that ensures that the available data always include some set of covariates that lead the CIA to hold, so that no justification of the conditioning variables is required. We do not hold this view. Instead, we find it helpful to think about what we know from theory, the institutional context, and existing empirical evidence about the determinants of training participation and of labor market outcomes in this population, list the desired conditioning variables they imply, and then argue that our data do (or do not) contain them and/or reasonable proxies for them.

The first thing to recognize about this institutional context is that it is a two-sided selection problem. In order for training to happen, the WIA participant has to want training and the WIA caseworker has to want to give them training. WIA participants' desires for training will depend on things like their perception of the job market for their current skill set, their age, which affects the time they have to recoup their investment in new skills, their motivation, their ability to learn in a classroom setting (and their utility from doing so), their beliefs about the value of training on offer in their community, the availability of alternative funds, via transfers from the government or from family and friends, to provide the basics of life during the training and so on. Many of these factors, such as motivation, ability and inclination to learn and the market value of their skills, also affect outcomes in the absence of training. Indeed, the short-term outcome in the absence of training represents the opportunity cost of training. The caseworker will have beliefs 
about all these factors as well. In addition, the caseworker will have information about the budget set of the local WIA.

We observe some of these variables directly, such as age and the most recent industry of employment, and so can enter them into the conditioning set. For others, such as motivation and ability, we have to rely on proxies; in our case, realized pre-program labor market outcomes serve as the proxies. Motivated workers, and high ability workers, should do persistently well in the labor market; if so, conditioning on earlier labor market outcomes will remove any selection bias that results from motivation and ability also helping to determine training receipt. The extant literature clearly shows the importance of conditioning on pre-program labor market outcomes; it is less clear about whether they can serve as all or just part of a successful identification strategy. In addition to lagged outcomes, we can use geographic indicators to proxy for both the state of the local economy, which affects the opportunity costs of training, as well as differences in local training emphasis and opportunity.

Furthermore, the broader literature claims that we have most of what we need. In particular, the important study of Lechner and Wunsch (2013) compares alternative sets of conditioning variables in the context of über-rich German administrative data and identifies those that solve the selection problem in their context. ${ }^{9}$ Of the variables they identify, we lack variables related to family status, part-time work, occupation in last job and more detailed information on past qualifications than the simple years of schooling variable present in our data. Also worth noting are variables that do not make a difference in their study, which include firm characteristics (just

${ }^{9}$ This list includes control variables sets $0-6$ and $8 \mathrm{a}$ in their Table 2; see also the discussion in their Section 5.3. 
as we find below), industry- and occupation-specific experience, health-related variables, openness to mobility and various caseworker-related variables, job-search behavior, and local labor markets (as we find below). Along this same line, Caliendo and Mitnik (2013) link survey data on various non-cognitive skills to the German administrative data and find that they do not make a difference to the impact estimates. While we certainly advocate further work along the lines of Lechner and Wunsch (2013) and Caliendo and Mitnik (2013) using US data, their studies increase our confidence in our identification strategy and in the conclusions we draw from comparing estimates based on different conditioning variables.

We consider six different sets of conditioning variables $X$. Model 1, inspired by Dehejia and Wahba $(1999,2002)$, contains only sex, race, age, education and two calendar years of preenrollment earnings. It serves as a minimalist baseline that incorporates only variables available in commonly used datasets such as the CPS. Our prior, given the performance of similar specifications in other contexts in Smith and Todd (2005) and Heckman et al. (1997, Table 6a), is that this conditioning set does not suffice for the CIA.

Model 2 represents our approximation of the specification employed in Heinrich et al. (2012), but leaving aside indicators for geographic location. Relative to Model 1, it includes calendar year and calendar quarter indicators, a more flexible age specification, disability and veteran status indicators, flexible employment and earnings histories over the eight calendar quarters prior to registration including the industry of the most recent employer, and UI benefit receipt and Employment Service (ES) participation over the same period. The notes to Table 3 and Table A-2 provide more details regarding variable definitions. 
Model 3 adds locational indicators to the model; in particular, we include indicator variables for the local One-Stop office at which the participant enrolled. These indicators approximately represent indicators for counties. Model 4 then adds a range of characteristics of the firms for which each worker most recently worked, including indicators for quintiles of the firm "fixed effect" from the LEHD, which captures the firm wage premium after conditioning on various firm and worker characteristics (with a separate category for those not employed in the preprogram period). Model 4 also adds variables related to worker turnover at the most recent employer, as well as firm size and proportion of low wage workers.

Model 5 conditions on an extra four quarters of pre-program earnings and employment information relative to Model 3. Finally, Model 6 starts with Model 3 and adds both the LEHD firm variables included in Model 4 and the additional quarters of pre-program earnings included in Model 5 to create one grand propensity score model. This model will serve as our preferred specification throughout the remainder of the paper.

To evaluate the importance of including particular variables in the conditioning set, we compare the non-experimental impacts they imply because we do not have an experimental benchmark. This strategy, which loosely says that if you keep adding conditioning variables and the estimates do not change, then probably you have solved the selection problem, is not an uncommon one in the literature; see e.g. Black, Daniel and Smith (2005, Tables 2-4). Heckman and Navarro (2004) provide a very useful formalization of this strategy that makes clear that it requires the absence of a variable or variables affecting both treatment and outcomes unrelated to the conditioning sets under consideration. We cannot rule this out with certainty, but we think it is implausible, as we have trouble thinking of a variable that would affect earnings and postprogram labor market outcomes while not affecting the pre-program outcomes included in our 
conditioning set. We also note that, from the narrow perspective of whether or not it passes a researcher / funder cost-benefit test to go to the time and trouble of linking to the LEHD for the additional conditioning variables it provides, it does not matter whether or not we get the correct answer; rather, it only matters whether the estimates change or not.

\subsection{Conditional bias stability}

The conditional Bias Stability Assumption (BSA) assumes that unconfoundness holds but only conditional on a unit-specific fixed effect. Put differently, BSA assumes that the available conditioning variables do not suffice to solve the problem of non-random selection into treatment on their own, but do suffice once the fixed effect has been removed by differencing (or some other panel data estimation strategy). In terms of our notation, the propensity score version of the BSA corresponds to:

$E\left(Y_{0 t}-Y_{0 t^{\prime}} \mid P(X), D=1\right)=E\left(Y_{0 t}-Y_{0 t^{\prime}} \mid P(X), D=0\right)$

where $t$ denotes an "after" period and $t$ ' denotes a "before" period. Written in this way the BSA is sometimes called the "common trends" assumption, as it assumes that, conditional on $X$, the mean of the untreated outcome has the same time trend for the treated and untreated units. See e.g. Heckman et al. (1998), Rosenbaum (2001) or Lechner (2010) for more on the BSA.

Substantively, the motivation for BSA relative to the CIA comes from the concern that some relatively stable unobserved characteristic, such as ability or motivation or attractiveness or grit, may affect labor market outcomes in a persistent way, but not get fully captured by conditioning on observed pre-program labor market outcomes over a relatively short period, like two or three years in our context. 
The literature suggests that this issue may arise in some contexts but not others. For example, Smith and Todd (2005) find that difference-in-differences matching, motivated by the BSA, does better at matching the experimental estimates in the context of the National Supported Work (NSW) Demonstration data studied in LaLonde (1986) than does cross-sectional matching motivated by the CIA, but argue that it largely solves problems related to using different outcome measures for the treated and untreated units as well as severe geographic mismatch. In contrast, while Heckman and Smith (1999) find what looks like both selection on transitory shocks to labor market outcomes and on persistent difference in the unconditional earnings patterns in the National Job Training Partnership Act Study non-experimental data, they find no strong pattern of differences in estimates between their cross-sectional and conditional difference-in-differences estimates, suggesting that the conditioning on pre-program outcomes sufficed in that context to capture the not-directly-observed time invariant characteristics. ChabéFerret (2012) compares matching estimators motivated by the CIA and the BSA and describes the earnings processes under which each estimator performs better. Given the state of the literature, we think it worthwhile to examine estimators based on the BSA in addition to our preferred estimation strategy based on the CIA.

\section{Estimation}

The literature offers a wide variety of estimators for use with our identification strategies. In the context of the "selection on observed variables" we consider two different estimators with contrasting costs and benefits. Inverse propensity weighting (IPW), despite an academic pedigree dating back (in the not unrelated non-response context) to Horvitz and Thompson (1952), has become popular in the treatment effects literature only recently. Key papers in the literature are Hirano, Imbens and Ridder (2003) and Hirano and Imbens (2001). IPW has three primary 
benefits for our purposes: First, it does very well relative to other estimators in recent Monte Carlo horseraces run by Huber, Lechner and Wunsch (2013) and Busso, DiNardo and McCrary (2013). Second, it has the desirable asymptotic property that it attains the "semi-parametric efficiency bound", which means that (under certain conditions) it attains minimum asymptotic variance within the class of semi-parametric estimators; see Hirano, Imbens and Ridder (2003) on this point. Third, unlike many other semi-parametric treatment effects estimators, it does require the choice of a bandwidth or other tuning parameter. In terms of our notation, the IPW estimator is given by

$$
\hat{\Delta}_{T T}=\frac{1}{n_{1}} \sum_{i=1}^{n} Y_{i} D_{i}-\frac{1}{n_{0}} \sum_{i=1}^{n}\left(\frac{1}{n_{0}} \sum_{i=1}^{n} \frac{\hat{P}(X)\left(1-D_{i}\right)}{1-\hat{P}(X)}\right)^{-1} \frac{\hat{P}\left(X_{i}\right) Y_{i}\left(1-D_{i}\right)}{1-\hat{P}\left(X_{i}\right)},
$$

where $n_{0}$ denotes the number of untreated units and $n_{1}$ the number of treated units.

The downside to IPW lies in its sensitivity to estimated propensity scores close to zero or one in finite samples. A quick look at the estimator makes the source of the trouble clear enough; the estimator divides by both $P(X)$ and $1-P(X)$. As a result, when the propensity score lies very near zero, small changes in the value of the propensity score can move the estimate a lot. In our application, we do not have this problem.

The Monte Carlo literature, in particular Busso, DiNardo and McCrary (2013), emphasizes the importance of normalizing the weights to sum to one in the sample for the finite sample 
performance of the estimator. The formula given here embodies that normalization. We obtain estimated standard errors by bootstrapping. ${ }^{10}$

We utilize nearest neighbor matching on the propensity score as our secondary estimator of choice. We do so despite its uniformly poor performance in terms of mean squared error in the Monte Carlo studies just cited, as well as in Frölich (2004). That poor performance in mean squared error terms masks a combination of quite good performance on bias, and truly awful performance on variance. The latter is perhaps not surprising given that nearest neighbor matching, particularly the most common variant with a single nearest neighbor used with replacement, completely ignores the information available in the data from comparison observations close to, but not closest to, particular treated units. The low bias, combined with relative insensitivity to propensity scores close to zero and one makes nearest neighbor matching, in our view, a good complement to IPW. We present nearest neighbor estimates using one, three and five nearest neighbors. Increasing the number of neighbors trades off bias (due to using more distant matches) and variance (which decreases in the number of untreated units used to construct the counterfactual). We chose these bandwidths on a priori grounds rather than, say, via cross-validation as in Black and Smith (2004). Abadie and Imbens (2008) show that the bootstrap fails to provide consistent standard error estimates for the nearest neighbor estimator. Instead, we employ the consistent estimator in Abadie and Imbens (2012). ${ }^{11}$

\footnotetext{
${ }^{10}$ In the current version of the paper, the bootstrap standard errors for the IPW estimator do not include the estimation of the scores and so likely have a marginal downward bias. We will fix this at revision time when we regain access to the data.

${ }^{11}$ In the current version of the paper, we do report bootstrap standard errors for the nearest neighbor estimator. The Monte Carlo analysis in Abadie and Imbens (2008) suggests that while
} 
We use the same set of estimators when relying on the conditional bias stability assumption for identification, but instead of an outcome level as the dependent variable, we have a pre-post difference in outcomes as the dependent variable, as in e.g. Smith and Todd (2005).

\section{Results: determinants of training receipt}

Tables $3 \mathrm{a}$ to $3 \mathrm{~d}$ present average derivatives from the six propensity score model specifications described in Section 5.1. As we do throughout the paper, we present completely separate estimates for each funding stream (i.e. adult and dislocated worker) in each state.

Many of the univariate differences between trainees and non-trainees prove robust to conditioning. In particular, differences in the incidence of training by age (younger participants get more) and education (participants in the middle of the education distribution get more) group generally persist as we condition on progressively richer sets of baseline variables. The large differences we observed by race represent the partial exception to this broader pattern. Consider,

for example, adults in State A. In Table 1a, 58 percent of adult trainees are black, compared to 70 percent of non-trainees. In Table 3a, which reports the results from the quite parsimonious Model 1, blacks have a -0.19 difference in the conditional probability of training relative to whites. In contrast, in the models with the richest covariate sets, namely Models 3 to 6, the difference, though still statistically significant, falls to around -0.015 . The addition of the geographic variables to the conditioning set appears to make the difference. A similar pattern appears for adults and dislocated workers in State B, while for dislocated workers in State A, blacks have a

not zero, the inconsistency in the bootstrap will generally not lead to severely misleading inferences. We will fix this at revision time when we regain access to the data. 
statistically significantly higher probability of training receipt of about 0.039 starting with Model 2.

\section{Results: impacts on earnings and employment}

\subsection{Full sample}

Tables $4 \mathrm{a}$ and $4 \mathrm{~b}$ present estimates from Model 6, our preferred specification, obtained using our preferred IPW estimators. ${ }^{12}$ In each table, we present impacts on earnings and employment for the first 12 calendar quarters after registration. We also present two summary measures of earnings impacts: the sum over all 12 quarters and the sum over quarters 9-12. The latter measure completely avoids the "lock-in" period when trainees are receiving training.

Our estimates display several important patterns. First, in both states and both streams we observe the lock-in effects of negative impacts in the initial quarters after WIA registration. This results from trainees reducing or eliminating job search during their training while the comparison group actively engages the job market during and after their receipt of core and/or intensive services. Second, we find for both states and streams that the quarterly impacts gradually increase until they appear to stabilize, usually around eight quarters after registration.

Third, we find substantively important and surprisingly large differences in impacts between the adult and dislocated worker funding streams. In State A, the impacts for adults stabilize around $\$ 300$ per quarter while those for dislocated workers stabilize at around $-\$ 150$; similarly, in State B the adults stabilize at $\$ 450$ or so while the dislocated workers, which start out with large

\footnotetext{
${ }^{12}$ When we regain access to the data, we will add a line for the reweighted comparison group to Figures 1 and 2, providing a graphical display of the temporal pattern of the impacts.
} 
negative impacts, have positive and significant impacts of over $\$ 300$ in the last two quarters of the data. Given that essentially all the dislocated worker participants could have received services under the adult funding stream and that many of the adults could have received services under the dislocated worker stream, this difference puzzles us. ${ }^{13}$ Fourth, the employment impacts track the earnings impacts except for the dislocated worker stream in State A, where negative earnings impacts in later quarters coincide with positive employment impacts, suggesting that training in State A leads to lower-paying jobs but more of them. Fifth, we find modest differences across states, with larger impacts in State B than in State A for both funding streams.

We consider the likely persistence of the impacts in the context of our cost-benefit discussion in Section 12. For the moment, it suffices to say that the estimates that sum over all 12 quarters do a reasonable job of foreshadowing our main conclusions.

\subsection{Men and women}

As discussed in e.g. LaLonde (1995), earlier evaluations of employment and training programs in the US have typically found larger impacts for women than for men. Table 5 presents separate estimates for men and women in our context for the two summative earnings impact measures: one for quarters 9-12 and one for all 12 calendar quarters after registration. The point estimates for the adult stream match the usual finding, with women having larger impacts than men over the full 12 quarters. However, the close similarity of the estimates for men and women in the four final quarters suggests that the overall difference derives mainly from differences in opportunity cost, with men giving up higher earnings while in training. In contrast, for the

\footnotetext{
${ }^{13}$ When we regain data access, we will examine whether differences in characteristics, combined with impacts that vary with characteristics, can explain the difference in impacts between the two funding streams.
} 
dislocated worker stream, women have more negative impacts overall but, as with the adult stream, a much smaller difference in quarters 9 to 12 . None of these differences attain conventional levels of statistical significance. Given the lack of clear evidence of impact differences, we pool men and women in our other analyses.

In results not presented here, we also produced subgroup estimates broken down by race / ethnicity and by years of schooling. As with men and women, we did not observe substantively important subgroup differences in the estimates.

\subsection{Comparisons to the literature}

How do our findings comport with those in Heinrich et al. (2012) and Hollenbeck (2009)? Though they provide similar analyses, we should note a few differences. First, the different studies look at different states. Our states do not constitute a proper subset of those considered in Heinrich et al. (2013) nor is Indiana, the state considered by Hollenbeck (2009), one of our two states. Second, the time periods differ, with Heinrich et al. (2012) considering participants who exited between July 2003 and June 2007, and Hollenbeck (2009) considering exits from program year 2006. Third, though both studies assume a selection on observed variables identification strategy and rely on administrative data for the conditioning variables, the exact propensity score specifications and matching / weighting estimators differ in the details. Finally, Hollenbeck (2009) measures outcomes relative to program exit rather than relative to registration. ${ }^{14}$

Heinrich et al. (2012) Figures 5 and 8 present estimates of the impact of training versus core / intensive services for adults and dislocated workers, respectively. They pool the data from the

\footnotetext{
${ }^{14}$ In an e-mail to one of us, Hollenbeck indicated that this choice did not make much difference to his results.
} 
states in their analysis but present separate impacts for men and women. At a broad level, they find the same patterns that we do, including a substantial lock-in effect in the initial quarters (other than male adults), impacts that increase in relative time and then stabilize (other than male adults), slightly more positive impacts for women than men, and much more positive impacts for adults than for dislocated workers. As shown in their Table 4, in their WIA versus no-WIA analysis they also find cross-state variation in impacts, which lends some support to our finding of differential impacts of WIA training versus core / intensive services in our two states.

Hollenbeck (2009) focuses almost exclusively on WIA versus no-WIA treatment effects; the sole exception comes in his Table 6, where he separately compares WIA training to no-WIA and WIA-without-training to no-WIA. The difference between these provides an indirect estimate of the impact of training versus core/intensive. Read this way, for adults he finds surprisingly large employment effects of around 10 percentage points in Q+3 and Q+7, along with modest earnings effects of around $\$ 450$. For dislocated workers, he finds negative employment effects of about 23 percentage points combined with positive earnings effects of about $\$ 150$. The information he provides does not allow the calculation of standard errors for these estimates.

In sum, our estimates generally tell the same stories about WIA training impacts as other studies applying roughly the same methods to similar data in other times and places. Perhaps most importantly, our brief sojourn into the literature strongly suggests that the poor performance of the displaced worker stream does not represent an anomaly that affects only one or two states.

\section{Results: Firm characteristics}

We now turn to our estimated impacts on outcomes related to the jobs that WIA participants obtain in the post-program period. From a long list of possible (and interesting!) candidate firm- 
related outcomes, we confine ourselves to just six to avoid concerns about multiple comparisons. We chose our six based on the prior literature and before looking at any impact estimates.

Three of our outcome measures relate to the firm "fixed effect" contained in the LEHD data. These fixed effects, described in detail in Abowd and Kramarz (1999), condition on fixed effects of the workers as well as some firm characteristics, and so represent a relatively clean measure of job "quality". We include three outcomes related to the fixed effect: (1) an indicator for having a job at a firm with a fixed effect above the median; (2) an indicator for having no available firm fixed effect, which implies either having no job in the twelve calendar quarters after registration or only jobs at firms with fewer than 25 employees; and (3) the (continuous) firm fixed effect itself. Note that we code the first indicator as zero for observations with the second indicator equal to one, so that both indicators are defined for all sample members. As a result, we do not have to deal with selection into employment (or employment at a firm with at least 25 workers) when analyzing those variables. When using the continuous fixed effect as an outcome, we simply drop the observations without a fixed effect; the resulting selection problem, a non-trivial one given the treatment effects on employment described above, leads us to interpret the corresponding estimates as merely suggestive.

Our fourth firm-related outcome consists of an indicator for working at a firm with at least 100 employees. A large literature, e.g. Parsons (1986) and Brown et al. (1990), links firm size and compensation levels. The fifth measure consists of an indicator for working at a high turnover firm, defined as having a turnover rate above the median, since the literature has found that employment at high turnover firms is systematically associated with lower compensation (Holzer et al., 2004). The sixth measure is an indicator for changing industries between the last preregistration employer and the last post-registration employer. This last represents an ambiguous 
measure in the sense that changing industries may represent a good thing, as when moving from a declining to a growing industry, or a bad thing, due to leaving behind industry-specific human capital, or some combination of the two. As with the indicators related to the firm fixed effects, for all three of these variables we code workers without post-registration employment as zeros. Andersson et al. (2005) and Holzer et al. (2011) provide evidence on the correlations among the firm-related variables in the LEHD.

All six measures refer to the last firm that employed the worker in our 12 quarters of postregistration data. While WIA might arguably have the largest direct effect on the first firm with which the worker matches, we thought it more important to focus on longer-run outcomes. By looking at the last firm we may capture the result of a sequence of jobs induced by the program, while missing potentially promising job matches that end quickly.

Tables $6 \mathrm{a}$ and $6 \mathrm{~b}$ present impacts on the firm-related outcomes measured as of the twelfth calendar quarter after WIA registration. For adults, the pattern of point estimates shows a desirable effect on every outcome measure (e.g. a higher probability of working at a high fixed effect firm, and lower probability of working at a high turnover firm and so on). In State A, the effects are all quite small and not statistically different from zero. In State B, we find larger, though still modest, effects, some of which do attain conventional levels of statistical significance. Given the earnings impacts presented above, it will perhaps not startle the reader to learn that the estimates for dislocated workers tell a more negative story. In both states, all of the point estimates on the variables related to the firm fixed effect, as well as the firm size and turnover indicators, suggest that training leads workers to worse firms on average, though in this case none of the estimates differs statistically from zero. 
In regard to the more ambiguous industry switching outcome, we find positive and substantively large impacts for adults in State B and dislocated workers in both states, with a fairly precise zero impact for adults in State A. Though the data speak louder about switching industries than about any of the other firm outcomes we examine, they do not speak clearly, in the sense that it is hard to interpret these impacts when they coincide with moves to better firms for adults and to worse firms for dislocated workers.

How should we think about these estimates? First, we can think about them as illustrating mechanisms through which WIA generates impacts on earnings. Larger firms pay higher wages; for adults, WIA training generates earnings impacts in part because trainees get jobs at larger firms. Second, we can think about them as providing information relative to the likely duration of impacts. The literature on worker-firm matches suggests that the more frequent placements at larger, lower turnover firms likely bodes well for the persistence of the adult impacts we find. Third, we can think about them as informative of the potential for general equilibrium effects, particularly displacement, to lead our partial equilibrium estimates to overstate the social benefits of WIA training. If WIA training just changes who gets the "good jobs" at the larger, lower turnover, higher fixed effect firms, then it may have some equity benefits, but it will not increase efficiency. Finally, the firm fixed effects results have an ambiguous interpretation to the extent that higher wages mean fewer other forms of remuneration, e.g. lower fringes or less pleasant work, as in a compensating differences world, rather than functioning as a one-dimensional measure of overall firm quality as in the standard search literature. 


\section{Results: Alternative identification strategies}

\subsection{CIA with alternative conditioning sets}

This section addresses one of our primary questions of interest: does having information on the firms at which WIA participants worked prior to participation move the estimates relative to the conditioning variables available only from the union of the WIASRD and UI administrative datasets. It does so by comparing estimates obtained using our preferred cross-sectional IPW specification but with propensity scores containing the various sets of conditioning variables described in Section 5.1. Doing so also allows us to address other substantive questions from the literature related to the value of administrative data from UI records, to the number of years of pre-program earnings to condition on and to the importance of local labor markets.

To start off, Table 7 presents correlations among the predicted probabilities of training from the six propensity score models described in Section 5.1 for the four samples defined by state and funding stream. At the grandest level, the table has one very obvious pattern: Models 1 and 2 are "not like the others". The correlation between Model 1 and Model 2 ranges between 0.68 and 0.88, while those between Model 1 and Models 3-6 range from 0.37 to 0.61 and those between Model 2 and Models 3-6 range from 0.55 to 0.71. In contrast, the correlations among Models 3, 4, 5 and 6 all exceed 0.99. Clearly, the variables added in going from Model 1 to Model 2, or from Model 2 to Model 3, add real substance to the propensity score model. In contrast, the additional variables added beyond Model 3, which includes both the firm variables drawn from the LEHD and the additional four quarters of pre-program earnings, do not. These patterns have clear implications for how the impact estimates will change (or not) as we vary the conditioning set. 
Table 8 presents the impact estimates associated with the different specifications. To save space, we focus solely on the aggregated impacts for the 12 quarters after enrollment and for quarters 912 after enrollment and focus on our preferred IPW estimator applied to earnings levels. As Table 7 suggested that they would, the estimates differ substantially between the rather sparse specification of Model 1 and the richer conditioning sets in the other models. In the case of the adults, Model 1 produces less positive estimates while in the case of the dislocated workers they turn out more negative. Given the differences between the estimates, combined with our earlier arguments regarding the variables required for credibility of the CIA, we interpret these differences as bias. Thus, in substantive terms, we conclude that producing credible impact estimates for WIA training requires (at least) conditioning relatively flexibly on the information available from the UI administrative data.

The data also provide pretty clear responses to the other substantive questions that motivated our investigation of alternative specifications. The value of investing in obtaining the firm variables from the LEHD to use as conditioning variables shows up in the differences in estimates, if any, between Model 4 and Model 3 and between Model 6 and Model 5. In all but one case, those differences turn out quite minor indeed. For example, looking at the sum of earnings over Q+9 to $\mathrm{Q}+12$, the changes are quite small (just eight dollars in one case) except for dislocated workers in State A. The additional firm variables in LEHD data clearly do not pass a researcher cost-benefit test in this context based on what they add in terms of the credibility of the CIA.

A comparison of Model 5 with Model 4 provides evidence on the importance of adding an additional year of quarterly pre-program earnings (from Q-9 to Q-12) to the conditioning set we modeled on that of Heinrich et al. (2012). In our data, the additional year of quarterly earnings 
barely moves the estimates. We conclude that the additional pre-program earnings variables do not add anything to the credibility of the CIA in this context.

Finally, a comparison of Model 3 with Model 2 signals the value of adding indicators for the local one-stop at which the participant enrolled in WIA. As noted above, we interpret these primarily as indicators for local labor markets. Our states each contain multiple urban labor markets as well as rural ones. As a result, we expected these variables to matter, though the ambivalent findings in the literature muted our prior: while e.g. Heckman et al. (1998) and Friedlander and Robins (1995) find that local labor markets matter a lot, Dolton and Smith (2011) do not. In our data, even given the conditioning already present in Model 2, additional conditioning on local labor markets moves the impact estimates substantially. This finding reflects substantial geographic heterogeneity in training receipt within our states.

\subsection{Conditional bias stability}

Table 9 presents the estimates that assume the conditional bias stability assumption. We again report estimates for two after periods: $\mathrm{Q}+1$ to $\mathrm{Q}+12$ and $\mathrm{Q}+9$ to $\mathrm{Q}+12$. In both cases, we use the symmetric pre-program period as the before period for the difference-in-differences estimator; that is, we use Q-1 to Q-12 as the before period in the first case and Q-9 to Q-12 in the second case. An alternative strategy would avoid the period of the Ashenfelter dip by using Q-9 to Q-12 as the before period in both cases; Heckman and Smith (1999) document that grave programs result from including the period of the dip in their context. We do not do that here due to the lack of apparent selection into training based on transitory shocks shown in Figure 1. We do not report impacts at the quarterly level to save space. In all cases, we employ our preferred IPW estimator, which now becomes a difference-in-differences weighting estimator. 
Somewhat to our surprise, the difference-in-differences estimates in Table 9 differ only marginally from the cross-sectional estimates discussed above and shown in Table 6. The impacts are just a bit more positive among the dislocated in both states. This similarity suggests that our conditioning variables do a very fine job indeed of capturing time-invariant differences in outcome levels between the trainees and the non-trainees in our sample of WIA enrollees.

\section{Results: Alternative econometric estimators}

In this section, we briefly examine the sensitivity of our estimates to alternative econometric estimators. In particular, Table 10 compares our preferred IPW estimator to estimates obtained using nearest neighbor matching with replacement on the estimated propensity score with one, three and five nearest neighbors. The table reveals little substantive difference between the estimates generated by the different estimators. We do not find this particularly surprising given our relatively large sample sizes and given that our estimated propensity scores do not stray too close to zero and one. ${ }^{15}$

\section{WIA Costs and benefits}

This section performs relatively crude cost-benefit calculations for WIA training versus no training using our preferred estimates from Table 6 . Before presenting the results of our calculations we briefly discuss several issues that arise when performing them. See e.g. Bloom et

\footnotetext{
${ }^{15}$ At revision time, when we again have access to the data, we will examine three additional estimators: pooled OLS, OLS estimated using only the untreated units, and pooled median regression to examine sensitivity to outliers. We also doubt the current nearest neighbor estimates (and so do not say much about them in this version) and look forward to re-generating them using the new routines in Stata 13 rather than the old routines in SAS.
} 
al. (1997), Heckman et al. (1999, Section 10.1), Schochet et al. (2006) and Hollenbeck (2011) for more detailed discussions.

First, WIA, like JTPA before it, stands out for its lack of serious data on programs costs. As such, we examine the cost-benefit performance of WIA training using two different numbers for the costs, neither of them particularly satisfactory. The lower value of $\$ 2500$ draws on the discussion in Heinrich et al. (2011), who in turn cite average direct cost (to WIA) values for the twelve states in their study. Their numbers correspond to all WIA participants, rather than to trainees versus non-trainees, but still likely provide a lower bound, given the strong difference in relative direct costs between the two groups. The higher value of $\$ 7500$ draws on Table 4 in Hollenbeck (2012) and reflects data from Washington State on the cost of providing career and technical education inclusive of the large state subsidies to the community colleges providing the training. We have trimmed down Hollenbeck's numbers a bit to account for the fact that we seek the difference in costs between training and core services, rather than difference between training and no treatment, and because receiving training from WIA may reduce costs to the public of subsidized training provided via other programs (e.g. Pell grants). We assume that all direct costs occur in the first quarter following enrollment.

Second, our data limit us to estimating impacts for 12 quarters following WIA enrollment. Yet the impacts of WIA training may last far longer than that. The literature provides conflicting evidence or, put differently, the literature has too few studies with long-term follow-up data to allow it to sort out what factors do and do not predict persistent impacts; Smith (2011) provides further discussion and citations to the literature. To account for the uncertainty about the persistence of the impacts, our calculations embody three scenarios: (1) zero impacts after the 
data run out; (2) the impacts in Q+12 persist for an additional eight quarters then fall to zero; and (3) the impacts in $Q+12$ continue indefinitely.

Third, we need to say something about the social discount rate and the marginal social cost of public funds (MSCPF). As far as we know, the US does not have any sort of official social discount rate. As such, we follow Heckman et al. (1999) and use 0.05 and 0.10 as annual rates. The MSCPF includes both the direct costs of operating the tax system (e.g. the IRS) and the lost output due to the use of distortionary rather than lump-sum taxes. Estimates of the MSCPF vary widely across studies; see Auerbach and Hines (2002) and Dahlby (2008) for overviews. To account for this variability, we consider values of zero, 0.25 and 0.50 , where e.g. 0.25 means that each dollar of government funds costs society $\$ 1.25$ in output.

Finally, our cost-benefit calculations omit both general equilibrium effects and effects on outcomes other than earnings. General equilibrium effects can result from displacement, wherein the trained worker takes a job that otherwise would have gone to someone else (who is likely not in our no training WIA participant comparison group) or from changes in relative skill prices.

We expect our failure to consider equilibrium effects to lead us to overstate the social benefits of WIA training; see e.g. Lise et al. (2004) or Cahuc and Le Barbanchon (2010) for more on these issues. Effects on other outcomes, such as crime or the well-being of children could in principal go either way; for example, Job Corps' negative effects on crime represent a large portion of its benefits, as shown in Schochet et al. (2008), while Morris and Michalopoulos (2003) find that Canada's Self-Sufficiency Project had mixed effects on child outcomes that depend on child age. On net, we think our failure (a direct result of the limitations imposed by our data) to take other outcomes into consideration likely leads us to understate the benefits of WIA training. Though it 
would make life easier for us and for the reader, the literature provides no reason for thinking the biases from these two omissions cancel each other out.

With all the foregoing in mind, turn now to Tables $11 \mathrm{a}$ and $11 \mathrm{~b}$, which present the results of our calculations for State A and State B, respectively. This table largely follows the structure of Table 20 in Heckman et al. (1999). In each table, the first column indicates the assumed duration of the program impacts, the second the assumed marginal social cost of public funds (a.k.a. the welfare cost of taxation), and the third the assumed discount rate. The next two present discounted net present values per participant from the perspective of society for adults and dislocated workers assuming \$2500 in direct costs, while the final two columns repeat the exercise under the assumption of $\$ 7500$ in direct costs.

For the adult stream, the assumptions make a difference in both states. In both states, the adult stream always passes a cost-benefit test when the impacts last forever. In State A, but not State $\mathrm{B}$, it passes even when the benefits cease after three years, so long as the discount rate, MSCPF and direct costs are not too high. When the impacts last for five years, in both states the adult program has positive net social benefits for many (but not all) parameter combinations. On the other hand (and not at all surprisingly given the impact estimates) the dislocated worker stream essentially never passes a cost-benefit test except for State B under the optimistic assumption that program impacts never fade out.

\section{Conclusions}

Our examination of the impacts of receiving WIA training rather than solely core and/or intensive services in two anonymous states has yielded a wealth of important findings both substantive and methodological. We start by reviewing our substantive findings. 
We find differences in probabilities of training receipt as a function of race, age and education. Substantial unconditional differences by race largely, but not entirely, disappear with conditioning. Differences by age and schooling comport with standard human capital theory and with the types of training offered by WIA.

Our preferred estimates indicate positive earnings and employment effects for the adult funding stream and mostly negative estimates for the dislocated worker stream. This difference, for which we lack a good explanation, parallels findings in the broader literature and represents an important (and highly policy-relevant) open question in this area. Surprisingly, we do not find statistically different impacts for men and women, though our point estimates generally show large impacts for women, in line with the literature. Using the linked data from the LEHD, we find modest impacts on the characteristics of firms where workers get jobs, in directions consistent with the impacts on earnings. We find modest impacts for most groups on switching industries relative to the last pre-WIA employer. The impacts on firm characteristics illustrate one mechanism through which WIA training affects earnings, but also raises concerns about general equilibrium effects. Our estimates imply that the dislocated worker programs likely do not pass a social cost-benefit test, while for the adult programs the sign of the cost-benefit calculation depends on assumptions regarding discount rates, duration of impacts outside the data, the marginal social cost of public funds and the direct social cost of training. Particularly for State A, most reasonable assumptions yield a passing grade.

Our data cover WIA participants who entered the program between 1999 and 2005, inclusive. To what extent would we expect our findings to generalize to the latter part of the last decade, or to the present day? As the institutional framework of WIA has not changed much in the last decade, external validity will hinge on changes in the participant population and on changes in program 
impacts with the business cycle. Published WIASRD data show some important changes in the participant population since 2005. For one thing, the sizes of the adult and dislocated populations have grown quite dramatically; in program years 2001-05, the adults and dislocated worker populations nationwide average about 230,000 and 185,000 respectively. But in PY 2006 the number of adults rises to over 500,000, and in PY 2009 it rose to over 1.1 million. Over time, the populations trend towards containing relatively fewer minority, less-educated and/or low-earning workers; these trends start even before 2007 and become even stronger afterwards, as we might expect to occur during a major recession. Given our finding of no substantively important subgroup differences by sex, race or education, changes in the mix of participants along these variables should not lead to concerns about generalizability. The literature, see Lechner and Wunsch (2009) and the references therein, suggests that partial equilibrium impacts of active labor market programs increase during downturns, because the opportunity cost for trainees falls. Our data also include a downturn, but one not as severe as the Great Recession. This suggests that bumping them up a bit when generalizing to the present. Finally, expanding the scale of the program so dramatically may change the nature of any general equilibrium effects, on which point one could tell stories in either direction. Overall, with think our estimates likely generalize well to the present day but, as always when extrapolating out of sample, with some added uncertainty.

On the methodological side, our most important (and, to us, surprising) conclusion is that adding variables related to the last employer prior to WIA participation to the conditioning set does not budge our "selection on observed variables" estimates. Nor does adding an additional four quarters of lagged earnings move the estimates. In contrast, conditioning on indicators for local labor markets does move the estimates. Comparing our cross-sectional estimates to the 
difference-in-differences estimates also shows little change, suggesting either that selection into training occurs mainly on the something other than relatively time-invariant differences in labor market performance and/or that the conditioning set available in the UI administrative data does a good job of capturing the time invariant differences that matter. While further research linking the UI administrative data to other data sets that would provide alternative conditioning variables, such as psychometric tests, information on other household members and more detailed academic histories remains of great value, we think that taken together, our methodological findings suggest that current practice, as embodied particularly in this paper and in Heinrich et al. (2012), likely removes much of the bias for this estimand.

We conclude with a final point on evaluation policy: why does the federal government, which provides the funding for WIA, not require states to cooperate with serious, policy-relevant research efforts in exchange? In our view, important opportunities for program improvement via research remain largely unexploited because current law allows state administrators too much leeway in restricting access to data over privacy concerns that are not always compelling. We would like to see this change in the future. 


\section{References}

Abadie, Alberto and Guido Imbens. 2008. "On the Failure of the Bootstrap for Matching Estimators." Econometrica 76(6): 1537-1557.

Abadie, Alberto and Guido Imbens. 2012. "Matching on the Estimated Propensity Score." Unpublished manuscript, Harvard University.

Abowd, John and Francis Kramarz. 2002. "The Analysis of Labor Markets Using Matched Employer-Employee Data.” In Orley Ashenfelter and David Card eds. Handbook of Labor Economics, Volume 3B. Amsterdam: North Holland. 2629-2710.

Abowd, John, Bryce E. Stephens, Lars Vilhuber, Fredrik Andersson, Kevin McKinney, Marc Roemer, and Simon Woodcock. 2009. "The LEHD infrastructure files and the creation of the Quarterly Workforce Indicators." In Timothy Dunne, J. Bradford Jensen and Mark Roberts eds. Producer Dynamics: New Evidence from Micro Data. Chicago: University of Chicago Press. 149-230.

Abowd, John, Paul Lengermann and Kevin McKinney. 2002. "The Measurement of Human Capital in the U.S. Economy." LEHD Technical Paper TP-2002-09, US Bureau of the Census.

Almandsmith, Sherry, Lorena Adams and Hans Bos. 2006. Evaluation of the Strengthening the Connections Between Unemployment Insurance and the One-Stop Delivery Systems Demonstration Project in Wisconsin: Final Report. Oakland: Berkeley Policy Associates.

Andersson, Fredrik, Harry Holzer and Julia Lane. 2005. Moving Up or Moving On: Who Advances in the Low-Wage Labor Market? New York: Russell Sage Foundation.

Ashenfelter, Orley. 1978. "Estimating the Effect of Training Programs on Earnings." Review of Economics and Statistics 60(1): 47-57.

Auerbach, Alan and James Hines. 2002. "Taxation and Economic Efficiency." In Alan Auerbach and Martin Feldstein eds. Handbook of Public Fiance, Volume 3. Amsterdam: North-Holland. 1347-1421.

Barnow, Burt. 2011. "Lessons from WIA Performance Measures.” In Douglas Besharov and Phoebe Cottingham eds. The Workforce Investment Act: Implementation Experiences and Evaluation Findings. Kalamazoo MI: Upjohn Institute. 209-232.

Barnow, Burt and Jeffrey Smith. 2004. "Performance Management of U.S. Job Training Programs.” In Christopher O'Leary, Robert Straits and Stephen Wandner eds. Job Trainining Policy in the United States. Kalamazoo MI: Upjohn Institute. 21-56.

Barron, John, Mark Berger and Dan Black. 1997. On-the-Job Training. Kalamazoo MI: Upjohn Institute. 
Behnke, Stefanie, Markus Frölich, and Michael Lechner. 2010. "A Caseworker Like Me - Does the Similarity between the Unemployed and their Casewokers Increase Job Placements." Economic Journal 120(549): 1430-1459.

Bergemann, Annette and Gerard van den Berg. 2008. "Active Labor Market Policy Effects for Women in Europe - A Survey." Annals of Economics and Statistics 91/92: 384-408.

Besharov, Douglas and Phoebe Cottingham eds. 2011. The Workforce Investment Act: Implementation Experiences and Evaluation Findings. Kalamazoo MI: Upjohn Institute.

Black, Daniel and Jeffrey Smith. 2004. "How Robust is the Evidence on the Effects of College Quality? Evidence from Matching," Journal of Econometrics 121(1): 99-124.

Black, Dan, Kermit Daniel and Jeffrey Smith. 2005. "College Quality and Wages in the United States." German Economic Review 6(3): 415-443.

Black, Dan, Jeffrey Smith, Miana Plesca and Suzanne Shannon. 2003. Estimating the Duration of Unemployment Insurance Benefit Recipiency. Revised Final Report Prepared for the US Department of Labor.

Blank, Diane, Laura Heald and Cynthia Fagnoni. 2011. "An Overview of WIA.” In Douglas Besharov and Phoebe Cottingham eds. The Workforce Investment Act: Implementation Experiences and Evaluation Findings. Kalamazoo MI: Upjohn Institute. 49-80.

Bloom, Howard, Larry Orr, Stephen Bell, George Cave, Fred Doolittle, Winston Lin and Johannes Bos. 1997. "The Benefits and Costs of JTPA Title II-A Programs: Finidngs from the National Job Training Partnership Act Study." Journal of Human Resources 32: 549-576.

Brown Charles, James Hamilton and James Medoff. 1990. Employers Large and Small. Cambridge MA: Harvard University Press.

Busso, Matias, John DiNardo and Justin McCrary. 2013. "New Evidence on the Finite Sample Properties of Propensity Score Reweighting and Matching Estimators." Unpublished manuscript, University of California at Berkeley.

Cahuc, Pierre and Thomas Le Barbanchon. 2010. "Labor Market Policy Evaluation in Equilibrium: Some Lessons of the Job Search and Matching Model." Labour Economics 17(1): 196-205.

Caliendo, Marco and Oscar Mitnik. 2013. "Unobservable, But Unimportant! The Influence of Usually Unobserved Variables for Estimating Treatment Effects.” Unpublished manuscript, University of Potsdam.

Card, David, Joachim Kluve and Andrea Weber. 2010. "Active Labour Market Policy Evaluations: A Meta-Analysis.” Economic Journal 120(548): F452-F477. 
Chabé-Ferret, Sylvain. 2012. "Matching vs. Differencing when Estimating Treatment Effects with Panel Data: the Example of the Effect of Job Training Programs on Earnings." Unpublished manuscript, IRSTEA.

Courty, Pascal and Gerald Marschke. 2004. "An Empirical Investigation of Dysfunctional Responses to Explicit Performance Incentives.” Journal of Labor Economics 22(1): 23-56.

Dahlby, Bev. 2008. The Marginal Cost of Public Funds. Cambridge, MA: MIT Press.

D’Amico, Ronald, Kate Dunham, Annelies Goger, Charles Lea, Nicole Rigg, Sheryl Ude and Andrew Wiegand. 2009. Findings from a Study of One-Stop Self-Services: A Case Study Approach. Oakland: Social Policy Research Associates.

Decker, Paul. 2011. "Ten Years of WIA Research.” In Douglas Besharov and Phoebe Cottingham eds. The Workforce Investment Act: Implementation Experiences and Evaluation Findings. Kalamazoo MI: Upjohn Institute. 315-346.

Dehejia, Rajeev and Sadek Wahba. 1999. "Causal Effects in Nonexperimental Studies: Reevaluating the Evaluations of Training Programs." Journal of the American Statistical Association, 94(448): 1053-1062.

Dehejia, Rajeev and Sadek Wahba. 2002. "Propensity Score Matching Methods for Noexperimental Causal Studies." Review of Economics and Statistics, 84(1): 151-161.

Dolton, Peter and Jeffrey Smith. 2011. "The Impact of the UK New Deal for Lone Parents on Benefit Receipt.” IZA Discussion Paper No. 5491.

Fredriksson, Peter and Per Johansson. 2008. "Program Evaluation and Random Program Starts." Journal of Business and Economic Statistics 26(4): 435-445.

Friedlander, Daniel, David Greenberg and Philip Robins. 1997. "Evaluating Government Training Programs for the Economically Disadvantaged." Journal of Economic Literature 35(4): 1809-1855.

Friedlander, Daniel and Philip Robins. 2005. "Evaluating Program Evaluations: New Evidence on Commonly Used Experimental Methods.” American Economic Review 85(4): 923-937.

Frölich, Markus. 2004. "Finite-Sample Properties of Propensity-Score Matching and Weighting Estimators." Review of Economics and Statistics 86(1): 77-90.

Frost, Robert. 1920. “The Road Not Taken.” In: Robert Frost (ed.), Mountain Interval. New York: Henry Holt.

Greenberg, David, Charles Michalopoulos and Philip Robins. 2006. "Do Experimental and Nonexperimental Evaluations Given Different Answers About the Effectiveness of GovernmentFunding Training Programs?" Journal of Policy Analysis and Management 25(3): 523-552. 
Heckman, James, Carolyn Heinrich, Pascal Courty, Gerald Marschke and Jeffrey Smith. 2011. The Performance of Performance Standards. Kalamazoo, MI: W.E. Upjohn Institute for Employment Research.

Heckman, James, Hidehiko Ichimura and Petra Todd. 1997. "Matching as an Econometric Evaluation Estimator: Evidence from Evaluating a Job Training Programme." Review of Economic Studies 64(4): 605-654.

Heckman, James, Hidehiko Ichimura, Jeffrey Smith, and Petra Todd. 1998. "Characterizing Selection Bias Using Experimental Data,” Econometrica 66(5): 1017-1098.

Heckman, James and Salvador Navarro-Lozano. 2004. "Using Matching, Instrumental Variables and Control Functions to Estimate Economic Choice Models." Review of Economics and Statistics 86(1): 30-57.

Heckman, James, Robert LaLonde, and Jeffrey Smith. 1999. "The Economics and Econometrics of Active Labor Market Programs" in Orley Ashenfelter and David Card eds. Handbook of Labor Economics, Volume 3A. Amsterdam: North-Holland. 1865-2097.

Heckman, James, and Jeffrey Smith. 1995. "Assessing the Case for Social Experiments," Journal of Economic Perspectives 9(2): 85-110.

Heckman, James, and Jeffrey Smith. 1999. "The Pre-Program Earnings Dip and the Determinants of Participation in a Social Program: Implications for Simple Program Evaluation Strategies," Economic Journal 109(457): 313-348.

Heinrich, Carolyn, Peter Mueser, Kenneth Troske, Kyung-Seong Jeon and Daver Kahvecioglu. 2009. "A Nonexperimental Evaluation of WIA Programs." In Douglas Besharov and Phoebe Cottingham eds. The Workforce Investment Act: Implementation Experiences and Evaluation Findings. Kalamazoo MI: Upjohn Institute. 371-406.

Heinrich, Carolyn, Peter Mueser, Kenneth Troske, Kyung-Seong Jeon and Daver Kahvecioglu. 2012. "New Estimates of Public Employment and Training Program Net Impacts:

Nonexperimental Evaluation of the Workforce Investment Act Program." Unpublished manuscript, University of Kentucky.

Heinrich, Carolyn and Christopher King. 2010. "How Effective are Workforce Development Programs?" Presented at the 40th Anniversary Conference of the Ray Marshall Center, University of Texas, Austin TX, October.

Hirano, Keisuke and Guido Imbens. 2001. "Estimation of Causal Effects Using Propensity Score Weighting: An Application to Data on Right Heart Catheterization." Health Services and Outcomes Research Methodology 2: 259-278.

Hirano, Keisuke, Guido Imbens, and Geert Ridder. 2003. "Efficient Estimation of Average Treatment Effects Using the Estimated Propensity Score.” Econometrica 71(4): 1161-1189. 
Hollenbeck, Kevin. 2009. "Return on Investment Analysis of a Selected Set of Workforce System Programs in Indiana." Report submitted to the Indiana Chamber of Commerce Foundation, Indianapolis, Indiana. http://research.upjohn.org/reports/15.

Hollenbeck, Kevin. 2012. "Return on Investment in Workforce Development Programs." Upjohn Institute Working Paper 12-188. Kalamazoo, MI: W.E. Upjohn Institute for Employment Research. http://research.upjohn.org/up_workingpapers/188.

Holzer, Harry. 2009. "Workforce Development Policy as an Antipoverty Tool: What Do We Know? What Can We Do?" In Maria Cancian and Sheldon Danziger eds. Changing Poverty, Changing Policy. New York: Russell Sage Foundation. 301-329.

Holzer, Harry, Julia Lane and Lars Vilhuber. 2004. "Escaping Poverty for Low-Wage Workers: The Role of Employer Characteristics and Changes." Industrial and Labor Relations Review 57(4): 560-578.

Holzer, Harry, Julia Lane, David Rosenblum and Fredrik Andersson. 2011. Where Are All the Good Jobs Going? What National and Local Job Quality and Dynamics Mean for U.S. Workers. New York: Russell Sage Foundation.

Horvitz, D. and D. Thompson. 1952. "A Generalization of Sampling Without Replacement from a Finite Universe.” Journal of the American Statistical Association 47(260): 663-685.

Hotz, V. Joseph and Karl Scholz. 2002. "Measuring Employment and Income Outcomes for Low-Income Populations with Administrative and Survey Data." In Studies of Welfare Populations: Data Collection and Research Issues. National Research Council: National Academy Press. 275-315.

Huber, Martin, Michael Lechner and Conny Wunsch. 2013. "The Performance of Estimators Based on the Propensity Score." Journal of Econometrics 175:1-21.

Jacobson, Lou, Robert Lalonde and Daniel Sullivan. 2005. "The Impact of Community College Retraining on Older Displaced Workers: Should We Teach Old Dogs New Tricks?” Industrial and Labor Relations Review 58(3):398-415.

King, Christopher. 2004. "The Effectiveness of Publicly Financed Training in the United States." In Christopher O'Leary, Robert Straits and Stephen Wandner. eds. Job Training Policy in the United States. Kalamazoo MI: Upjohn Institute. 57-100.

King, Christopher and Burt Barnow. 2011. "The Use of Market Mechanisms.” In Douglas Besharov and Phoebe Cottingham eds. The Workforce Investment Act: Implementation Experiences and Evaluation Findings. Kalamazoo, MI: Upjohn Institute. 81-112.

Kornfeld, Robert and Howard Bloom. 1999. "Measuring Program Impacts on Earnings and Employment: Do Unemployment Insurance Wage Reports from Employers Agree with Surveys of Individuals? Journal of Labor Economics 17: 168-197.

Lalonde, Robert. 1995. "The Promise of Public-Sector Training." Journal of Economic Perspectives 9(2): 149-168. 
Lalonde, Robert. 1986. "Evaluating the Econometric Evaluations of Training Programs with Experimental Data.” American Economic Review 76(4): 604-620.

Lechner, Michael. 2010. “The Estimation of Causal Effects by Difference-in-Difference Methods" Foundations and Trends in Econometrics 4(3): 165-224.

Lechner, Michael and Conny Wunsch. 2009. "Are Training Programs More Effective When Unemployment is High?” Journal of Labor Economics 27(4): 653-692.

Lechner, Michael and Conny Wunsch. 2013. "Sensitivity of Matching-Based Program Evaluations to the Availability of Control Variables." Labour Economics 21:111-121.

Lise, Jeremy, Shannon Seitz and Jeffrey Smith. 2004. "Equilibrium Policy Experiments and the Evaluation of Social Programs.” NBER Working Paper No. 10283.

McConnell, Sheena, Paul Decker and Irma Perez-Johnson. 2006. "The Role of Counseling in Voucher Programs: Findings from the Individual Training Account Experiment." Princeton NJ: Mathematica Policy Research.

Morris, Pamela and Charles Michalopoulos. 2003. "Findings from the Self-Sufficiency Project: Effects on Children and Adolescents of a Program That Increased Employment and Earnings." Journal of Applied Developmental Psychology 24(2): 201-239.

Parsons, Donald. 1986. “The Employment Relationship: Job Attachment, Work Effort and the Nature of Contracts.” In Orley Ashenfelter and Richard Layard eds. Handbook of Labor Economics, Volume 1. Amsterdam: North Holland. 789-848.

Pope, Devon and Justin Sydnor. 2011. "Implementing Anti-Discrimination Policies in Statistical Profiling Models.” American Economic Journal: Economic Policy 3(3): 206-231.

Rosenbaum, Paul and Donald Rubin. 1983. "The Central Role of the Propensity Score in Observational Studies for Causal Effects.” Biometrika 70(1): 41-55.

Rosenbaum, Paul. 2001. "Stability in the Absence of Treatment." Journal of the American Statistical Association 96: 210-219.

Schochet, Peter, John Burghardt, and Sheena McConnell. 2006. National Job Corps Study and Longer-Term Follow-Up Study: Impact and Benefit-Cost Findings Using Survey and Summary Earnings Records Data, Final Report. Washington, DC: Mathematica Policy Research.

Schochet, Peter, John Burghardt, and Sheena McConnell. 2008. "Does Job Corps Work? Impact Findings from the National Job Corps Study." American Economic Review 98(5): 1864-86.

Sianesi, Barbara. 2004. "An Evaluation of the Swedish System of Active Labor Market Programs in the 1990s." Review of Economics and Statistics 86(1): 133-155.

Smith, Jeffrey and Petra Todd. 2005. "Does Matching Overcome LaLonde's Critique of Nonexperimental Methods?" Journal of Econometrics 125(1-2): 305-353. 
Stevens, David. 2007. "Employment That Is Not Covered by State Unemployment Insurance Laws.” U.S. Census Bureau (Washington, DC) LEHD Technical Paper No. TP-2007-04.

US Department of Labor. Bureau of Labor Statistics. 1997. Bureau of Labor Statistics Handbook of Methods. Washington DC: Government Printing Office.

Van Horn, Carl and Aaron Fichtner. 2011. "Eligible Training Provider Lists and Consumer Report Cards." In Douglas Besharov and Phoebe Cottingham eds. The Workforce Investment Act: Implementation Experiences and Evaluation Findings. Kalamazoo MI: Upjohn Institute.153-176.

Wallace, Geoffrey and Robert Haveman. 2007. "The Implications of Differences between Employer and Worker Employment/Earnings Reports for Policy Evaluation." Journal of Policy Analysis and Management 26 (4): 737-753. 
TABLE 1a: Descriptive Statistics for Characteristics, State A

\begin{tabular}{|c|c|c|c|c|c|}
\hline & & \multicolumn{2}{|c|}{ Adult } & \multicolumn{2}{|c|}{ Dislocated } \\
\hline & & Treated & Untreated & Treated & Untreated \\
\hline & Male & 0.38 & 0.41 & 0.44 & 0.40 \\
\hline \multirow[t]{3}{*}{ Race } & White & 0.36 & 0.24 & 0.51 & 0.47 \\
\hline & Other & 0.06 & 0.07 & 0.09 & 0.12 \\
\hline & Black & 0.58 & 0.70 & 0.40 & 0.41 \\
\hline \multicolumn{2}{|c|}{ Age at Registration (years) } & 35.32 & 36.20 & 42.01 & 42.65 \\
\hline \multirow{5}{*}{ Education } & Less than High School & 0.10 & 0.25 & 0.04 & 0.08 \\
\hline & High School & 0.60 & 0.54 & 0.53 & 0.43 \\
\hline & Some College & 0.20 & 0.11 & 0.24 & 0.23 \\
\hline & College or More & 0.09 & 0.08 & 0.20 & 0.25 \\
\hline & Missing & 0.01 & 0.03 & 0.00 & 0.02 \\
\hline \multirow[t]{7}{*}{ Year of Registration } & 1999 & 0.00 & 0.00 & 0.00 & 0.00 \\
\hline & 2000 & 0.08 & 0.11 & 0.07 & 0.08 \\
\hline & 2001 & 0.32 & 0.31 & 0.24 & 0.28 \\
\hline & 2002 & 0.23 & 0.26 & 0.28 & 0.28 \\
\hline & 2003 & 0.20 & 0.17 & 0.28 & 0.19 \\
\hline & 2004 & 0.11 & 0.09 & 0.09 & 0.13 \\
\hline & 2005 & 0.06 & 0.06 & 0.04 & 0.05 \\
\hline \multirow[t]{4}{*}{ Quarter of Registrat } & 1 & 0.29 & 0.23 & 0.26 & 0.27 \\
\hline & 2 & 0.23 & 0.24 & 0.28 & 0.26 \\
\hline & 3 & 0.28 & 0.31 & 0.26 & 0.26 \\
\hline & 4 & 0.20 & 0.21 & 0.20 & 0.21 \\
\hline \multicolumn{2}{|c|}{ Earnings in 1st Previous Year } & 13355 & 12349 & 29618 & 29623 \\
\hline \multicolumn{2}{|c|}{ Zero Earnings in 1st Previous Year } & 0.21 & 0.21 & 0.10 & 0.10 \\
\hline \multicolumn{2}{|c|}{ Earnings in 2nd Previous Year } & 14012 & 13837 & 29474 & 30108 \\
\hline \multicolumn{2}{|c|}{ Zero Earnings in 2nd Previous Year } & 0.24 & 0.24 & 0.13 & 0.13 \\
\hline \multirow[t]{10}{*}{ Age at Registration } & $<20$ & 0.08 & 0.08 & 0.01 & 0.01 \\
\hline & $21-25$ & 0.17 & 0.16 & 0.05 & 0.05 \\
\hline & $26-30$ & 0.14 & 0.13 & 0.08 & 0.08 \\
\hline & $31-35$ & 0.14 & 0.13 & 0.13 & 0.12 \\
\hline & $36-40$ & 0.14 & 0.14 & 0.17 & 0.15 \\
\hline & $41-45$ & 0.12 & 0.14 & 0.18 & 0.18 \\
\hline & $46-50$ & 0.09 & 0.10 & 0.16 & 0.16 \\
\hline & $51-55$ & 0.06 & 0.07 & 0.12 & 0.13 \\
\hline & $56-60$ & 0.03 & 0.04 & 0.07 & 0.08 \\
\hline & $61+$ & 0.02 & 0.02 & 0.02 & 0.03 \\
\hline
\end{tabular}


TABLE 1a: Descriptive Statistics for Characteristics, State A

\begin{tabular}{|c|c|c|c|c|c|}
\hline & & Ad & ult & Disloc & cated \\
\hline & & Treated & Untreated & Treated & Untreated \\
\hline Firm Industry & Construction & 0.03 & 0.03 & 0.03 & 0.03 \\
\hline & Manufacturing & 0.09 & 0.07 & 0.22 & 0.13 \\
\hline & Wholesale & 0.03 & 0.03 & 0.06 & 0.05 \\
\hline & Retail & 0.15 & 0.13 & 0.12 & 0.12 \\
\hline & Transportation & 0.02 & 0.02 & 0.02 & 0.02 \\
\hline & Information & 0.02 & 0.02 & 0.04 & 0.04 \\
\hline & Finance & 0.03 & 0.03 & 0.05 & 0.06 \\
\hline & Professional & 0.04 & 0.05 & 0.09 & 0.11 \\
\hline & Support & 0.13 & 0.18 & 0.10 & 0.12 \\
\hline & Education & 0.03 & 0.03 & 0.03 & 0.03 \\
\hline & Health Care & 0.10 & 0.09 & 0.06 & 0.08 \\
\hline & Hotels/Food & 0.12 & 0.12 & 0.03 & 0.04 \\
\hline & Public Administration & 0.02 & 0.03 & 0.02 & 0.02 \\
\hline & Other & 0.03 & 0.03 & 0.03 & 0.03 \\
\hline & Other Services & 0.03 & 0.03 & 0.03 & 0.03 \\
\hline & Unemployed & 0.12 & 0.11 & 0.07 & 0.06 \\
\hline Disabled & & 0.06 & 0.03 & 0.03 & 0.03 \\
\hline Veteran & & 0.06 & 0.05 & 0.08 & 0.07 \\
\hline Transition: Em & oyed & 0.29 & 0.26 & 0.43 & 0.41 \\
\hline Transition: Em & mployed & 0.30 & 0.25 & 0.35 & 0.35 \\
\hline Transition: No & mployed & 0.26 & 0.38 & 0.14 & 0.17 \\
\hline Transition: No & ot Employed & 0.15 & 0.11 & 0.08 & 0.07 \\
\hline TANF in Quart & & 0.06 & 0.08 & 0.00 & 0.01 \\
\hline TANF in Quart & & 0.05 & 0.07 & 0.00 & 0.01 \\
\hline TANF in Quart & & 0.04 & 0.07 & 0.00 & 0.01 \\
\hline TANF in Quart & & 0.05 & 0.07 & 0.00 & 0.01 \\
\hline TANF in Quart & & 0.06 & 0.09 & 0.01 & 0.02 \\
\hline TANF in Quart & & 0.06 & 0.09 & 0.01 & 0.02 \\
\hline Firm Size $>=1$ & & 0.65 & 0.68 & 0.67 & 0.64 \\
\hline Low-Wage Pro & & 0.20 & 0.21 & 0.10 & 0.11 \\
\hline High Turnover & & 0.23 & 0.24 & 0.28 & 0.27 \\
\hline Firm Fixed Eff & & 0.08 & 0.10 & 0.21 & 0.23 \\
\hline Firm Fixed Eff & & 0.10 & 0.10 & 0.18 & 0.14 \\
\hline Firm Fixed Eff & & 0.13 & 0.11 & 0.15 & 0.14 \\
\hline Firm Fixed Eff & & 0.18 & 0.18 & 0.13 & 0.13 \\
\hline Firm Fixed Eff & & 0.25 & 0.27 & 0.11 & 0.13 \\
\hline No Firm Fixed & & 0.14 & 0.13 & 0.15 & 0.17 \\
\hline
\end{tabular}

Source: Authors' calculations from WIA and LEHD data.

Notes: The industry labeled 'Other' comprises agriculture, utilities, mining, real estate, management of

companies, and entertainment. Previous year refers to the four quarters prior to the quarter of WIA

registration. Prior industry refers to the most recent job prior to quarter of WIA registration. 
TABLE 1b: Descriptive Statistics for Characteristics, State B

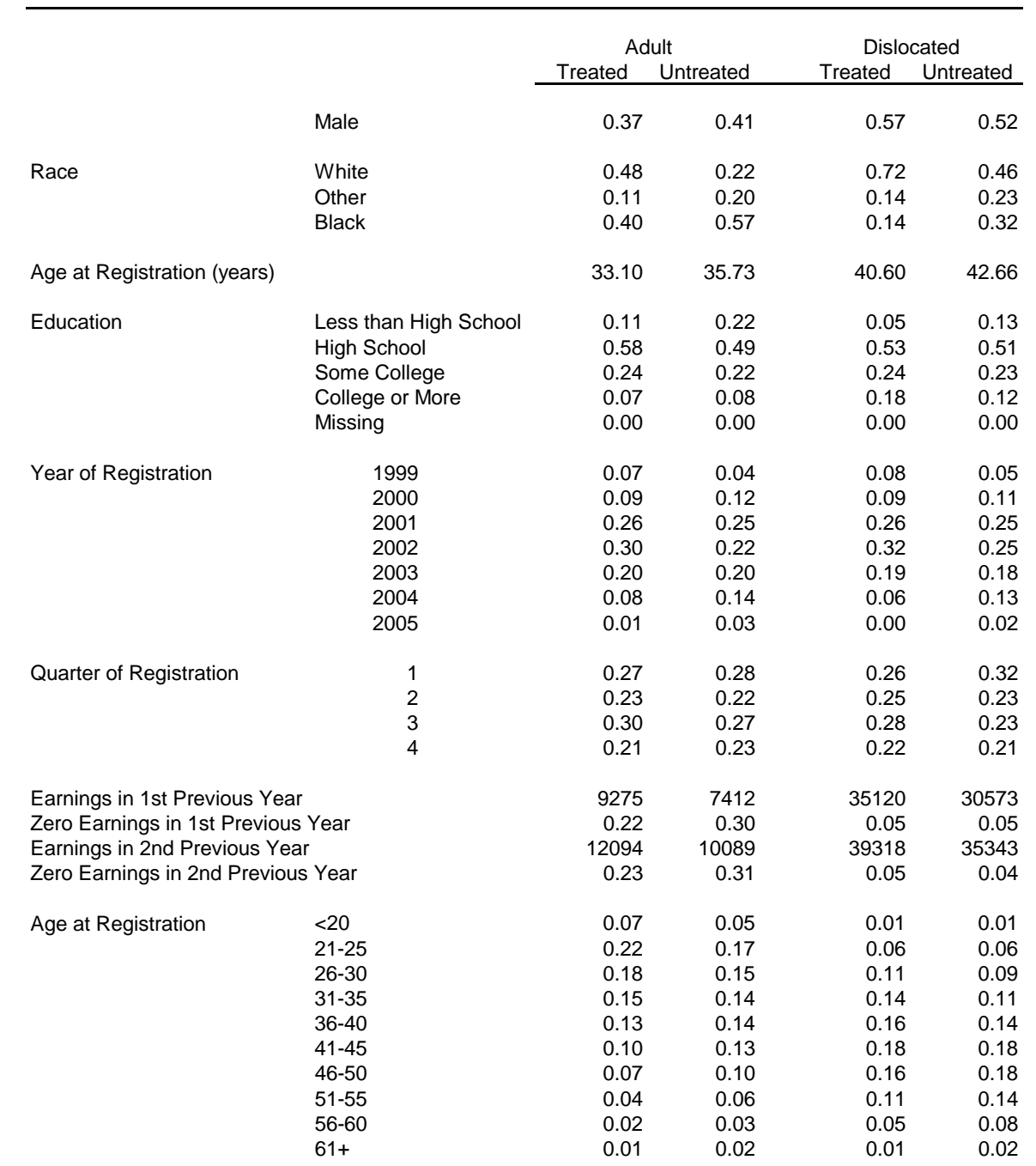


TABLE 1b: Descriptive Statistics for Characteristics, State B

\begin{tabular}{|c|c|c|c|c|c|}
\hline & & \multicolumn{2}{|c|}{ Adult } & \multicolumn{2}{|c|}{ Dislocated } \\
\hline & & Treated & Untreated & Treated & Untreated \\
\hline \multirow[t]{16}{*}{ Firm Industry } & Construction & 0.02 & 0.01 & 0.01 & 0.01 \\
\hline & Manufacturing & 0.11 & 0.11 & 0.39 & 0.39 \\
\hline & Wholesale & 0.03 & 0.02 & 0.05 & 0.04 \\
\hline & Retail & 0.13 & 0.11 & 0.08 & 0.09 \\
\hline & Transportation & 0.04 & 0.04 & 0.04 & 0.04 \\
\hline & Information & 0.02 & 0.02 & 0.05 & 0.04 \\
\hline & Finance & 0.02 & 0.03 & 0.04 & 0.06 \\
\hline & Professional & 0.03 & 0.03 & 0.08 & 0.04 \\
\hline & Support & 0.16 & 0.19 & 0.08 & 0.08 \\
\hline & Education & 0.02 & 0.02 & 0.02 & 0.01 \\
\hline & Health Care & 0.13 & 0.09 & 0.04 & 0.05 \\
\hline & Hotels/Food & 0.12 & 0.10 & 0.02 & 0.04 \\
\hline & Public Administration & 0.02 & 0.01 & 0.01 & 0.02 \\
\hline & Other & 0.03 & 0.03 & 0.04 & 0.04 \\
\hline & Other Services & 0.02 & 0.02 & 0.02 & 0.02 \\
\hline & Unemployed & 0.10 & 0.16 & 0.03 & 0.02 \\
\hline \multirow{2}{*}{\multicolumn{2}{|c|}{$\begin{array}{l}\text { Disabled } \\
\text { Veteran }\end{array}$}} & 0.05 & 0.08 & 0.03 & 0.02 \\
\hline & & 0.05 & 0.05 & 0.10 & 0.09 \\
\hline \multicolumn{2}{|c|}{ Transition: Employed to Employed } & 0.26 & 0.19 & 0.49 & 0.48 \\
\hline \multirow{2}{*}{\multicolumn{2}{|c|}{ Transition: Employed to Not Employed }} & 0.32 & 0.28 & 0.37 & 0.33 \\
\hline \multirow{2}{*}{\multicolumn{2}{|c|}{$\begin{array}{l}\text { Transition: Not Employed to Employed } \\
\text { Transition: Not Employed to Not Employed }\end{array}$}} & 0.27 & 0.36 & 0.10 & 0.16 \\
\hline & & 0.15 & 0.17 & 0.04 & 0.03 \\
\hline \multicolumn{2}{|c|}{ No UI Experience in Quarter t-1 or t-2 } & 0.94 & 0.92 & 0.87 & 0.820 \\
\hline \multicolumn{2}{|c|}{ No UI Experience in Quarter $\mathrm{t}-3$ or $\mathrm{t}-4$} & 0.97 & 0.95 & 0.97 & 0.933 \\
\hline \multicolumn{2}{|c|}{ No UI Experience in Quarters $t-5$ to $t-8$} & 0.99 & 0.98 & 0.99 & 0.978 \\
\hline \multicolumn{2}{|c|}{ Any UI Experience in Quarters t- 1 to $t-4$} & 0.07 & 0.10 & 0.13 & 0.187 \\
\hline \multirow{2}{*}{\multicolumn{2}{|c|}{$\begin{array}{l}\text { Any UI Experience in Quarters } t-1 \text { to } t-8 \\
\text { Anv ES Service Events in Ouarter t-1 or t-2 }\end{array}$}} & 0.07 & 0.11 & 0.13 & 0.188 \\
\hline \multirow{2}{*}{\multicolumn{2}{|c|}{$\begin{array}{l}\text { Any ES Service Events in Quarter t-1 or t-2 } \\
\text { Any ES Service Events in Quarter t-3 or t-4 }\end{array}$}} & 0.04 & 0.06 & 0.03 & 0.040 \\
\hline & & 0.03 & 0.03 & 0.01 & 0.018 \\
\hline \multicolumn{2}{|c|}{ Any ES Service Events in Quarters t- 5 or t-8 } & 0.03 & 0.03 & 0.01 & 0.013 \\
\hline \multirow{2}{*}{\multicolumn{2}{|c|}{$\begin{array}{l}\text { Received any ES Service Events in Quarters } \mathrm{t}-1 \text { to } \mathrm{t}-4 \\
\text { Received any ES Service Events in Quarters } \mathrm{t}-1 \text { to } \mathrm{t}-8\end{array}$}} & 0.05 & 0.07 & 0.04 & 0.048 \\
\hline & & 0.06 & 0.08 & 0.04 & 0.053 \\
\hline \multicolumn{2}{|c|}{ Firm Size $>=100$} & 0.69 & 0.69 & 0.78 & 0.81 \\
\hline \multicolumn{2}{|c|}{ Low-Wage Proportion } & 0.26 & 0.24 & 0.09 & 0.10 \\
\hline \multicolumn{2}{|l|}{ High Turnover } & 0.17 & 0.17 & 0.26 & 0.26 \\
\hline \multirow{2}{*}{\multicolumn{2}{|c|}{$\begin{array}{l}\text { Firm Fixed Effects Quintile } 1 \\
\text { Firm Fixed Effects Quintile } 2\end{array}$}} & 0.07 & 0.06 & 0.31 & 0.23 \\
\hline & & 0.08 & 0.09 & 0.21 & 0.23 \\
\hline \multicolumn{2}{|c|}{ Firm Fixed Effects Quintile 3} & 0.11 & 0.11 & 0.12 & 0.17 \\
\hline \multicolumn{2}{|c|}{ Firm Fixed Effects Quintile 4} & 0.21 & 0.20 & 0.12 & 0.15 \\
\hline \multirow{2}{*}{\multicolumn{2}{|c|}{$\begin{array}{l}\text { Firm Fixed Effects Quintile } 5 \\
\text { No Firm Fixed Effects Ouintile }\end{array}$}} & 0.29 & 0.28 & 0.09 & 0.12 \\
\hline & & 0.13 & 0.10 & 0.10 & 0.08 \\
\hline
\end{tabular}

Source: Authors' calculations from WIA and LEHD data.

Notes: The industry labeled 'Other' comprises agriculture, utilities, mining, real estate, management of

companies, and entertainment. Previous year refers to the four quarters prior to the quarter of WIA

registration. Prior industry refers to the most recent job prior to quarter of WIA registration. 
TABLE 2a: Descriptive Statistics for Earnings \& Employment, State A

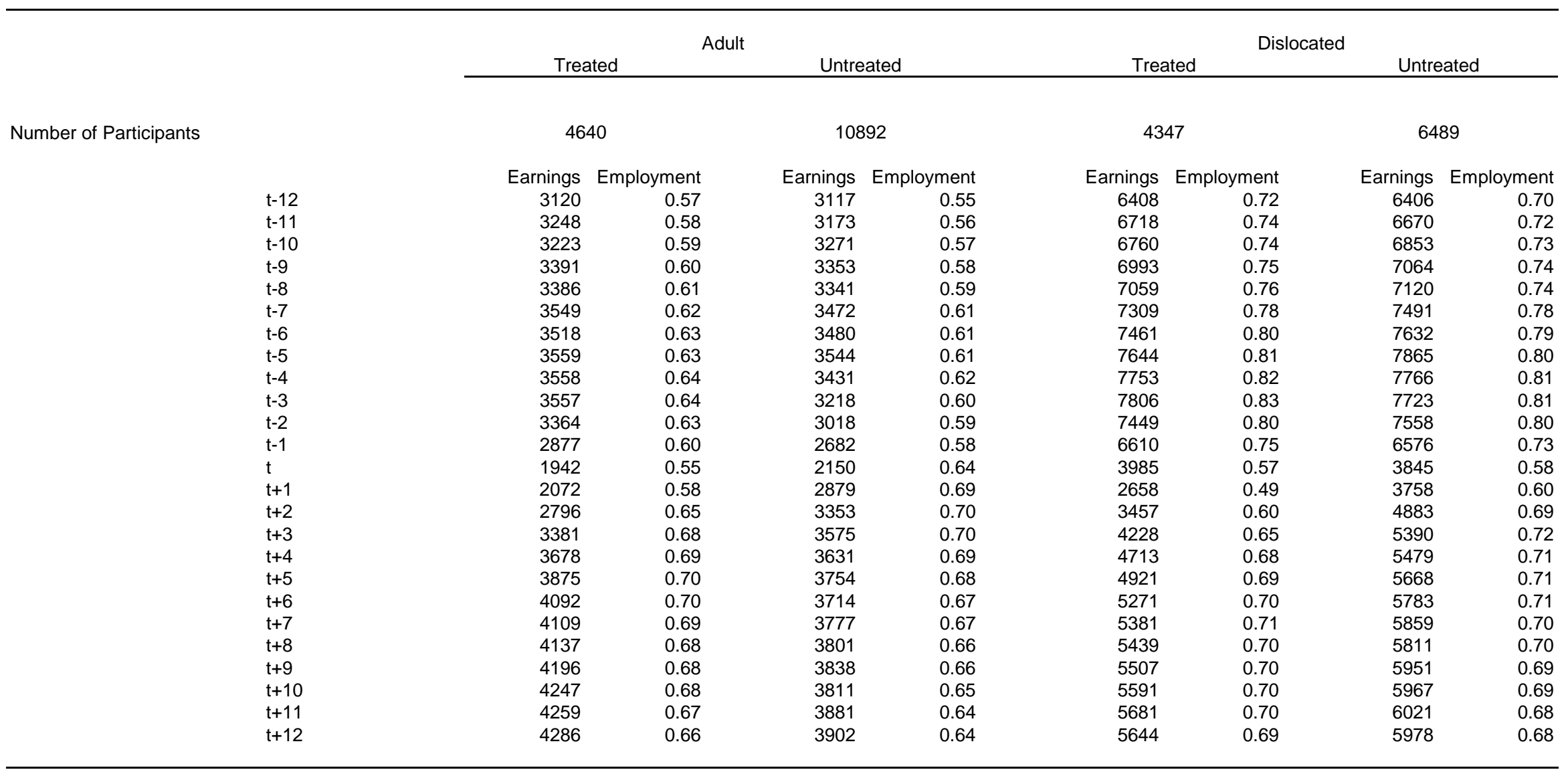

Source: Authors' calculations from WIA and LEHD data.

Notes: Earnings are in 2008\$. Employment is proportion employed. 
TABLE 2b: Descriptive Statistics for Earnings \& Employment, State B

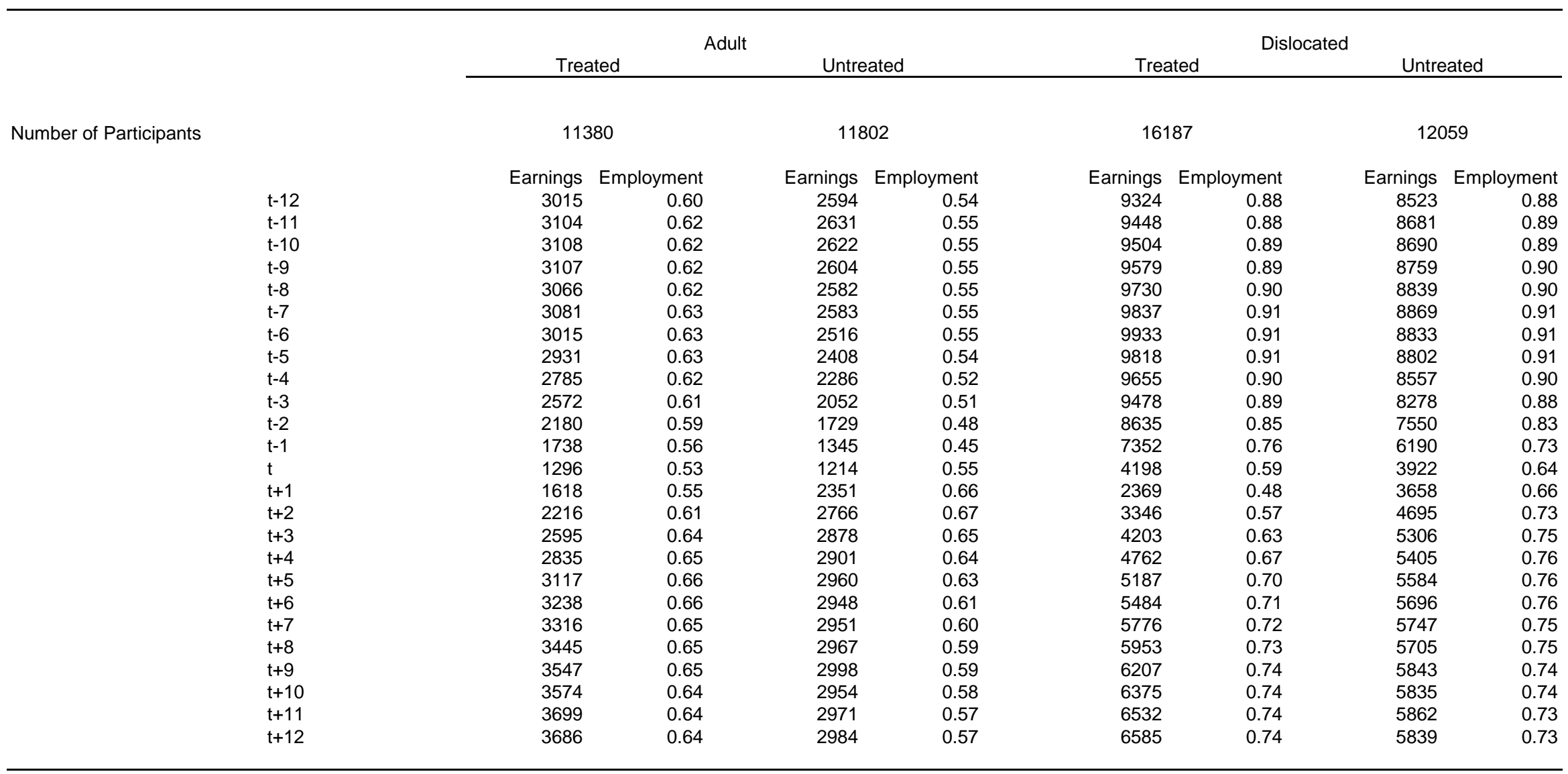

Source: Authors' calculations from WIA and LEHD data.

Notes: Earnings are in 2008\$. Employment is proportion employed. 


\begin{tabular}{|c|c|c|c|c|c|c|c|c|c|c|c|c|c|}
\hline $\begin{array}{l}\text { Omitted } \\
\text { Category }\end{array}$ & Variable & \multicolumn{2}{|l|}{$\begin{array}{r}\text { Model } 1 \\
\text { Avgarainal }\end{array}$} & \multicolumn{2}{|c|}{$\begin{array}{l}\text { Model } 2 \\
\text { Avg }\end{array}$} & \multicolumn{2}{|l|}{$\begin{array}{r}\text { Model } 3 \\
\text { Avg Marainal }\end{array}$} & \multicolumn{2}{|l|}{$\begin{array}{r}\text { Model } 4 \\
\text { Avg }\end{array}$} & \multicolumn{2}{|l|}{$\begin{array}{r}\text { Model } 5 \\
\text { Avg Maroinal }\end{array}$} & \multicolumn{2}{|l|}{$\begin{array}{r}\text { Model } 6 \\
\text { Avgaral }\end{array}$} \\
\hline Quarter 1 & Registered in Ouarter 2 & & & $-0,042$ & 0.000 & -0.017 & 0.000 & -0.017 & 0,000 & -0.017 & 0,000 & -0.017 & 0000 \\
\hline Quarter 1 & Registered in Quarter 3 & & & -0.043 & 0.000 & -0.044 & 0.000 & -0.044 & 0.000 & -0.044 & 0.000 & -0.044 & 0.000 \\
\hline Quarter 1 & Registered in Quarter 4 & & & -0.039 & 0.000 & -0.043 & 0.000 & -0.043 & 0.000 & -0.043 & 0.000 & -0.043 & 0.000 \\
\hline 2002 & Registered in 2000 & & & 0.024 & 0.000 & 0.016 & 0.000 & 0.016 & 0.000 & 0.017 & 0.000 & 0.016 & 0.000 \\
\hline 2002 & Registered in 2001 & & & 0.040 & 0.000 & 0.029 & 0.000 & 0.029 & 0.000 & 0.029 & 0.000 & 0.029 & 0.000 \\
\hline 2002 & Registered in 2003 & & & 0.058 & 0.000 & -0.005 & 0.000 & -0.004 & 0.000 & -0.005 & 0.000 & -0.004 & 0.000 \\
\hline 2002 & Registered in 2004 & & & 0.044 & 0.000 & -0.043 & 0.000 & -0.042 & 0.000 & -0.042 & 0.000 & -0.042 & 0.000 \\
\hline 2002 & Registered in 2005 & & & 0.025 & 0.000 & $\begin{array}{l}-0.043 \\
-0.044\end{array}$ & 0.000 & $\begin{array}{l}-0.042 \\
-0.043\end{array}$ & 0.000 & $\begin{array}{l}-0.048 \\
-0.044\end{array}$ & 0.000 & $\begin{array}{l}-0.042 \\
-0.043\end{array}$ & 0.000 \\
\hline Female & Male & -0.012 & 0.000 & -0.025 & 0.000 & 0.023 & 0.000 & 0.023 & 0.000 & 0.023 & 0.000 & 0.023 & 0.000 \\
\hline White & Other & -0.103 & 0.000 & -0.097 & 0.000 & -0.018 & 0.000 & -0.019 & 0.000 & -0.018 & 0.000 & -0.018 & 0.000 \\
\hline White & Black & -0.121 & 0.000 & -0.104 & 0.000 & 0.015 & 0.000 & 0.014 & 0.000 & 0.015 & 0.000 & 0.014 & 0.000 \\
\hline High School & Less than $\mathrm{HS}$ & -0.190 & 0.000 & -0.187 & 0.000 & -0.168 & 0.001 & -0.168 & 0.001 & -0.168 & 0.001 & -0.167 & 0.001 \\
\hline High School & Some College & 0.094 & 0.000 & 0.087 & 0.000 & 0.045 & 0.000 & 0.045 & 0.000 & 0.045 & 0.000 & 0.045 & 0.000 \\
\hline High School & College or More & -0.004 & 0.000 & 0.001 & 0.000 & -0.015 & 0.000 & -0.015 & 0.000 & -0.015 & 0.000 & -0.015 & 0.000 \\
\hline High School & Education Missing & -0.135 & 0.000 & $\begin{array}{r}-0.151 \\
\end{array}$ & 0.000 & -0.044 & 0.000 & -0.044 & 0.000 & $\begin{array}{l}-0.044 \\
-0.044\end{array}$ & 0.000 & $\begin{array}{l}-0.044 \\
-0.044\end{array}$ & 0.000 \\
\hline $26-30$ & Age $<20$ & & & -0.027 & 0.000 & -0.013 & 0.000 & -0.012 & 0.000 & -0.012 & 0.000 & -0.012 & 0.000 \\
\hline $26-30$ & $21-25$ & & & 0.003 & 0.000 & 0.001 & 0.000 & 0.000 & 0.000 & 0.001 & 0.000 & 0.000 & 0.000 \\
\hline $26-30$ & $31-35$ & & & -0.011 & 0.000 & -0.010 & 0.000 & -0.010 & 0.000 & -0.010 & 0.000 & -0.010 & 0.000 \\
\hline $26-30$ & $36-40$ & & & -0.030 & 0.000 & -0.016 & 0.000 & -0.017 & 0.000 & -0.016 & 0.000 & -0.017 & 0.000 \\
\hline $26-30$ & $41-45$ & & & -0.081 & 0.000 & -0.047 & 0.000 & -0.047 & 0.000 & -0.046 & 0.000 & -0.046 & 0.000 \\
\hline $26-30$ & $46-50$ & & & -0.090 & 0.000 & -0.054 & 0.000 & -0.054 & 0.000 & -0.054 & 0.000 & -0.054 & 0.000 \\
\hline $26-30$ & $51-55$ & & & -0.116 & 0.000 & -0.061 & 0.000 & -0.061 & 0.000 & -0.060 & 0.000 & -0.060 & 0.000 \\
\hline \multirow{17}{*}{$\begin{array}{l}26-30 \\
26-30\end{array}$} & $56-60$ & & & -0.163 & 0.000 & -0.100 & 0.000 & -0.100 & 0.000 & -0.100 & 0.000 & -0.099 & 0.000 \\
\hline & $61+$ & & & -0.062 & 0.000 & -0.060 & 0.000 & -0.061 & 0.000 & -0.060 & 0.000 & -0.060 & 0.000 \\
\hline & Disabled & & & 0.128 & 0.000 & 0.094 & 0.000 & 0.094 & 0.000 & 0.094 & 0.000 & 0.094 & 0.000 \\
\hline & Veteran & & & 0.037 & 0.000 & 0.005 & 0.000 & 0.005 & 0.000 & 0.005 & 0.000 & 0.005 & 0.000 \\
\hline & Never Employed & & & -0.066 & 0.000 & 0.001 & 0.000 & 0.005 & 0.000 & 0.000 & 0.000 & 0.004 & 0.000 \\
\hline & $\begin{array}{l}\text { Model } 1 \text { Earnings variables } \\
\text { Model } 1 \text { Age variables }\end{array}$ & $\begin{array}{l}\text { Include } \\
\text { Include }\end{array}$ & & & & & & & & & & & \\
\hline & Industry of Employing Firm & & & Include & & Include & & Include & & Include & & Include & \\
\hline & No Employment in quarters $t-1$ to $t-8$ & & & Include & & Include & & Include & & Include & & Include & \\
\hline & Earnings in quarters $\mathrm{t}-1$ to $\mathrm{t}-\mathrm{8}$ & & & Include & & Include & & Include & & Include & & Include & \\
\hline & Square of Earnings in quarters $t-1$ to $t-8$ & & & Include & & Include & & Include & & Include & & Include & \\
\hline & $\begin{array}{l}\text { Employment Transitions } \\
\text { Em lo }\end{array}$ & & & Include & & Include & & Include & & Include & & Include & \\
\hline & Positive Earnings in certain periods & & & Include & & Include & & Include & & Include & & Include & \\
\hline & Zero Earnings in certain periods & & & Include & & Include & & Include & & Include & & Include & \\
\hline & TANF Benefits in certain periods (women only) & & & Include & & Include & & Include & & Include & & Include & \\
\hline & WIA Location & & & & & Include & & Include & & Include & & Include & \\
\hline & Firm Variables & & & & & & & Include & & & & Include & \\
\hline & Extra Earnings variables & & & & & & & & & Include & & Include & \\
\hline
\end{tabular}

Source: Authors' calculations from WIA and LEHD data.

Notes: Model 1 earnings variables are earnings in year before WIA registration, a dummy variable for zero earnings in year before WIA registration, earnings in 2nd year before WIA registration, and a dummy variable for zero earnings in 2nd year before WIA registration. Model 1 age variables are age at time of WIA registration and square of age at time of WIA registration. Firm variables are Firm Size >=100, Low-Wage Proportion, High Turnover, and a series of dummy variables for Firm Fixed Effects Quintile. Extra earnings variables are mean earnings in quarters $\mathrm{t}-12$ through $\mathrm{t}-\mathrm{5}$, the standard deviation of earnings in quarters $\mathrm{t}-12$ through $\mathrm{t}-\mathrm{5}$, and a series of dummy variables for the number of quarters with zero earnings. 


\begin{tabular}{|c|c|c|c|c|c|c|c|c|c|c|c|c|c|}
\hline $\begin{array}{l}\text { Omitted } \\
\text { Category }\end{array}$ & Variable & \multicolumn{2}{|c|}{$\begin{array}{l}\text { Model } 1 \\
\text { Avg. Marginal }\end{array}$} & \multicolumn{2}{|l|}{$\begin{array}{r}\text { Model } 2 \\
\text { Avg }\end{array}$} & \multicolumn{2}{|l|}{$\begin{array}{c}\text { Model } 3 \\
\text { Avg }\end{array}$} & \multicolumn{2}{|c|}{$\begin{array}{c}\text { Model } 4 \\
\text { Avg Marainal }\end{array}$} & \multicolumn{2}{|l|}{$\begin{array}{r}\text { Model } 5 \\
\text { Avg Mainal }\end{array}$} & \multicolumn{2}{|l|}{$\begin{array}{l}\text { Model } 6 \\
\text { Ava }\end{array}$} \\
\hline Quarter 1 & Registered in Quarter 2 & & & 0.003 & 0.000 & 0.003 & 0.000 & 0.005 & 0.000 & 0.004 & 0.000 & 0.004 & 0,000 \\
\hline Quarter 1 & Registered in Quarter 3 & & & -0.013 & 0.000 & -0.013 & 0.000 & -0.015 & 0.000 & -0.015 & 0.000 & -0.015 & 0.000 \\
\hline Quarter 1 & Registered in Quarter 4 & & & -0.010 & 0.000 & -0.010 & 0.000 & -0.014 & 0.000 & -0.013 & 0.000 & -0.015 & 0.000 \\
\hline 2002 & Registered in 2000 & & & 0.054 & 0.000 & 0.054 & 0.000 & 0.054 & 0.000 & 0.055 & 0.000 & 0.055 & 0.000 \\
\hline 2002 & Registered in 2001 & & & -0.023 & 0.000 & -0.023 & 0.000 & -0.022 & 0.000 & -0.024 & 0.000 & -0.022 & 0.000 \\
\hline 2002 & Registered in 2003 & & & 0.034 & 0.000 & 0.034 & 0.000 & 0.032 & 0.000 & 0.034 & 0.000 & 0.032 & 0.000 \\
\hline 2002 & Registered in 2004 & & & $\begin{array}{l}-0.074 \\
-0.074\end{array}$ & 0.000 & $\begin{array}{l}-0.074 \\
-0.074\end{array}$ & 0.000 & $\begin{array}{l}-0.074 \\
-0.074\end{array}$ & 0.000 & -0.073 & 0.000 & -0.074 & 0.000 \\
\hline 2002 & Registered in 2005 & & & -0.064 & 0.000 & -0.064 & 0.000 & -0.065 & 0.000 & -0.064 & 0.000 & -0.065 & 0.000 \\
\hline Female & Male & 0.048 & 0.000 & 0.040 & 0.000 & 0.040 & 0.000 & 0.041 & 0.000 & 0.041 & 0.000 & 0.041 & 0.000 \\
\hline White & Other & -0.073 & 0.000 & 0.005 & 0.000 & 0.005 & 0.000 & 0.004 & 0.000 & 0.005 & 0.000 & 0.004 & 0.000 \\
\hline White & Black & -0.028 & 0.000 & 0.039 & 0.000 & 0.039 & 0.000 & 0.035 & 0.000 & 0.038 & 0.000 & 0.035 & 0.000 \\
\hline High School & Less than HS & -0.190 & 0.000 & -0.140 & 0.000 & -0.140 & 0.000 & -0.140 & 0.000 & -0.141 & 0.000 & -0.141 & 0.000 \\
\hline High School & Some College & -0.042 & 0.000 & -0.006 & 0.000 & -0.006 & 0.000 & -0.007 & 0.000 & -0.006 & 0.000 & -0.006 & 0.000 \\
\hline High School & College or More & -0.107 & 0.000 & -0.046 & 0.000 & -0.046 & 0.000 & -0.046 & 0.000 & -0.046 & 0.000 & -0.047 & 0.000 \\
\hline High School & Education Missing & -0.602 & 0.001 & -0.404 & 0.001 & -0.404 & 0.001 & -0.406 & 0.001 & -0.404 & 0.001 & -0.406 & 0.001 \\
\hline $26-30$ & Age $<20$ & & & -0.117 & 0.000 & -0.117 & 0.000 & -0.120 & 0.000 & -0.114 & 0.000 & -0.117 & 0.000 \\
\hline $26-30$ & $21-25$ & & & -0.005 & 0.000 & -0.005 & 0.000 & -0.007 & 0.000 & -0.005 & 0.000 & -0.006 & 0.000 \\
\hline $26-30$ & $31-35$ & & & 0.012 & 0.000 & 0.012 & 0.000 & 0.012 & 0.000 & 0.012 & 0.000 & 0.012 & 0.000 \\
\hline $26-30$ & $36-40$ & & & 0.015 & 0.000 & 0.015 & 0.000 & 0.015 & 0.000 & 0.015 & 0.000 & 0.016 & 0.000 \\
\hline $26-30$ & $41-45$ & & & -0.012 & 0.000 & -0.012 & 0.000 & -0.011 & 0.000 & -0.011 & 0.000 & -0.010 & 0.000 \\
\hline $26-30$ & $46-50$ & & & -0.007 & 0.000 & -0.007 & 0.000 & -0.006 & 0.000 & -0.007 & 0.000 & -0.006 & 0.000 \\
\hline $26-30$ & $51-55$ & & & -0.039 & 0.000 & -0.039 & 0.000 & -0.037 & 0.000 & -0.038 & 0.000 & -0.036 & 0.000 \\
\hline & $56-60$ & & & -0.057 & 0.000 & -0.057 & 0.000 & -0.055 & 0.000 & -0.057 & 0.000 & -0.055 & 0.000 \\
\hline \multirow{16}{*}{$\begin{array}{l}26-30 \\
26-30\end{array}$} & $61+$ & & & -0.065 & 0.000 & -0.065 & 0.000 & -0.063 & 0.000 & -0.063 & 0.000 & -0.061 & 0.000 \\
\hline & Disabled & & & 0.013 & 0.000 & 0.013 & 0.000 & 0.012 & 0.000 & 0.013 & 0.000 & 0.012 & 0.000 \\
\hline & Veteran & & & -0.004 & 0.000 & -0.004 & 0.000 & -0.005 & 0.000 & -0.004 & 0.000 & -0.005 & 0.000 \\
\hline & Never Employed & & & -0.034 & 0.000 & -0.034 & 0.000 & 0.001 & 0.000 & -0.029 & 0.000 & 0.002 & 0.000 \\
\hline & $\begin{array}{l}\text { Model } 1 \text { Earnings variables } \\
\text { Model } 1 \text { Age variables }\end{array}$ & $\begin{array}{l}\text { Includec } \\
\text { Includec }\end{array}$ & & & & & & & & & & & \\
\hline & Industry of Employing Firm & & & Includec & & Includes & & Include & & Includes & & Included & \\
\hline & No Employment in quarters $t-1$ to $t-8$ & & & Included & & Include & & Include & & Include & & Included & \\
\hline & Earnings in quarters $\mathrm{t}-1$ to $\mathrm{t}-8$ & & & Includes & & Includes & & Include & & Include & & Included & \\
\hline & Square of Earnings in quarters $t-1$ to $t-8$ & & & Includes & & Includes & & Include & & Include & & Included & \\
\hline & $\begin{array}{l}\text { Employment Transitions } \\
\text { Em }\end{array}$ & & & Includec & & Includer & & Include & & Includer & & Included & \\
\hline & Positive Earnings in certain periods & & & Includec & & Includes & & Include & & Includes & & Included & \\
\hline & Zero Earnings in certain periods & & & Includes & & Includes & & Include & & Include & & Included & \\
\hline & TANF Benefits in certain periods (women only) & & & Includec & & Includer & & Include & & Includes & & Included & \\
\hline & WIA Location & & & & & Include & & Include & & Include & & Included & \\
\hline & Firm Variables & & & & & & & Include & & & & Included & \\
\hline & Extra Earnings variables & & & & & & & & & Include & & Included & \\
\hline
\end{tabular}

Source: Authors' calculations from WIA and LEHD data.

Notes: Model 1 earnings variables are earnings in year before WIA registration, a dummy variable for zero earnings in year before WIA registration, earnings in 2 2nd year before WIA registration, and a dummy variable for zero earnings in 2 2nd year before WIA registration. Model 1 age variables are age at time of WIA registration and square of age at time of WIA registration. Firm variables are Firm Size >=100, Low-Wage Proportion, High Turnover, and a series of dummy variables for Firm Fixed Effects Quintile. Extra earnings variables are mean earnings in quarters $t-12$ through $t-5$, the standard deviation of earnings in quarters $t-12$ through $t-5$, and a series of dummy variables for the number of quarters with zero earnings. 


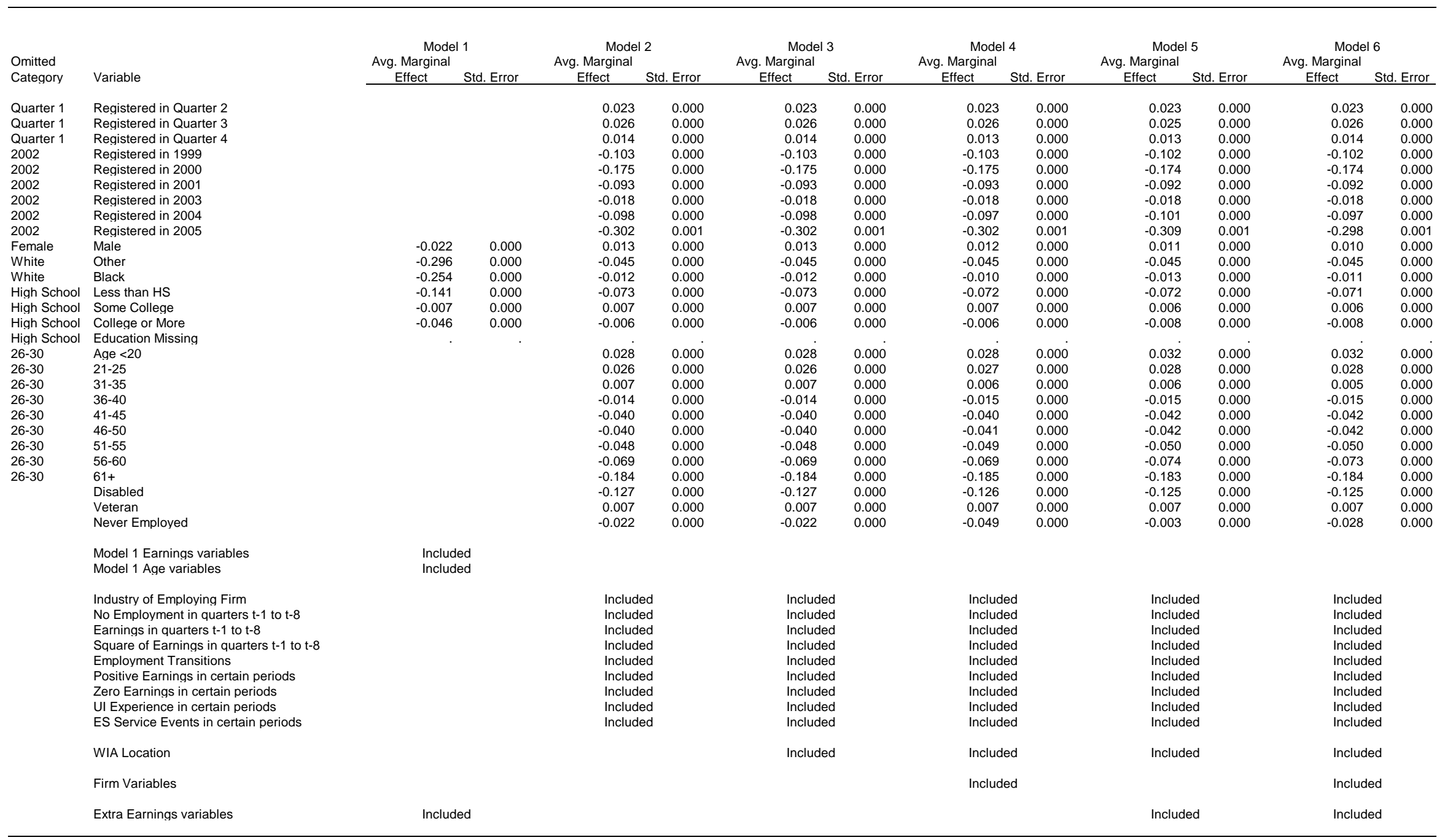

Source: Authors' calculations from WIA and LEHD data.

Notes: Model 1 earnings variables are earnings in year before WIA registration, a dummy variable for zero earnings in year before WIA registration, earnings in 2 nd year before WIA registration, and a dummy variable for zero earnings in 2 2nd year before WIA registration. Model 1 age variables are age at time of WIA registration and square of age at time of WIA registration. Firm variables are Firm Size $>=100$, LoW-Wage Proportion, High Turnover, and a series of dummy variables for Firm Fixed Effects Quintile. Extra earnings variables are mean earnings in quarters $t-12$ through $t-5$, the standard deviation of earnings in quarters $t-12$ through $t-5$, and a series of dummy variables for the number of quarters with zero earnings. 


\begin{tabular}{|c|c|c|c|c|c|c|c|c|c|c|c|c|c|}
\hline $\begin{array}{l}\text { Omitted } \\
\text { Category }\end{array}$ & Variable & \multicolumn{2}{|c|}{$\begin{array}{c}\text { Model } 1 \\
\text { Avg. Marginal }\end{array}$} & \multicolumn{2}{|l|}{$\begin{array}{c}\text { Model } 2 \\
\text { Avg. Marginal }\end{array}$} & \multicolumn{2}{|l|}{$\begin{array}{c}\text { Model } 3 \\
\text { Avg Marginal }\end{array}$} & \multicolumn{2}{|l|}{$\begin{array}{c}\text { Model } 4 \\
\text { Avg Marginal }\end{array}$} & \multicolumn{2}{|l|}{$\begin{array}{l}\text { Model } 5 \\
\text { Avg. Marginal }\end{array}$} & \multicolumn{2}{|l|}{$\begin{array}{l}\text { Model } 6 \\
\text { Avg. Marginal }\end{array}$} \\
\hline Quarter 1 & Registered in Quarter 2 & & & 0.028 & 0.000 & 0.028 & 0.000 & 0.026 & 0.000 & 0.027 & 0.000 & 0.026 & 0.000 \\
\hline Quarter 1 & Registered in Quarter 3 & & & 0.043 & 0.000 & 0.043 & 0.000 & 0.044 & 0.000 & 0.044 & 0.000 & 0.045 & 0.000 \\
\hline Quarter 1 & Registered in Quarter 4 & & & 0.015 & 0.000 & 0.015 & 0.000 & 0.016 & 0.000 & 0.016 & 0.000 & 0.017 & 0.000 \\
\hline 2002 & Registered in 1999 & & & -0.066 & 0.000 & -0.066 & 0.000 & -0.066 & 0.000 & -0.064 & 0.000 & -0.065 & 0.000 \\
\hline 2002 & Registered in 2000 & & & -0.129 & 0.000 & -0.129 & 0.000 & -0.130 & 0.000 & -0.129 & 0.000 & -0.130 & 0.000 \\
\hline 2002 & Registered in 2001 & & & -0.067 & 0.000 & -0.067 & 0.000 & -0.065 & 0.000 & -0.065 & 0.000 & -0.065 & 0.000 \\
\hline 2002 & Registered in 2003 & & & -0.029 & 0.000 & -0.029 & 0.000 & -0.028 & 0.000 & -0.029 & 0.000 & -0.028 & 0.000 \\
\hline 2002 & Registered in 2004 & & & -0.136 & 0.000 & -0.136 & 0.000 & $\begin{array}{l}-0.134 \\
-0.134\end{array}$ & 0.000 & -0.135 & 0.000 & -0.133 & 0.000 \\
\hline 2002 & Registered in 2005 & & & -0.308 & 0.001 & -0.308 & 0.001 & -0.309 & 0.001 & -0.306 & 0.001 & -0.306 & 0.001 \\
\hline Female & Male & 0.011 & 0.000 & 0.020 & 0.000 & 0.020 & 0.000 & 0.019 & 0.000 & 0.018 & 0.000 & 0.018 & 0.000 \\
\hline White & Other & -0.203 & 0.000 & -0.025 & 0.000 & -0.025 & 0.000 & -0.024 & 0.000 & -0.026 & 0.000 & -0.024 & 0.000 \\
\hline White & Black & -0.285 & 0.000 & -0.047 & 0.000 & -0.047 & 0.000 & -0.046 & 0.000 & -0.047 & 0.000 & -0.045 & 0.000 \\
\hline High School & Less than HS & -0.143 & 0.000 & -0.060 & 0.000 & -0.060 & 0.000 & -0.059 & 0.000 & -0.059 & 0.000 & -0.058 & 0.000 \\
\hline High School & Some College & 0.012 & 0.000 & 0.015 & 0.000 & 0.015 & 0.000 & 0.014 & 0.000 & 0.015 & 0.000 & 0.014 & 0.000 \\
\hline High School & College or More & 0.063 & 0.000 & 0.026 & 0.000 & 0.026 & 0.000 & 0.025 & 0.000 & 0.023 & 0.000 & 0.023 & 0.000 \\
\hline High School & Education Missing & & & & & & & & & & & & \\
\hline $26-30$ & Age $<20$ & & & -0.009 & 0.000 & -0.009 & 0.000 & -0.005 & 0.000 & -0.002 & 0.000 & 0.001 & 0.000 \\
\hline $26-30$ & $21-25$ & & & 0.010 & 0.000 & 0.010 & 0.000 & 0.010 & 0.000 & 0.011 & 0.000 & 0.011 & 0.000 \\
\hline $26-30$ & $31-35$ & & & -0.005 & 0.000 & -0.005 & 0.000 & -0.004 & 0.000 & -0.006 & 0.000 & -0.005 & 0.000 \\
\hline $26-30$ & $36-40$ & & & -0.021 & 0.000 & -0.021 & 0.000 & -0.020 & 0.000 & -0.022 & 0.000 & -0.021 & 0.000 \\
\hline $26-30$ & $41-45$ & & & -0.052 & 0.000 & -0.052 & 0.000 & -0.051 & 0.000 & -0.053 & 0.000 & -0.052 & 0.000 \\
\hline $26-30$ & $46-50$ & & & -0.077 & 0.000 & -0.077 & 0.000 & -0.075 & 0.000 & -0.078 & 0.000 & -0.076 & 0.000 \\
\hline $26-30$ & $51-55$ & & & -0.119 & 0.000 & -0.119 & 0.000 & -0.116 & 0.000 & -0.120 & 0.000 & -0.117 & 0.000 \\
\hline $26-30$ & $56-60$ & & & -0.151 & 0.000 & -0.151 & 0.000 & -0.148 & 0.000 & -0.152 & 0.000 & -0.150 & 0.000 \\
\hline \multirow[t]{17}{*}{$26-30$} & $61+$ & & & -0.175 & 0.000 & -0.175 & 0.000 & -0.172 & 0.000 & -0.175 & 0.000 & -0.172 & 0.000 \\
\hline & Disabled & & & -0.023 & 0.000 & -0.023 & 0.000 & -0.023 & 0.000 & -0.024 & 0.000 & -0.023 & 0.000 \\
\hline & Veteran & & & -0.007 & 0.000 & -0.007 & 0.000 & -0.007 & 0.000 & -0.007 & 0.000 & -0.008 & 0.000 \\
\hline & Never Employed & & & -0.001 & 0.000 & -0.001 & 0.000 & -0.039 & 0.000 & 0.010 & 0.000 & -0.024 & 0.000 \\
\hline & $\begin{array}{l}\text { Model } 1 \text { Earnings variables } \\
\text { Model } 1 \text { Age variables }\end{array}$ & $\begin{array}{l}\text { Included } \\
\text { Included }\end{array}$ & & & & & & & & & & & \\
\hline & Industry of Employing Firm & & & \multirow{9}{*}{\multicolumn{2}{|c|}{$\begin{array}{l}\text { Included } \\
\text { Included } \\
\text { Included } \\
\text { Included } \\
\text { Included } \\
\text { Included } \\
\text { Included } \\
\text { Included } \\
\text { Included }\end{array}$}} & \multirow{9}{*}{\multicolumn{2}{|c|}{$\begin{array}{l}\text { Included } \\
\text { Included } \\
\text { Included } \\
\text { Included } \\
\text { Included } \\
\text { Included } \\
\text { Included } \\
\text { Included } \\
\text { Included }\end{array}$}} & \multicolumn{2}{|c|}{ Included } & \multicolumn{2}{|c|}{ Included } & \multicolumn{2}{|l|}{ Included } \\
\hline & No Employment in quarters $t-1$ to $t-8$ & & & & & & & \multicolumn{2}{|c|}{ Included } & \multirow{2}{*}{\multicolumn{2}{|c|}{ Included }} & \multicolumn{2}{|c|}{ Included } \\
\hline & Earnings in quarters t- 1 to $t-8$ & & & & & & & Include & & & Included & \multicolumn{2}{|c|}{ Included } \\
\hline & $\begin{array}{l}\text { Square of Earnings in quarters } t-1 \text { to } t-8 \\
\text { S }\end{array}$ & & & & & & & \multicolumn{2}{|c|}{ Included } & Includec & & Included & \\
\hline & $\begin{array}{l}\text { Employment Transitions } \\
\text { Emplo }\end{array}$ & & & & & & & \multicolumn{2}{|c|}{ Included } & Includec & & Included & \\
\hline & Positive Earnings in certain periods & & & & & & & Include & & Includec & & Included & \\
\hline & Zero Earnings in certain periods & & & & & & & Include & & Includes & & Included & \\
\hline & UI Experience in certain periods & & & & & & & 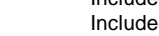 & & Includec & & Included & \\
\hline & ES Service Events in certain periods & & & & & & & Include & & Includes & & Included & \\
\hline & WIA Location & & & & & Include & & Include & & Includec & & Included & \\
\hline & Firm Variables & & & & & & & Include & & & & Included & \\
\hline & Extra Earnings variables & Includec & & & & & & & & Includec & & Included & \\
\hline
\end{tabular}

Source: Authors' calculations from WIA and LEHD data.

Notes: Model 1 earnings variables are earnings in year before WIA registration, a dummy variable for zero earnings in year before WIA registration, earnings in 2 2nd year before WIA registration, and a dummy variable for zero earnings in 2 2nd year before WIA registration. Model 1 age variables are age at time of WIA registration and square of age at time of WIA registration. Firm variables are Firm Size $>=100$, Low-Wage Proportion, High Turnover, and a series of dummy variables for Firm Fixed Effects Quintile. Extra earnings variables are mean earnings in quarters $t-12$ through $t-5$, the standard deviation of earnings in quarters $t-12$ through $t-5$, and a series of dummy variables for the number of quarters with zero earnings. 
TABLE 4a: Impacts on Earnings \& Employment, Inverse Propensity Score Weighting, Model 6, State A

\begin{tabular}{|c|c|c|c|c|c|c|}
\hline & \multicolumn{3}{|c|}{ Adult Classification } & \multicolumn{3}{|c|}{ Dislocated Classification } \\
\hline & $\begin{array}{c}\text { Treatment } \\
\text { Effect }\end{array}$ & $\begin{array}{c}\text { Standard } \\
\text { Error }\end{array}$ & P-value & $\begin{array}{c}\text { Treatment } \\
\text { Effect }\end{array}$ & $\begin{array}{c}\text { Standard } \\
\text { Error }\end{array}$ & P-value \\
\hline \multicolumn{7}{|l|}{ Earnings, Differences } \\
\hline$t+1$ & -597 & 55 & $<.0001$ & -939 & 104 & $<.0001$ \\
\hline$t+2$ & -464 & 59 & $<.0001$ & -1121 & 102 & $<.0001$ \\
\hline$t+3$ & -276 & 67 & $<.0001$ & -969 & 105 & $<.0001$ \\
\hline$t+4$ & -39 & 67 & 0.597 & -546 & 104 & $<.0001$ \\
\hline$t+5$ & -11 & 69 & 0.887 & -478 & 105 & $<.0001$ \\
\hline$t+6$ & 214 & 74 & 0.009 & -281 & 112 & 0.014 \\
\hline$t+7$ & 245 & 69 & 0.001 & -180 & 110 & 0.103 \\
\hline$t+8$ & 274 & 70 & 0.000 & -154 & 112 & 0.174 \\
\hline$t+9$ & 304 & 72 & 0.000 & -491 & 161 & 0.002 \\
\hline$t+10$ & 393 & 72 & $<.0001$ & -155 & 114 & 0.179 \\
\hline$t+11$ & 261 & 74 & 0.001 & -123 & 124 & 0.330 \\
\hline$t+12$ & 299 & 75 & 0.000 & -129 & 118 & 0.281 \\
\hline Total, $\mathrm{t}+1$ to $\mathrm{t}+12$ & 602 & 641 & 0.387 & -5567 & 1047 & $<.0001$ \\
\hline Total, $t+9$ to $t+12$ & 1257 & 270 & $<.0001$ & -899 & 447 & 0.045 \\
\hline \multicolumn{7}{|l|}{ Employed } \\
\hline$t+1$ & -0.070 & 0.008 & $<.0001$ & -0.067 & 0.010 & $<.0001$ \\
\hline$t+2$ & -0.030 & 0.008 & 0.000 & -0.055 & 0.009 & $<.0001$ \\
\hline$t+3$ & -0.013 & 0.007 & 0.121 & -0.030 & 0.009 & 0.001 \\
\hline$t+4$ & -0.003 & 0.007 & 0.729 & -0.001 & 0.009 & 0.886 \\
\hline$t+5$ & 0.012 & 0.007 & 0.126 & 0.009 & 0.009 & 0.316 \\
\hline$t+6$ & 0.022 & 0.007 & 0.007 & 0.026 & 0.009 & 0.004 \\
\hline$t+7$ & 0.021 & 0.007 & 0.009 & 0.043 & 0.009 & $<.0001$ \\
\hline$t+8$ & 0.007 & 0.007 & 0.366 & 0.039 & 0.009 & $<.0001$ \\
\hline$t+9$ & 0.018 & 0.008 & 0.032 & 0.035 & 0.009 & 0.000 \\
\hline$t+10$ & 0.028 & 0.008 & 0.001 & 0.036 & 0.009 & $<.0001$ \\
\hline$t+11$ & 0.018 & 0.008 & 0.028 & 0.051 & 0.009 & $<.0001$ \\
\hline$t+12$ & 0.022 & 0.008 & 0.008 & 0.037 & 0.009 & $<.0001$ \\
\hline
\end{tabular}

Source: Authors' calculations from WIA and LEHD data. 
TABLE 4b: Impacts on Earnings \& Employment, Inverse Propensity Score Weighting, Model 6, State B

\begin{tabular}{|c|c|c|c|c|c|c|}
\hline & \multicolumn{3}{|c|}{ Adult Classification } & \multicolumn{3}{|c|}{ Dislocated Classification } \\
\hline & $\begin{array}{c}\text { Treatment } \\
\text { Effect }\end{array}$ & $\begin{array}{c}\text { Standard } \\
\text { Error }\end{array}$ & P-value & $\begin{array}{c}\text { Treatment } \\
\text { Effect }\end{array}$ & $\begin{array}{c}\text { Standard } \\
\text { Error }\end{array}$ & P-value \\
\hline \multicolumn{7}{|l|}{ Earnings, Differences } \\
\hline$t+1$ & -688 & 37 & $<.0001$ & -1258 & 63 & $<.0001$ \\
\hline$t+2$ & -633 & 43 & $<.0001$ & -1295 & 62 & $<.0001$ \\
\hline$t+3$ & -374 & 45 & $<.0001$ & -1179 & 66 & $<.0001$ \\
\hline$t+4$ & -184 & 46 & $<.0001$ & -852 & 65 & $<.0001$ \\
\hline$t+5$ & 24 & 49 & 0.630 & -662 & 66 & $<.0001$ \\
\hline$t+6$ & 81 & 50 & 0.105 & -399 & 67 & $<.0001$ \\
\hline$t+7$ & 157 & 50 & 0.002 & -262 & 69 & 0.000 \\
\hline$t+8$ & 245 & 53 & $<.0001$ & -134 & 68 & 0.051 \\
\hline$t+9$ & 368 & 53 & $<.0001$ & -26 & 71 & 0.713 \\
\hline$t+10$ & 405 & 54 & $<.0001$ & 163 & 71 & 0.022 \\
\hline$t+11$ & 486 & 55 & $<.0001$ & 310 & 71 & $<.0001$ \\
\hline$t+12$ & 445 & 56 & $<.0001$ & 368 & 72 & $<.0001$ \\
\hline Total, $\mathrm{t}+1$ to $\mathrm{t}+12$ & 329 & 467 & 0.480 & -5227 & 653 & $<.0001$ \\
\hline Total, $\mathrm{t}+9$ to $\mathrm{t}+12$ & 1703 & 201 & $<.0001$ & 815 & 265 & 0.002 \\
\hline \multicolumn{7}{|l|}{ Employed } \\
\hline$t+1$ & -0.084 & 0.006 & $<.0001$ & -0.120 & 0.006 & $<.0001$ \\
\hline$t+2$ & -0.049 & 0.006 & $<.0001$ & -0.105 & 0.006 & $<.0001$ \\
\hline$t+3$ & -0.017 & 0.006 & 0.007 & -0.086 & 0.006 & $<.0001$ \\
\hline$t+4$ & 0.010 & 0.006 & 0.106 & -0.066 & 0.005 & $<.0001$ \\
\hline$t+5$ & 0.018 & 0.006 & 0.004 & -0.046 & 0.005 & $<.0001$ \\
\hline$t+6$ & 0.026 & 0.006 & $<.0001$ & -0.025 & 0.005 & $<.0001$ \\
\hline$t+7$ & 0.023 & 0.006 & 0.000 & -0.019 & 0.005 & 0.000 \\
\hline$t+8$ & 0.046 & 0.006 & $<.0001$ & -0.003 & 0.005 & 0.559 \\
\hline$t+9$ & 0.047 & 0.006 & $<.0001$ & 0.001 & 0.005 & 0.862 \\
\hline$t+10$ & 0.049 & 0.006 & $<.0001$ & 0.007 & 0.005 & 0.191 \\
\hline$t+11$ & 0.056 & 0.006 & $<.0001$ & 0.016 & 0.005 & 0.003 \\
\hline$t+12$ & 0.055 & 0.006 & $<.0001$ & 0.017 & 0.005 & 0.002 \\
\hline
\end{tabular}

Source: Authors' calculations from WIA and LEHD data. 
TABLE 5a: Impacts on Earnings, Inverse Propensity Score Weighting, Model 6, State A

\begin{tabular}{|c|c|c|c|c|c|c|c|}
\hline & & \multicolumn{3}{|c|}{ Adult Classification } & \multicolumn{3}{|c|}{ Dislocated Classification } \\
\hline & & $\begin{array}{l}\text { Treatment } \\
\text { Effect }\end{array}$ & $\begin{array}{l}\text { Standard } \\
\text { Error }\end{array}$ & P-value & $\begin{array}{c}\text { Treatment } \\
\text { Effect }\end{array}$ & $\begin{array}{l}\text { Standard } \\
\text { Error }\end{array}$ & P-value \\
\hline \multicolumn{8}{|l|}{ Women } \\
\hline & Total, $t+1$ to $t+12$ & 625 & 761 & 0.444 & $-7,254$ & 1229 & $<.0001$ \\
\hline & Total, $\mathrm{t}+9$ to $\mathrm{t}+12$ & 1,204 & 318 & 0.001 & $-1,119$ & 504 & 0.025 \\
\hline \multicolumn{8}{|l|}{ Men } \\
\hline & Total, $\mathrm{t}+1$ to $\mathrm{t}+12$ & 382 & 1123 & 0.758 & $-5,254$ & 1805 & 0.004 \\
\hline & Total, $t+9$ to $t+12$ & 1,256 & 477 & 0.019 & $-1,316$ & 792 & 0.096 \\
\hline
\end{tabular}

Source: Authors' calculations from WIA and LEHD data. 
TABLE 5b: Impacts on Earnings, Inverse Propensity Score Weighting, Model 6, State B

\begin{tabular}{|c|c|c|c|c|c|c|c|}
\hline & & \multicolumn{3}{|c|}{ Adult Classification } & \multicolumn{3}{|c|}{ Dislocated Classification } \\
\hline & & $\begin{array}{l}\text { Treatment } \\
\text { Effect }\end{array}$ & $\begin{array}{l}\text { Standard } \\
\text { Error }\end{array}$ & $\mathrm{P}$-value & $\begin{array}{l}\text { Treatment } \\
\text { Effect }\end{array}$ & $\begin{array}{c}\text { Standard } \\
\text { Error }\end{array}$ & P-value \\
\hline \multicolumn{8}{|l|}{ Women } \\
\hline & Total, $t+1$ to $t+12$ & 1,355 & 525 & 0.010 & $-5,074$ & 824 & $<.0001$ \\
\hline & Total, $t+9$ to $t+12$ & 2,238 & 228 & $<.0001$ & 566 & 338 & 0.096 \\
\hline \multicolumn{8}{|l|}{ Men } \\
\hline & Total, $t+1$ to $t+12$ & 236 & 861 & 0.784 & $-3,675$ & 949 & 0.000 \\
\hline & Total, $t+9$ to $t+12$ & 2,056 & 363 & $<.0001$ & 1,756 & 383 & $<.0001$ \\
\hline
\end{tabular}

Source: Authors' calculations from WIA and LEHD data. 
TABLE 6a: Impacts on Firm Characteristics, Inverse Propensity Score Weighting, Model 6, State A

\begin{tabular}{|c|c|c|c|c|c|c|}
\hline & \multicolumn{3}{|c|}{ Adult Classification } & \multicolumn{3}{|c|}{ Dislocated Classification } \\
\hline & $\begin{array}{c}\text { Treatment } \\
\text { Effect }\end{array}$ & $\begin{array}{l}\text { Standard } \\
\text { Error }\end{array}$ & P-value & $\begin{array}{c}\text { Treatment } \\
\text { Effect }\end{array}$ & $\begin{array}{l}\text { Standard } \\
\text { Error }\end{array}$ & P-value \\
\hline \multicolumn{7}{|l|}{ High Fixed Effect } \\
\hline$t+12$ & 0.006 & 0.007 & 0.401 & -0.001 & 0.008 & 0.892 \\
\hline \multicolumn{7}{|l|}{ No Fixed Effect } \\
\hline$t+12$ & 0.008 & 0.006 & 0.186 & 0.010 & 0.007 & 0.179 \\
\hline \multicolumn{7}{|l|}{ Continuous Fixed Effect } \\
\hline$t+12$ & 0.003 & 0.005 & 0.477 & -0.011 & 0.005 & 0.053 \\
\hline \multicolumn{7}{|l|}{ Firm Size $>=100$} \\
\hline$t+12$ & 0.005 & 0.009 & 0.637 & -0.015 & 0.011 & 0.167 \\
\hline \multicolumn{7}{|l|}{ High Turnover } \\
\hline$t+12$ & -0.009 & 0.008 & 0.301 & 0.006 & 0.009 & 0.481 \\
\hline \multicolumn{7}{|l|}{ Switched Industry } \\
\hline$t+12$ & -0.001 & 0.009 & 0.909 & 0.054 & 0.010 & $<.0001$ \\
\hline
\end{tabular}

Source: Authors' calculations from WIA and LEHD data. 
TABLE 6b: Impacts on Firm Characteristics, Inverse Propensity Score Weighting, Model 6, State B

\begin{tabular}{|c|c|c|c|c|c|c|}
\hline & \multicolumn{3}{|c|}{ Adult Classification } & \multicolumn{3}{|c|}{ Dislocated Classification } \\
\hline & $\begin{array}{c}\text { Treatment } \\
\text { Effect }\end{array}$ & $\begin{array}{l}\text { Standard } \\
\text { Error }\end{array}$ & P-value & $\begin{array}{c}\text { Treatment } \\
\text { Effect }\end{array}$ & $\begin{array}{l}\text { Standard } \\
\text { Error }\end{array}$ & P-value \\
\hline \multicolumn{7}{|l|}{ High Fixed Effect } \\
\hline $\mathrm{t}+12$ & 0.036 & 0.006 & $<.0001$ & -0.005 & 0.005 & 0.336 \\
\hline \multicolumn{7}{|l|}{ No Fixed Effect } \\
\hline$t+12$ & -0.006 & 0.004 & 0.172 & 0.014 & 0.004 & 0.001 \\
\hline \multicolumn{7}{|l|}{ Continuous Fixed Effect } \\
\hline$t+12$ & 0.002 & 0.004 & 0.530 & -0.001 & 0.003 & 0.850 \\
\hline \multicolumn{7}{|l|}{ Firm Size $>=100$} \\
\hline $\mathrm{t}+12$ & 0.030 & 0.007 & $<.0001$ & -0.011 & 0.006 & 0.075 \\
\hline \multicolumn{7}{|l|}{ High Turnover } \\
\hline$t+12$ & -0.012 & 0.006 & 0.073 & 0.004 & 0.005 & 0.398 \\
\hline \multicolumn{7}{|l|}{ Switched Industry } \\
\hline$t+12$ & 0.050 & 0.008 & $<.0001$ & 0.065 & 0.006 & $<.0001$ \\
\hline
\end{tabular}

Source: Authors' calculations from WIA and LEHD data. 
TABLE 7a: Correlation matrix of predictions from six propensity score models, State A

\begin{tabular}{|c|c|c|c|c|c|c|c|c|c|c|c|c|}
\hline Adult & & & & & & & Dislocated & & & & & \\
\hline Model 1 & Model 2 & Model 3 & Model 4 & Model 5 & Model 6 & & Model 1 & Model 2 & Model 3 & Model 4 & Model 5 & $\begin{array}{l}\text { Model } 6 \\
0.3692\end{array}$ \\
\hline 1.0000 & 0.7993 & 0.4563 & 0.4560 & 0.4562 & 0.4559 & Model 1 & 1.0000 & 0.6753 & 0.3712 & 0.3696 & 0.3708 & $\begin{array}{l}0.3692 \\
0.5517\end{array}$ \\
\hline & 1.0000 & 0.5681 & 0.5677 & 0.5681 & 0.5677 & Model 2 & & 1.0000 & 0.5547 & 0.5522 & 0.5542 & 0.5517 \\
\hline & & 1.0000 & 0.9993 & 0.9999 & 0.9991 & Model 3 & & & 1.0000 & 0.9958 & 0.9989 & 0.9947 \\
\hline & & & 1.0000 & 0.9991 & 0.9999 & Model 4 & & & & 1.0000 & 0.9947 & 0.9989 \\
\hline & & & & 1.0000 & 0.9993 & Model 5 & & & & & 1.0000 & 0.9958 \\
\hline & & & & & 1.0000 & Model 6 & & & & & & 1.0000 \\
\hline
\end{tabular}

Source: Authors' calculations from WIA and LEHD data. 
TABLE 7b: Correlation matrix of predictions from six propensity score models, State B

\begin{tabular}{|c|c|c|c|c|c|c|c|c|c|c|c|c|}
\hline $\begin{array}{l}\text { Adult } \\
\text { Model } 1\end{array}$ & Model 2 & Model 3 & Model 4 & Model 5 & Model 6 & & $\begin{array}{l}\text { Dislocated } \\
\text { Model } 1\end{array}$ & Model 2 & Model 3 & Model 4 & Model 5 & Model 6 \\
\hline 1.0000 & 0.8599 & 0.6144 & 0.6141 & 0.6140 & 0.6137 & Model 1 & 1.0000 & 0.8813 & 0.6132 & 0.6117 & 0.6126 & 0.6111 \\
\hline & 1.0000 & 0.7148 & 0.7143 & 0.7141 & 0.7136 & Model 2 & & 1.0000 & 0.6949 & 0.6931 & 0.6942 & 0.6926 \\
\hline & & 1.0000 & 0.9993 & 0.9989 & 0.9982 & Model 3 & & & 1.0000 & 0.9973 & 0.9990 & 0.996 \\
\hline & & & 1.0000 & 0.9983 & 0.9990 & Model 4 & & & & 1.0000 & 0.9963 & 0.9991 \\
\hline & & & & 1.0000 & 0.9994 & Model 5 & & & & & 1.0000 & 0.9974 \\
\hline & & & & & 1.0000 & Model 6 & & & & & & 1.0000 \\
\hline
\end{tabular}

Source: Authors' calculations from WIA and LEHD data. 
TABLE 8a: Impacts on Earnings, Inverse Propensity Score Weighting, Alternative Conditioning Variables, State A

\begin{tabular}{|c|c|c|c|c|c|c|}
\hline & \multicolumn{3}{|c|}{ Adult Classification } & \multicolumn{3}{|c|}{ Dislocated Classification } \\
\hline & $\begin{array}{c}\text { Treatment } \\
\text { Effect }\end{array}$ & $\begin{array}{c}\text { Standard } \\
\text { Error }\end{array}$ & P-value & $\begin{array}{c}\text { Treatment } \\
\text { Effect }\end{array}$ & $\begin{array}{l}\text { Standard } \\
\text { Error }\end{array}$ & P-value \\
\hline \multicolumn{7}{|c|}{ Combined change over $t+1$ through $t+12$} \\
\hline Model 1 & -1703 & 655 & 0.016 & -8819 & 1024 & $<.0001$ \\
\hline Model 2 & -603 & 648 & 0.388 & -8994 & 1025 & $<.0001$ \\
\hline Model 3 & 622 & 641 & 0.371 & -5671 & 1047 & $<.0001$ \\
\hline Model 4 & 626 & 641 & 0.368 & -5544 & 1048 & $<.0001$ \\
\hline Model 5 & 596 & 641 & 0.391 & -5679 & 1047 & $<.0001$ \\
\hline Model 6 & 602 & 641 & 0.387 & -5567 & 1047 & $<.0001$ \\
\hline \multicolumn{7}{|c|}{ Combined change over $t+9$ through $t+12$} \\
\hline Model 1 & 502 & 274 & 0.093 & -1777 & 431 & $<.0001$ \\
\hline Model 2 & 747 & 272 & 0.012 & -2048 & 433 & $<.0001$ \\
\hline Model 3 & 1277 & 270 & $<.0001$ & -935 & 449 & 0.038 \\
\hline Model 4 & 1263 & 270 & $<.0001$ & -901 & 448 & 0.045 \\
\hline Model 5 & 1270 & 270 & $<.0001$ & -927 & 447 & 0.039 \\
\hline Model 6 & 1257 & 270 & $<.0001$ & -899 & 447 & 0.045 \\
\hline
\end{tabular}

Source: Authors' calculations from WIA and LEHD data. 
TABLE 8b: Impacts on Earnings, Inverse Propensity Score Weighting, Alternative Conditioning Variables, State B

\begin{tabular}{|c|c|c|c|c|c|c|}
\hline & \multicolumn{3}{|c|}{ Adult Classification } & \multicolumn{3}{|c|}{ Dislocated Classification } \\
\hline & $\begin{array}{c}\text { Treatment } \\
\text { Effect }\end{array}$ & $\begin{array}{l}\text { Standard } \\
\text { Error }\end{array}$ & P-value & $\begin{array}{c}\text { Treatment } \\
\text { Effect }\end{array}$ & $\begin{array}{l}\text { Standard } \\
\text { Error }\end{array}$ & P-value \\
\hline \multicolumn{7}{|c|}{ Combined change over $t+1$ through $t+12$} \\
\hline Model 1 & -1293 & 463 & 0.005 & -9684 & 658 & $<.0001$ \\
\hline Model 2 & -82 & 463 & 0.860 & -7510 & 661 & $<.0001$ \\
\hline Model 3 & 704 & 465 & 0.130 & -5308 & 654 & $<.0001$ \\
\hline Model 4 & 668 & 465 & 0.151 & -5247 & 653 & $<.0001$ \\
\hline Model 5 & 347 & 467 & 0.457 & -5292 & 654 & $<.0001$ \\
\hline Model 6 & 329 & 467 & 0.480 & -5227 & 653 & $<.0001$ \\
\hline \multicolumn{7}{|c|}{ Combined change over $t+9$ through $t+12$} \\
\hline Model 1 & 1378 & 198 & $<.0001$ & -520 & 270 & 0.056 \\
\hline Model 2 & 1621 & 199 & $<.0001$ & 67 & 272 & 0.807 \\
\hline Model 3 & 1826 & 200 & $<.0001$ & 784 & 266 & 0.003 \\
\hline Model 4 & 1801 & 200 & $<.0001$ & 804 & 265 & 0.003 \\
\hline Model 5 & 1716 & 201 & $<.0001$ & 797 & 265 & 0.003 \\
\hline Model 6 & 1703 & 201 & $<.0001$ & 815 & 265 & 0.002 \\
\hline
\end{tabular}

Source: Authors' calculations from WIA and LEHD data. 
TABLE 9a: Differences-in-Differences Impacts on Earnings, Inverse Propensity Score Weighting, Model 6, State A

\begin{tabular}{|c|c|c|c|c|c|c|c|}
\hline & & \multicolumn{3}{|c|}{ Adult Classification } & \multicolumn{3}{|c|}{ Dislocated Classification } \\
\hline & & $\begin{array}{c}\text { Treatment } \\
\text { Effect }\end{array}$ & $\begin{array}{l}\text { Standard } \\
\text { Error }\end{array}$ & P-value & $\begin{array}{c}\text { Treatment } \\
\text { Effect }\end{array}$ & $\begin{array}{c}\text { Standard } \\
\text { Error }\end{array}$ & P-value \\
\hline \multicolumn{8}{|c|}{ Differences-in-Differences, $t+1$ to $t+12$} \\
\hline \multirow[t]{14}{*}{ Difference in } & Prior Earnings & -128 & 722 & 0.872 & -2562 & 1273 & 0.047 \\
\hline & Total Change & 729 & 738 & 0.373 & -3005 & 1329 & 0.026 \\
\hline & $t+1$ & -587 & 69 & $<.0001$ & -726 & 125 & $<.0001$ \\
\hline & $t+2$ & -453 & 70 & $<.0001$ & -908 & 125 & $<.0001$ \\
\hline & $t+3$ & -266 & 75 & 0.001 & -756 & 127 & $<.0001$ \\
\hline & $\mathrm{t}+4$ & -29 & 74 & 0.728 & -332 & 126 & 0.010 \\
\hline & $t+5$ & 0 & 76 & 0.999 & -264 & 126 & 0.041 \\
\hline & $t+6$ & 224 & 79 & 0.011 & -68 & 130 & 0.613 \\
\hline & $t+7$ & 255 & 74 & 0.002 & 33 & 129 & 0.801 \\
\hline & $t+8$ & 285 & 76 & 0.001 & 59 & 129 & 0.653 \\
\hline & $t+9$ & 315 & 77 & 0.000 & -278 & 175 & 0.104 \\
\hline & $t+10$ & 403 & 76 & $<.0001$ & 59 & 132 & 0.662 \\
\hline & $t+11$ & 271 & 78 & 0.002 & 90 & 141 & 0.531 \\
\hline & $t+12$ & 310 & 79 & 0.000 & 84 & 135 & 0.540 \\
\hline \multicolumn{8}{|c|}{ Differences-in-Differences, $t+9$ to $t+12$} \\
\hline \multirow[t]{6}{*}{ Difference in } & Prior Earnings & -81 & 273 & 0.787 & -807 & 475 & 0.093 \\
\hline & Total Change & 1337 & 321 & 0.000 & -92 & 568 & 0.873 \\
\hline & $t+9$ & 324 & 85 & 0.001 & -290 & 185 & 0.109 \\
\hline & $t+10$ & 413 & 84 & $<.0001$ & 47 & 143 & 0.748 \\
\hline & $t+11$ & 281 & 86 & 0.003 & 79 & 152 & 0.612 \\
\hline & $t+12$ & 319 & 86 & 0.001 & 73 & 146 & 0.625 \\
\hline
\end{tabular}

Source: Authors' calculations from WIA and LEHD data.

Notes: For differences-in-differences analysis, the pre-period is $t-12$ through $t-1$ when using $t+1$ to $t+12$ as the

post-period, and is $t-12$ through $t-9$ when using $t+9$ through $t+12$ as the post-period. 
TABLE 9b: Differences-in-Differences Impacts on Earnings, Inverse Propensity Score Weighting, Model 6, State B

\begin{tabular}{|c|c|c|c|c|c|c|c|}
\hline & & \multicolumn{3}{|c|}{ Adult Classification } & \multicolumn{3}{|c|}{ Dislocated Classification } \\
\hline & & $\begin{array}{c}\text { Treatment } \\
\text { Effect }\end{array}$ & $\begin{array}{c}\text { Standard } \\
\text { Error }\end{array}$ & P-value & $\begin{array}{c}\text { Treatment } \\
\text { Effect }\end{array}$ & $\begin{array}{c}\text { Standard } \\
\text { Error }\end{array}$ & P-value \\
\hline \multicolumn{8}{|c|}{ Differences-in-Differences, $t+1$ to $t+12$} \\
\hline \multirow[t]{14}{*}{ Difference in } & Prior Earnings & 836 & 493 & 0.091 & -1018 & 812 & 0.215 \\
\hline & Total Change & -506 & 525 & 0.335 & -4209 & 805 & $<.0001$ \\
\hline & $t+1$ & -758 & 47 & $<.0001$ & -1174 & 78 & $<.0001$ \\
\hline & $t+2$ & -703 & 50 & $<.0001$ & -1211 & 77 & $<.0001$ \\
\hline & $t+3$ & -444 & 51 & $<.0001$ & -1094 & 79 & $<.0001$ \\
\hline & $\mathrm{t}+4$ & -254 & 51 & $<.0001$ & -767 & 76 & $<.0001$ \\
\hline & $t+5$ & -46 & 53 & 0.387 & -578 & 76 & $<.0001$ \\
\hline & $t+6$ & 11 & 53 & 0.830 & -315 & 77 & $<.0001$ \\
\hline & $t+7$ & 87 & 53 & 0.102 & -177 & 78 & 0.025 \\
\hline & $t+8$ & 175 & 55 & 0.001 & -49 & 77 & 0.529 \\
\hline & $t+9$ & 298 & 55 & $<.0001$ & 59 & 80 & 0.468 \\
\hline & $t+10$ & 335 & 56 & $<.0001$ & 248 & 79 & 0.002 \\
\hline & $t+11$ & 416 & 57 & $<.0001$ & 395 & 80 & $<.0001$ \\
\hline & $t+12$ & 375 & 59 & $<.0001$ & 452 & 81 & $<.0001$ \\
\hline \multicolumn{8}{|c|}{ Differences-in-Differences, $t+9$ to $t+12$} \\
\hline \multirow[t]{6}{*}{ Difference in } & Prior Earnings & 291 & 217 & 0.180 & -251 & 304 & 0.414 \\
\hline & Total Change & 1412 & 250 & $<.0001$ & 1066 & 328 & 0.001 \\
\hline & $t+9$ & 295 & 64 & $<.0001$ & 37 & 86 & 0.673 \\
\hline & $t+10$ & 332 & 66 & $<.0001$ & 226 & 86 & 0.009 \\
\hline & $t+11$ & 413 & 66 & $<.0001$ & 373 & 86 & $<.0001$ \\
\hline & $t+12$ & 372 & 67 & $<.0001$ & 430 & 88 & $<.0001$ \\
\hline
\end{tabular}

Source: Authors' calculations from WIA and LEHD data.

Notes: For differences-in-differences analysis, the pre-period is $t-12$ through $t-1$ when using $t+1$ to $t+12$ as the

post-period, and is $t-12$ through $t-9$ when using $t+9$ through $t+12$ as the post-period. 
TABLE 10a: Impacts on Earnings, Model 6, Alternative Matching and Weighting Estimators, State A

\begin{tabular}{|c|c|c|c|c|c|c|}
\hline & \multicolumn{3}{|c|}{ Adult Classification } & \multicolumn{3}{|c|}{ Dislocated Classification } \\
\hline & $\begin{array}{l}\text { Treatment } \\
\text { Effect }\end{array}$ & $\begin{array}{l}\text { Standard } \\
\text { Error }\end{array}$ & T-value & $\begin{array}{l}\text { Treatment } \\
\text { Effect }\end{array}$ & $\begin{array}{l}\text { Standard } \\
\text { Error }\end{array}$ & T-value \\
\hline \multicolumn{7}{|c|}{ Combined change over $t+1$ through $t+12$} \\
\hline 1 Neighbor & 7923 & 3993 & 1.98 & -3374 & 4595 & -0.73 \\
\hline 3 Neighbors & 6541 & 3555 & 1.84 & -3268 & 3992 & -0.82 \\
\hline 5 Neighbors & 6651 & 3382 & 1.97 & -3648 & 3727 & -0.98 \\
\hline IPW & 729 & 738 & 0.99 & -3005 & 1329 & 2.30 \\
\hline \multicolumn{7}{|c|}{ Combined change over $t+9$ through $t+12$} \\
\hline 1 Neighbor & 3302 & 1813 & 1.82 & -794 & 2032 & -0.39 \\
\hline 3 Neighbors & 1393 & 807 & 1.73 & -23 & 908 & -0.02 \\
\hline 5 Neighbors & 3452 & 1480 & 2.33 & -930 & 1657 & -0.56 \\
\hline IPW & 1337 & 321 & 4.20 & -92 & 568 & 0.16 \\
\hline
\end{tabular}

Source: Authors' calculations from WIA and LEHD data. 
TABLE 10b: Impacts on Earnings, Model 6, Alternative Matching and Weighting Estimators, State B

\begin{tabular}{|c|c|c|c|c|c|}
\hline \multicolumn{3}{|c|}{ Adult Classification } & \multicolumn{3}{|c|}{ Dislocated Classification } \\
\hline Treatment & Standard & & Treatment & Standard & \\
\hline Effect & Error & T-value & Effect & Error & T-value \\
\hline
\end{tabular}

Combined change over $\mathrm{t}+1$ through $\mathrm{t}+12$

$\begin{array}{lrrrrrr}1 \text { Neighbor } & -4400 & 3437 & -1.28 & -1620 & 2844 & -0.57 \\ 3 \text { Neighbors } & -5067 & 2980 & -1.70 & 296 & 2386 & 0.12 \\ 5 \text { Neighbors } & -4706 & 2766 & -1.70 & 1648 & 2255 & 0.73 \\ \text { IPW } & -506 & 525 & 0.96 & -4209 & 805 & 5.23\end{array}$

Combined change over $\mathrm{t}+9$ through $\mathrm{t}+12$

$\begin{array}{lrrrrrr}1 \text { Neighbor } & 557 & 1496 & 0.37 & 979 & 1185 & 0.83 \\ 3 \text { Neighbors } & 577 & 682 & 0.85 & 585 & 513 & 1.14 \\ 5 \text { Neighbors } & 642 & 1236 & 0.52 & 1877 & 937 & 2.00 \\ \text { IPW } & 1412 & 250 & 5.66 & 1066 & 328 & 3.25\end{array}$

Source: Authors' calculations from WIA and LEHD data. 
TABLE 11a: Cost-Benefit Analysis, State A

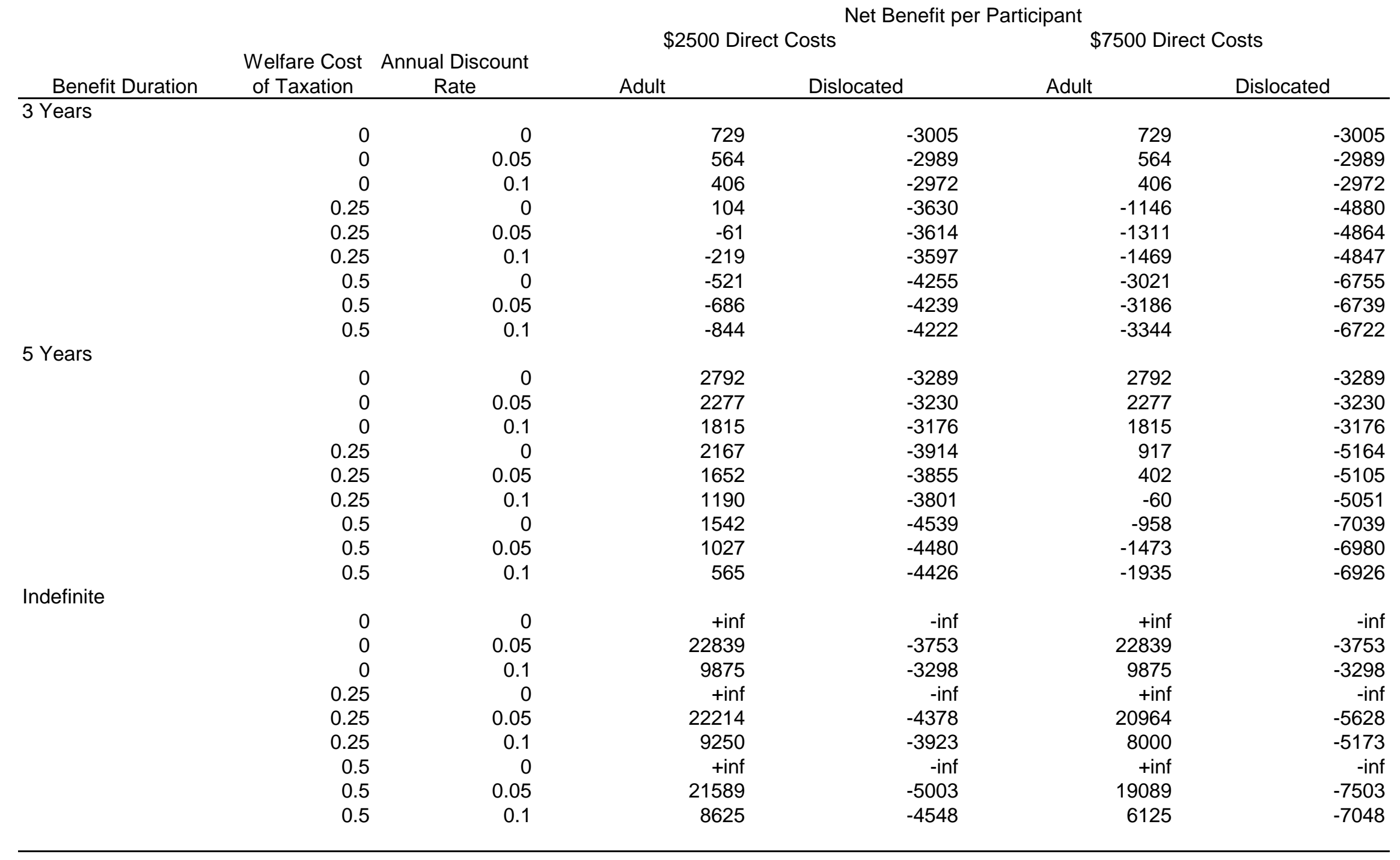

Source: Authors' calculations from WIA and LEHD data.

Notes: Estimates are drawn from Table 4. With an annual discount rate of 0 , the benefits under the assumption of indefinite benefit duration become infinite, whether positive ("+inf") or negative ("-inf"). Costs are assumed to entirely occur in the first quarter after WIA registration. 
TABLE 11a: Cost-Benefit Analysis, State B

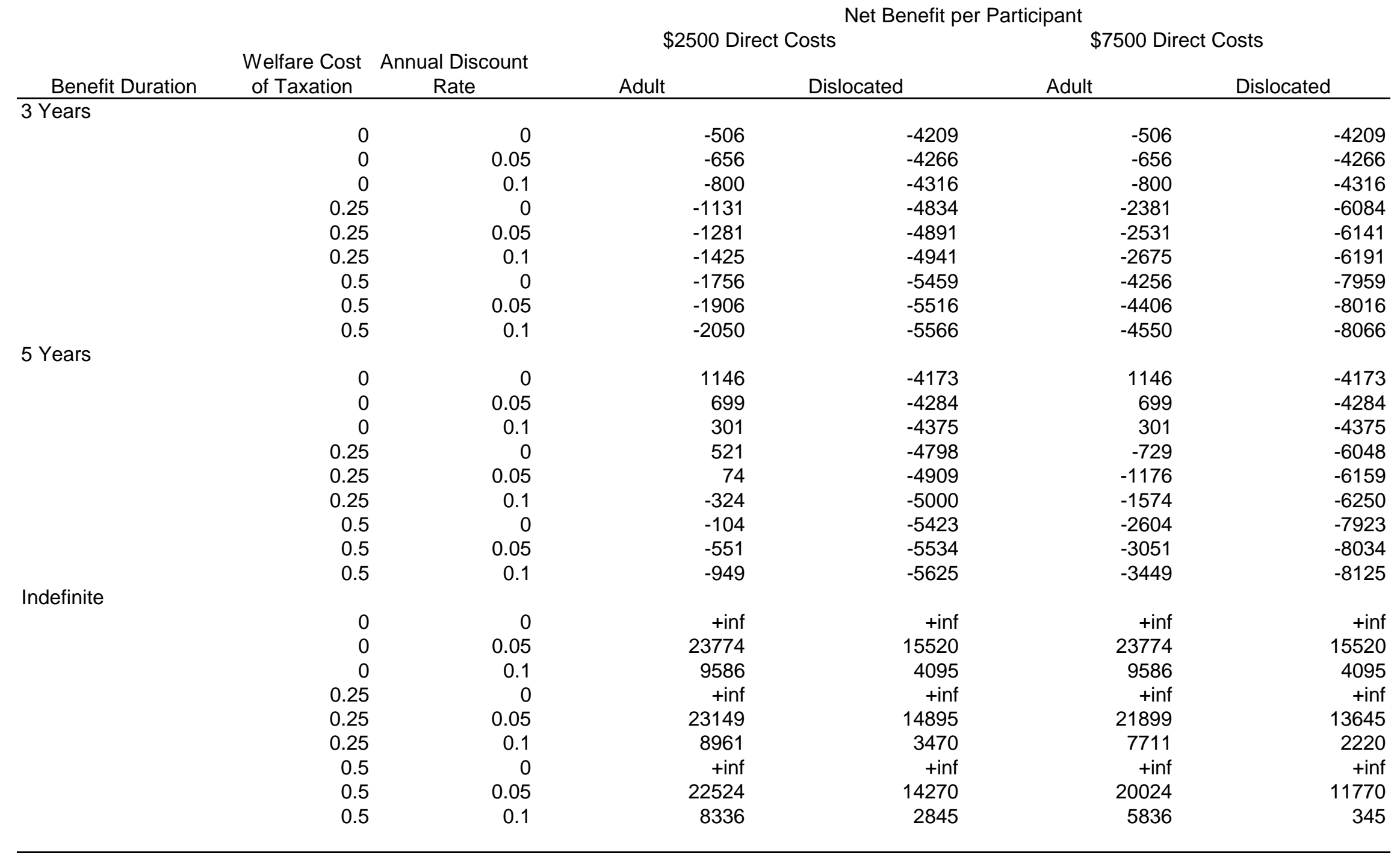

Source: Authors' calculations from WIA and LEHD data.

Notes: Estimates are drawn from Table 4. With an annual discount rate of 0 , the benefits under the assumption of indefinite benefit duration become infinite, whether positive ("+inf") or negative ("-inf"). Costs are assumed to entirely occur in the first quarter after WIA registration. 


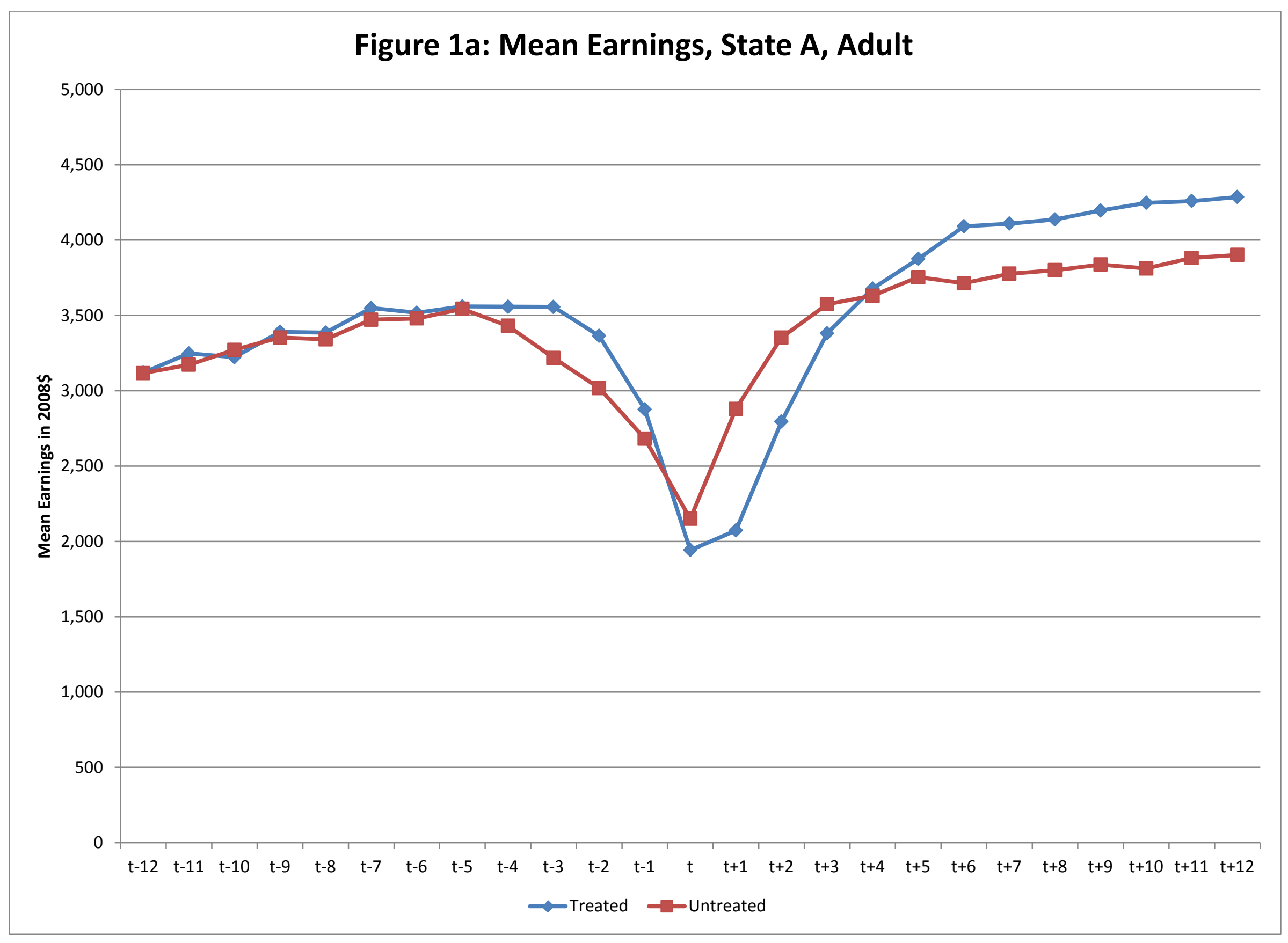




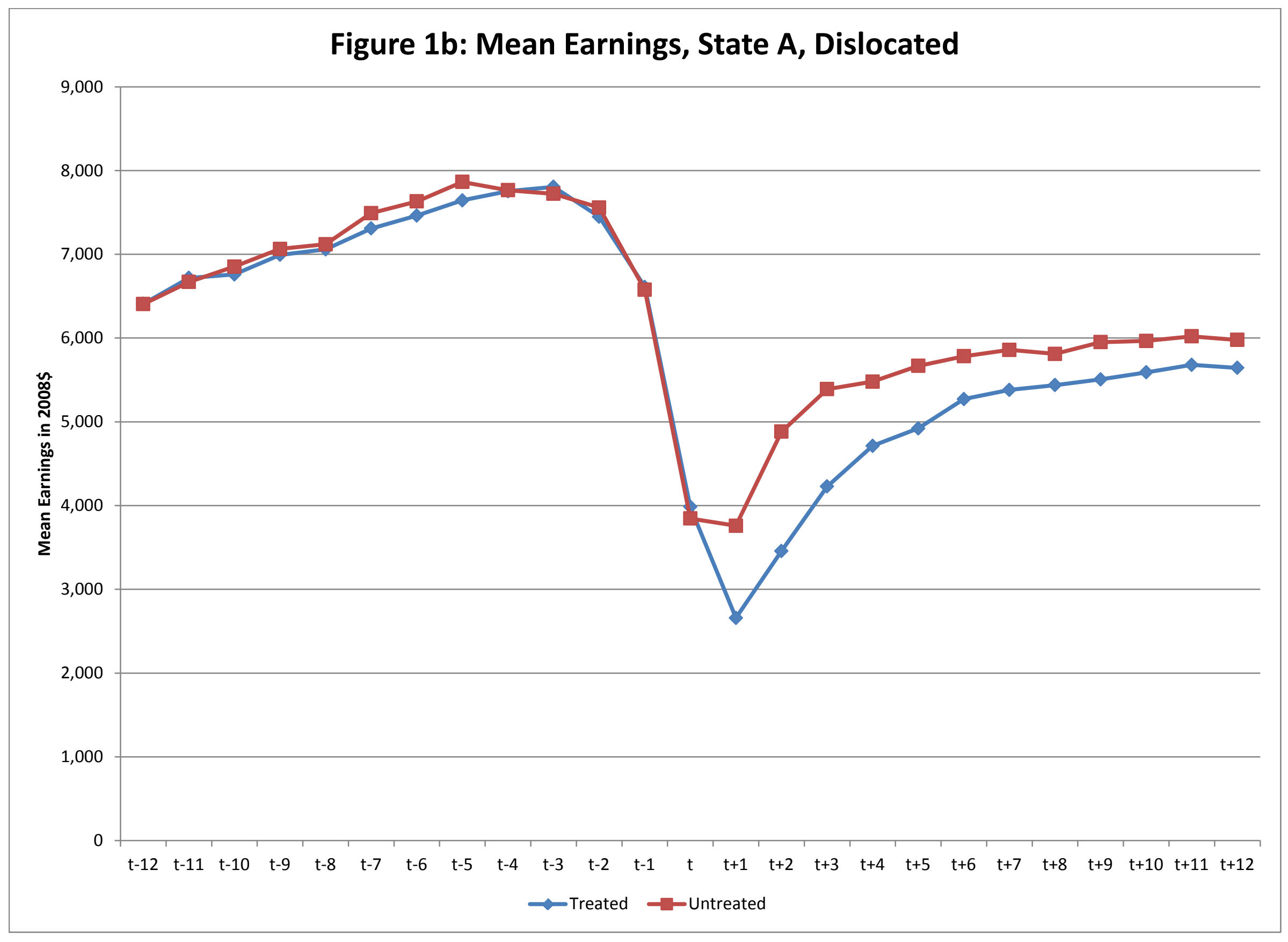




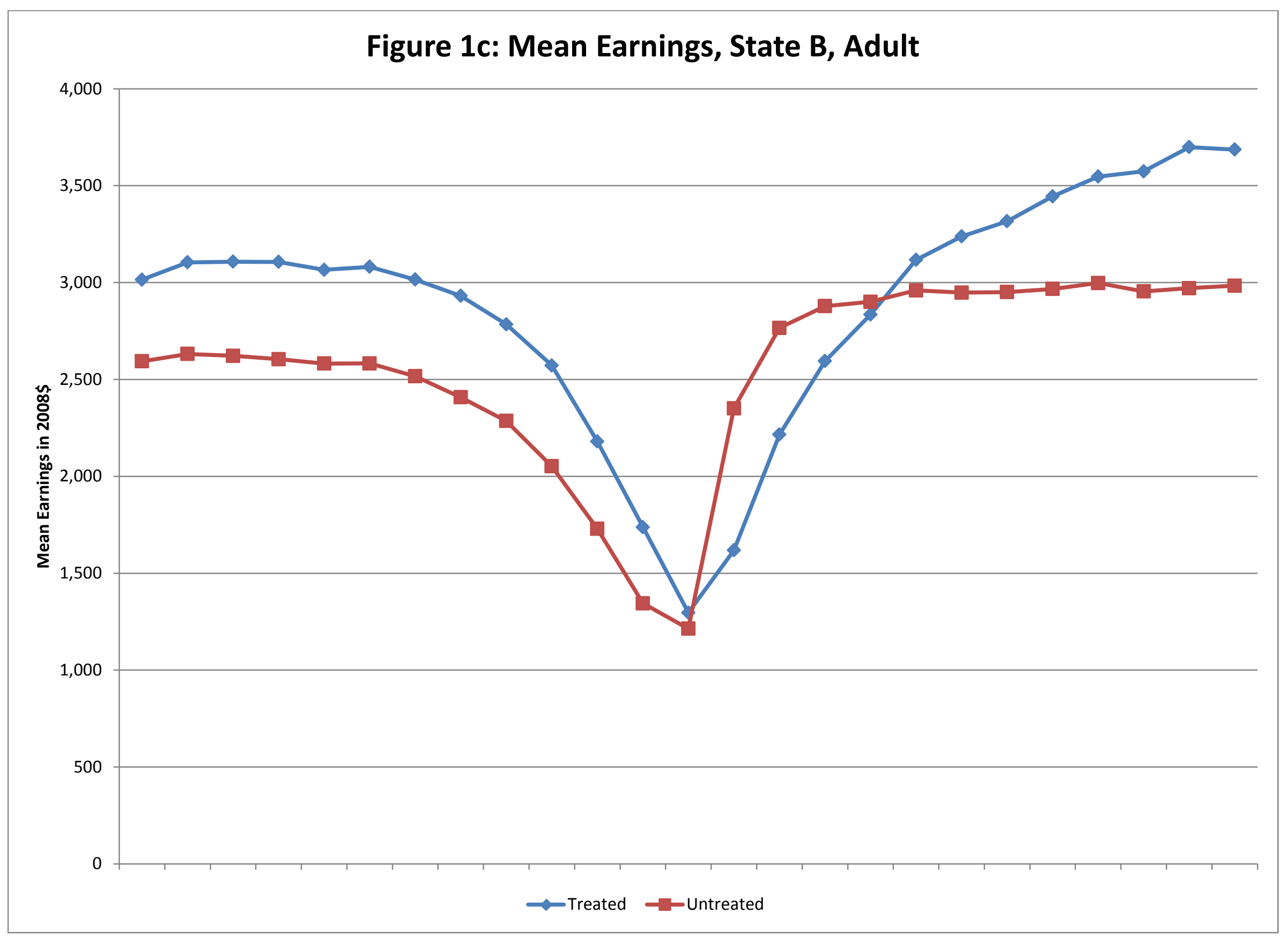




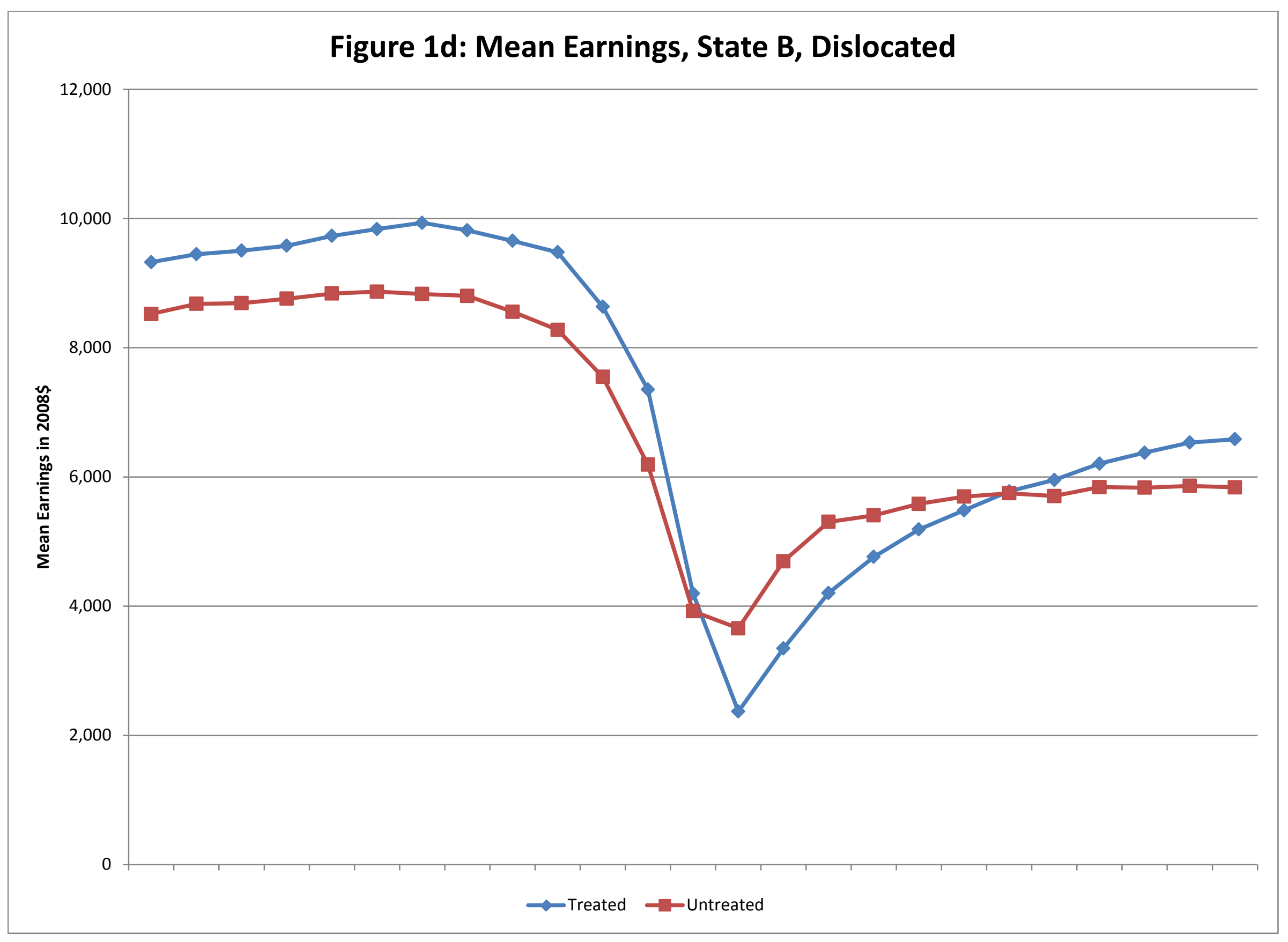




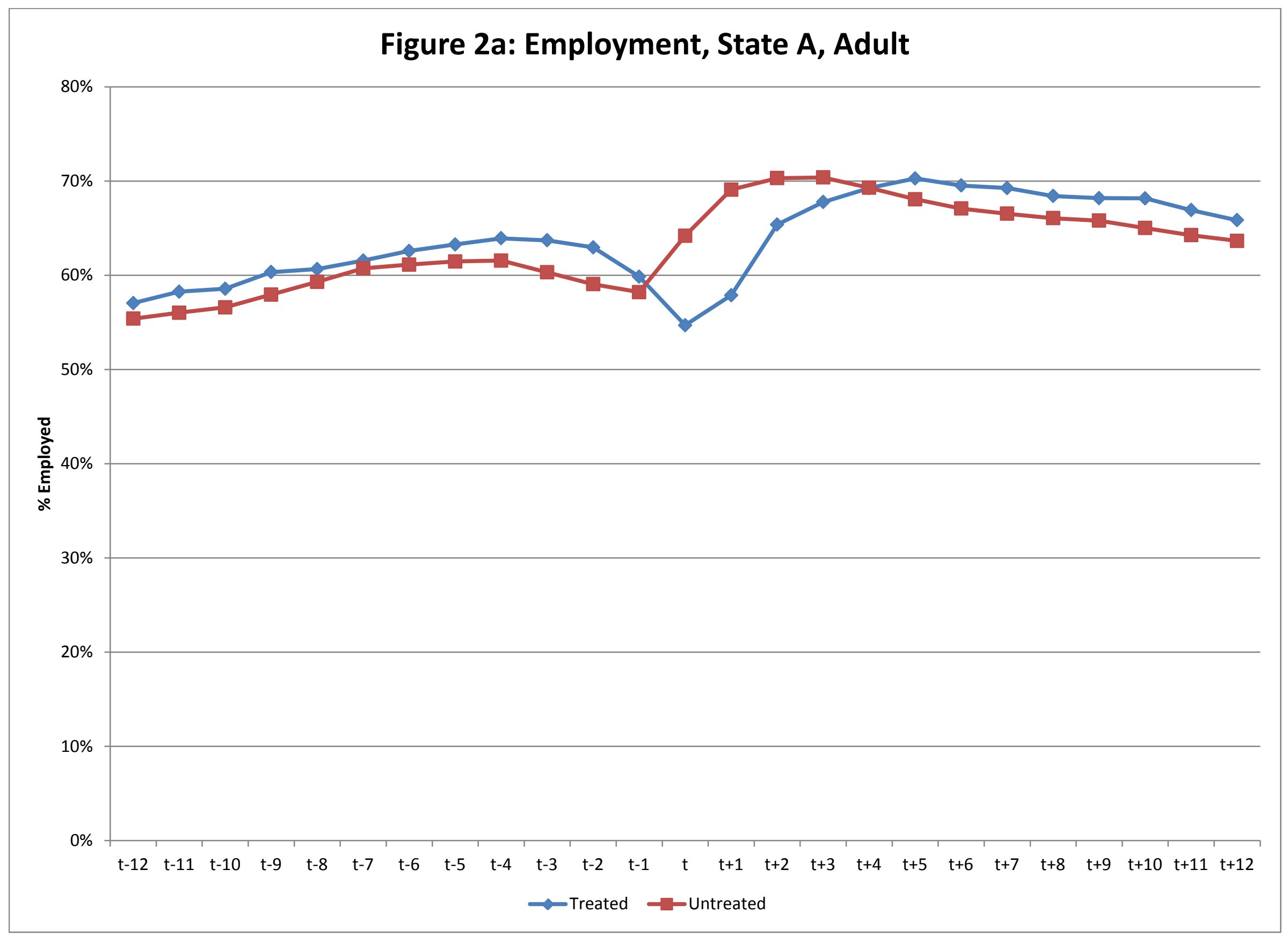




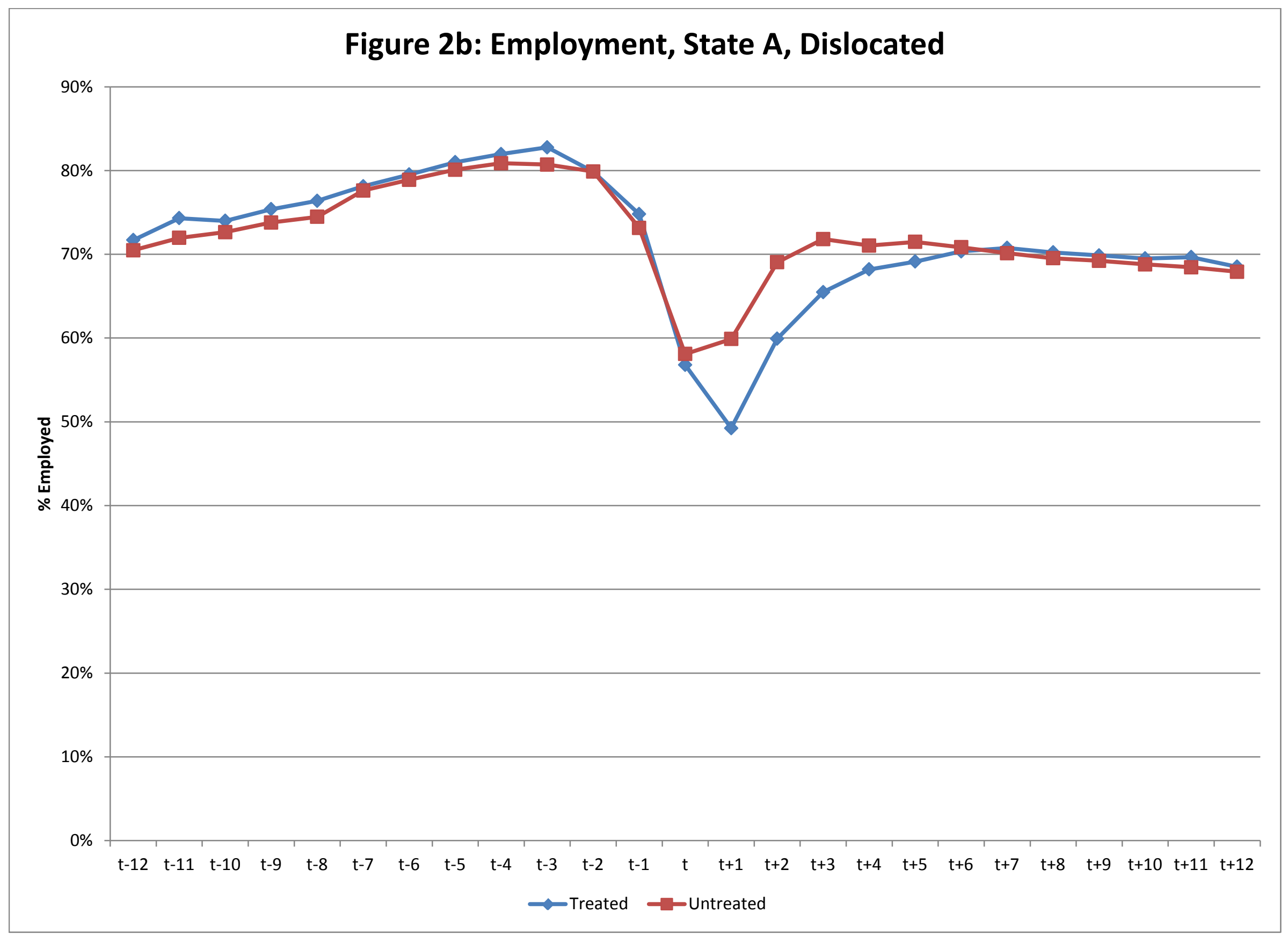


Figure 2c: Employment, State B, Adult

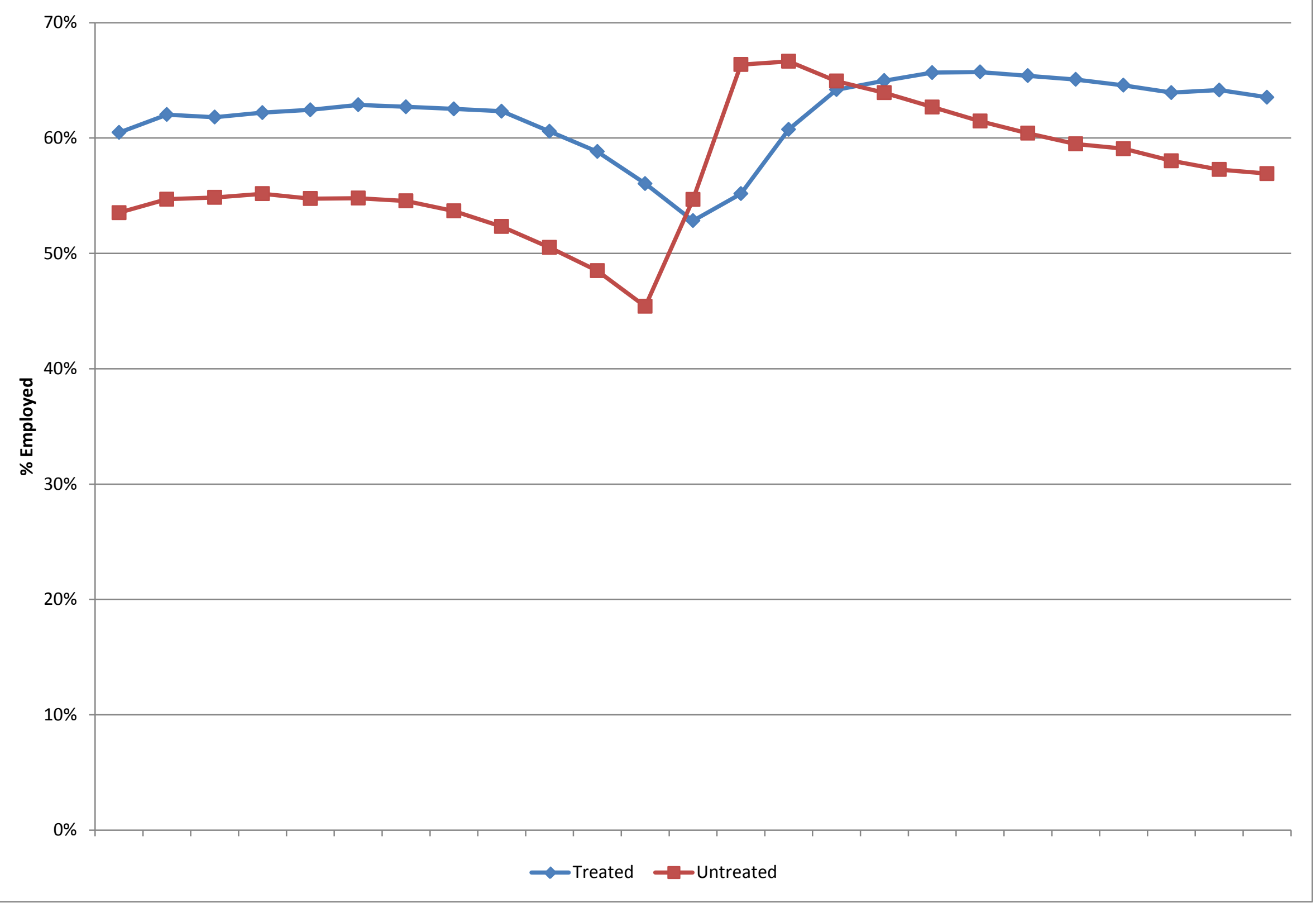




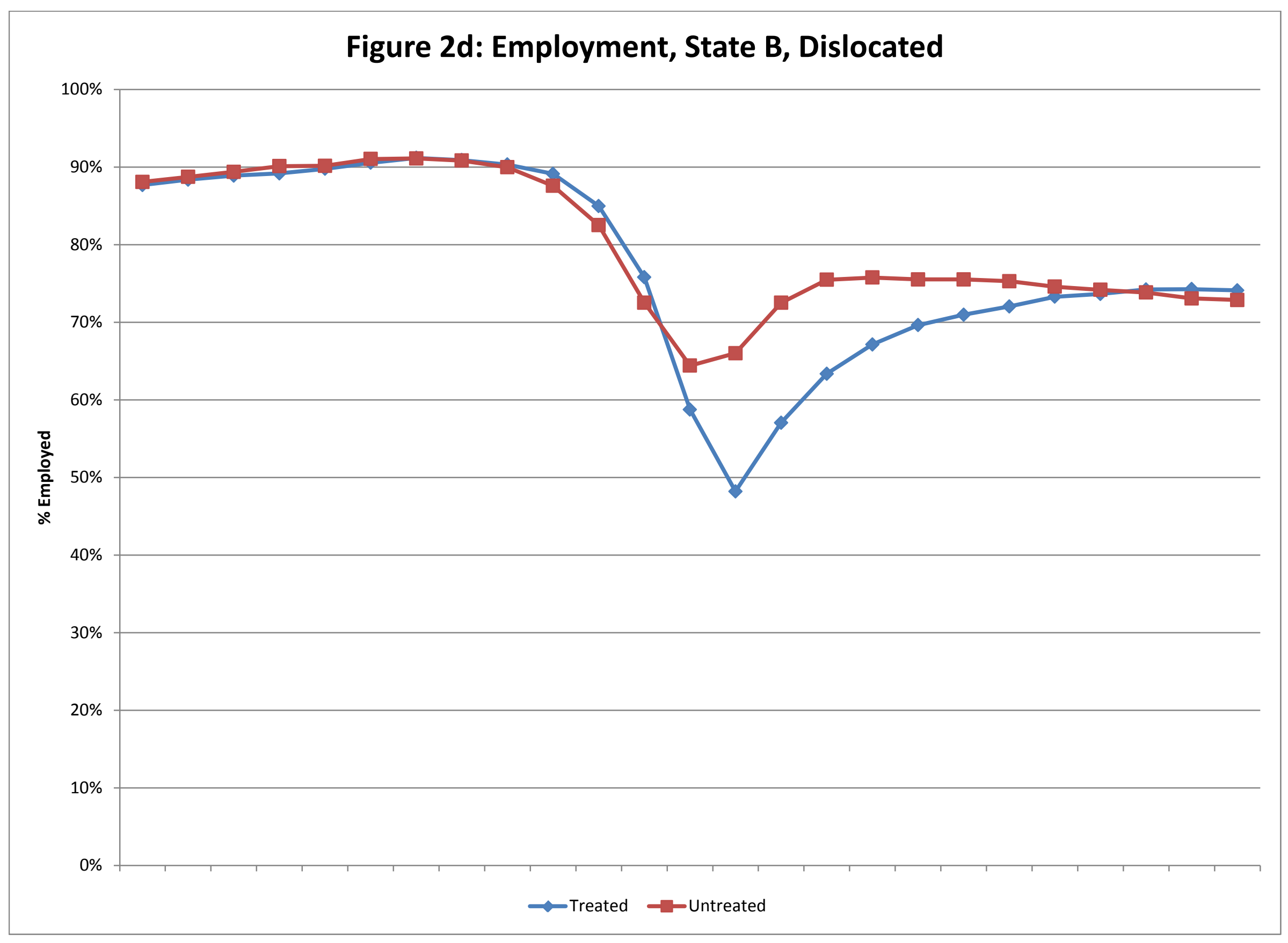


Variable

Male

White

Black

Age

Age

Education

Veteran

Year of Registration

Quarter of Registration

Age at Registration

Age at Registratio
WIA Location

Earnings in 1st Previous Year

Zero Earnings in 1st Previous Year Zero Earnings in 1st Previous Y
Earnings in 2nd Previous Year

Zero Earnings in 2nd Previous Year

No Employment

Quarterly Earnings

Square of Quarterly Earnings

Employment Transitions

Positive Earnings in certain periods Zero Earnings in certain periods

TANF Benefits in

UI Experience in certain periods

ES Service Events

Firm Industry

Firm Size $>=100$

Low-Wage Proportion

High Turnover

Firm Fixed Effects Quintile

Switched Industry
Description

(WIA) Dummy variable equal to 1 if the participant is male, and 0 otherwise

(WIA) Dummy variable equal to 1 if the participant lists white only as racial category and non-Hispanic, and 0 otherwise

(WIA) Dummy variable equal to 1 if the participant lists black only as racial category and non-Hispanic, and 0 otherwise

(WIA) Dummy variable equal to 1 if the values for White and Black are both 0 , and 0 otherwise

(WIA) Age in years at time of WIA registration

(WIA) Series of dummy variable equal to 1 if the participant has years of education in the relevant range, and 0 otherwise

(WIA) Dummy variable equal to 1 if the participanthas

WIA) Dummy variable equal to 1 if the participant has disabled status, and 0 otherwise

(WIA) Dummy variable equal to 1 if the participant has veteran status, and 0 otherwise

(WIA) Series of dummy variables equal to 1 if the participant registered in that year and 0 otherwise

(WIA) Series of dummy variables equal to 1 if the participant registered in that quarter and 0 otherwise

(WIA) Series of dummy variables equal to 1 if the participant registered in that area, and 0 otherwise

(LEHD) Total earnings in year before quarter of WIA registration (quarters $t-4$ through $\mathrm{t}-1$ ) in $2008 \$$

(LEHD) Dummy variable equal to 1 if participant had zero earnings in quarters $t-4$ through $t-1$, and 0 otherwise

(LEHD) Total earnings in 2nd-to-last year before quarter of WIA registration (quarters t-8 through t-5) in 2008

EHD) Dummy variable equal to 1 if participant had zero earnings in quarters $t-8$ through

LEHD) Series of dummy variables equal to 1 if the participant was not employed in that quarter, and 0 otherwise

(LEHD) Participant's earnings in that quarter in $2008 \$$

LEHD) Square of participant's earnings in that quarter in $2008 \$$

(LEHD) Series of 4 dummy variables. A participant is considered employed / employed if earnings were positive during the quarter of WIA entry and all five

previous quarters. A participant is considered not employed / employed if earnings were positive during the quarter of WIA entry but were zero in at least one of the five previous quarters. A participant is considered employed / not employed if earnings were zero during the quarter of WIA entry but were positive in at least one of he previous five quarters. A participant is considered not employed / not employed if earnings were zero during the quarter of WIA entry and all five previous (LEHD) Series of dummy variables equal to 1 if participant had positive earnings in relevant period, and 0 otherwise

(LEHD) Series of dummy variables equal to 1 if participant had zero earnings in relevant period, and 0 otherwise

ly (WIA) Series of dummy variables equal to 1 if participant received TANF benefits during relevant period, and 0 otherwise (State A only) (WIA) Series of dummy variables equal to 1 if participant had received UI benefits during relevant period, and 0 otherwise (State B only) (WIA) Series of dummy variables equal to 1 if participant received ES services during relevant period, and 0 otherwise (State B only)

(LEHD) Series of dummy variables equal to 1 if the participant's last employer before quarter of WIA registration was in that industry (by NAICS code), and 0 otherwise (LEHD) Dummy variable equal to 1 if the participant's employer had at least 100 employees, and 0 otherwise

(LEHD) Continuous variable equal to the percentage of workers at participant's employer who had annual earnings below $\$ 15,000$ and 0 otherwis

(LEHD) Dummy variable equal to 1 if the participant's employer had annual turnover of at least $75 \%$, and 0 otherwise

(LEHD) Series of dummy variables equal to 1 if participant's employer was within the relevant fixed effects quintile, and 0 otherwise

(LEHD) Dummy variable equal to 1 if the participant's employer post-WIA is in different industry than most-recent pre-registration employe 
Table A-2: \# Sample Loss in the Analysis Sample

\begin{tabular}{lrrrr} 
& \multicolumn{2}{c}{ State A } & \multicolumn{2}{c}{ State B } \\
& Adult & Dislocated & Adult & Dislocated \\
Before Eliminations & 29267 & 19376 & 24362 & 30025 \\
Duplicate observations & 20970 & 13727 & 24362 & 30025 \\
No registration date & 20970 & 13727 & 24362 & 30025 \\
No exit date & 16851 & 11512 & 24362 & 30025 \\
Exit before entrance & 16851 & 11512 & 24362 & 30025 \\
Entrance before 1999 & 16851 & 11512 & 23822 & 28962 \\
Earnings restrictions & 15532 & 10836 & 23182 & 28246
\end{tabular}

Source: Authors' calculations from WIA and LEHD data.

Notes: Earnings restrictions mean dropping participants in the top half percent of total earnings summed over the 12 quarters before WIA registration or in the top half percent of total earnings summed over the 12 quarters after WIA registration. In accordance with Census Bureau rules on reporting small differences, some cells where a very small number of participants were dropped are instead reported as no participants being dropped. 